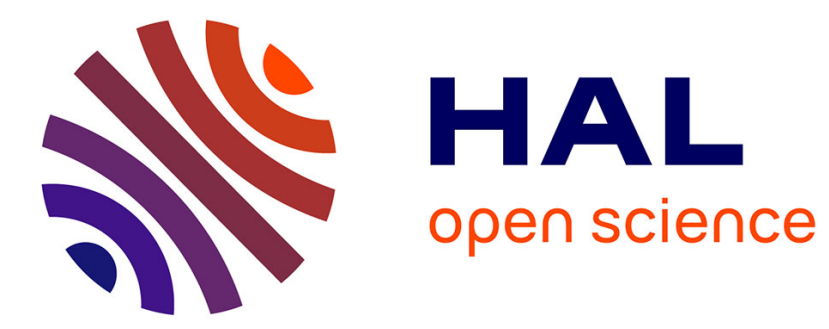

\title{
Better Alone? Evidence on the Costs of Intermunicipal Cooperation
}

\author{
Clemence Tricaud
}

\section{To cite this version:}

Clemence Tricaud. Better Alone? Evidence on the Costs of Intermunicipal Cooperation. LIEPP Working Paper, 2021, 125. hal-03380333

\section{HAL Id: hal-03380333}

https://hal-sciencespo.archives-ouvertes.fr/hal-03380333

\author{
Submitted on 15 Oct 2021
}

HAL is a multi-disciplinary open access archive for the deposit and dissemination of scientific research documents, whether they are published or not. The documents may come from teaching and research institutions in France or abroad, or from public or private research centers.
L'archive ouverte pluridisciplinaire HAL, est destinée au dépôt et à la diffusion de documents scientifiques de niveau recherche, publiés ou non, émanant des établissements d'enseignement et de recherche français ou étrangers, des laboratoires publics ou privés.

\section{다(1)(2)}

Distributed under a Creative Commons Attribution - ShareAlikel 4.0 International 


\section{SciencesPo}

\section{LABORATOIRE INTERDISCIPLINAIRE}

D'ÉVALUATION DES POLITIQUES PUBLIQUES

\section{LIEPP Working Paper}

October 2021, $\mathrm{n}^{\circ} 125$

\section{Better Alone? Evidence on the Costs of Intermunicipal Cooperation}

\section{Clemence TRICAUD}

UCLA Anderson School of Management, CEPR, LIEPP

clemence.tricaud@anderson.ucla.edu

\section{(c)(i)(2)}

Distributed under a Creative Commons Paternité.

Partage selon les Conditions Initiales 4.0 International License

www.sciencespo.fr/liepp

How to cite this publication:

TRICAUD, Clemence, Better Alone? Evidence on the Costs of Intermunicipal Cooperation, Sciences Po LIEPP Working Paper n¹25, 2021-10-15. 


\title{
Better Alone? Evidence on the Costs of Intermunicipal Cooperation
}

\author{
Clemence Tricaud*
}

October $2021^{\dagger}$

\begin{abstract}
This paper provides new evidence on why municipalities are often reluctant to integrate. Exploiting a French reform that made intermunicipal cooperation mandatory, I find that urban municipalities forced to integrate experienced a large increase in construction, consistent with NIMBYism explaining their resistance, while rural municipalities ended up with fewer local public services. I do not find the same effects for municipalities that had voluntarily integrated prior to the law, while both types of municipality enjoyed similar benefits in terms of public transport and fiscal revenues. These findings support the fact that municipalities resisted to avoid the local costs of integration.
\end{abstract}

Keywords: Local governments, Intermunicipal cooperation, Difference-in-differences, Housing regulations, Local public services

JEL Codes: H70, R52, R53

*UCLA Anderson School of Management and CEPR; Global Economics and Management Area, 110 Westwood Plaza, Entrepreneurs Hall, Los Angeles, CA 90005; clemence.tricaud@anderson.ucla.edu

${ }^{\dagger}$ I am grateful to Philippe Aghion, Alberto Alesina, Pierre Boyer, Julia Cagé, Guillaume Chapelle, Pierre-Philippe Combes, Bruno Crépon, Allan Drazen, Xavier D’Haultfoeuille, Antoine Ferey, Jeffry Frieden, Paola Giuliano, Edward Glaeser, Francis Kramarz, Isabelle Méjean, Vincent Pons, Giacomo Ponzetto, Pia Raffler, Alessandro Riboni, Benoit Schmutz, James Snyder, Stefanie Stantcheva, Mathias Thoenig, Clémentine Van Effenterre, and Romain Wacziarg for helpful comments, as well as seminar participants at Harvard, Ecole Polytechnique, CREST, LIEPP-Sciences Po, PSE, Collège de France, HEC Paris, Berkeley Haas, GATE, Chaire EPPP and conference participants at the NBER Public and Urban Summer Institute Workshops, ZEW Public Finance Conference, CREST Political Economy Workshop, ECHOPPE, Transatlantic Theory Workshop, Munich Political Economy and Public Economics Workshop, PEARL, UEA, QSE, AFSE/Tresor Conference, Virtual Seminars on Local Public Economics, OPESS, and CESifo Public Economics Conference. I thank Brice Fabre for sharing municipalities' account data prior to 2010, the team in charge of the building permits database at the Ministry of Sustainable Development for their help with the data, Bernard Pelamourgues for the CAF data on daycare, Cécile Queffelec for the Ministry of Culture data on public libraries, Laurent Chevereau for the CEREMA data on public transport, Thomas Delemotte for his help with the DADS data, and Pierre-Philippe Combes, Gilles Duranton and Laurent Gobillon for sharing their data on land use. I gratefully acknowledge Harvard University for its hospitality and Labex Ecodec for financial support. 


\section{Introduction}

Over the last century, developed countries have encouraged intermunicipal cooperation in order to create larger local jurisdictions and achieve economies of scale in the provision of public goods. However, municipalities are often reluctant to cooperate, slowing or even blocking the consolidation process. ${ }^{1}$ This opposition reflects the fundamental tradeoff of jurisdiction size. On the one hand, intermunicipal cooperation may improve overall efficiency by creating economies of scale and internalizing cross-municipal externalities. On the other, intermunicipal cooperation can be costly for municipalities, as they lose autonomy over local policies, reducing their ability to tailor policies to local preferences and protect local interests (Tiebout, 1956; Alesina and Spolaore, 1997; Bolton and Roland, 1997). Identifying the local costs of integration is key to understanding municipalities' opposition and to explaining why consolidation policies might fail.

Existing studies have mainly focused on the first side of the tradeoff, assessing whether intermunicipal cooperation reduces overall spending (e.g., Bel and Warner, 2015; Blom-Hansen et al., 2016) and tax competition (e.g., Charlot et al., 2015; Breuillé et al., 2018). But there is still little evidence on the local consequences of integration faced by individual municipalities. This reflects in part the general focus on mergers: after consolidation, administrative data are collected at the post-merger level, making it challenging to compare the situations of preexisting municipalities before and after integration. Moreover, cooperation is usually voluntary, implying that we observe the consequences of integration only for municipalities that were willing to cooperate and are thus least likely to bear the costs of integration.

This paper overcomes these challenges by studying a unique setting of forced cooperation. I exploit a 2010 reform in France that made intermunicipal cooperation mandatory, forcing around 1,800 municipalities to enter an intermunicipal community (IC). Importantly, when entering a community, municipalities do not disappear as they do in mergers. They coexist with this new higher level of governance and share their public policies with neighboring municipalities in the same community. While this form of cooperation is widespread across the world, ${ }^{2}$ France is the only country in which it became mandatory.

Using a difference-in-differences strategy, I compare, before and after 2010, municipalities forced to integrate with municipalities that have been part of an intermunicipal community for a

\footnotetext{
${ }^{1}$ Despite large financial incentives, voluntary mergers in Japan resulted in a higher number of municipalities than what the government would have chosen to impose (Weese, 2015); other countries, such as Denmark and Sweden, instead decided to force mergers (Lidström, 2010; Mouritzen, 2010); in the US, after a wave of consolidation in the 19th century, municipalities became more and more reluctant to integrate (Jackson, 1987); in France, the government failed to impose mergers in the 1970 s and then strove to promote the formation of intermunicipal communities.

${ }^{2}$ Many countries have intermunicipal organizations similar to those in France, including Finland, the Netherlands, Ireland, Brazil, Spain, and Italy (Hulst et al., 2009; De Mello and Lago-Peñas, 2013). Similarly, shared services in the UK and special or school districts in the US involve the creation of a new level of governance.
} 
long time. I provide extensive evidence supporting the common trend assumption. In particular, I show that those two groups, while selected, evolved similarly prior to the law. Along with extensive data collection at the municipal level, this strategy enables me to measure the causal impact of integration on municipalities that resisted it. I then compare their experience to that of municipalities that had voluntarily joined a community before the 2010 law, using a staggered adoption design in which the date of the treatment corresponds to the year of integration. ${ }^{3}$ Through this comparison, I can identify the local consequences of integration that explain why resisting municipalities opposed integration in the first place.

Municipalities that are part of the same community share several public policies; losing autonomy over these can be costly. First, urban planning policies become subject to the guidelines set by the IC, which decides where and how much to build in each member municipality. This can be costly for high-demand municipalities that have been using local housing regulations to prevent outsiders from coming in and to prevent further increases in housing density (Gyourko and Molloy, 2015). This local opposition to new construction is commonly referred to as NIMB Yism ("Not In My BackYard"). Sharing their housing and zoning policies with outsiders and would-be residents might therefore lead to more construction on their territory than desired. ${ }^{4}$ Second, integrated municipalities jointly finance and provide local public services: waste management, road maintenance, public transport, daycare facilities, and social, cultural, and sports facilities. While pooling resources for large-scale services such as public transport seems generally beneficial, sharing decisions over the location of public service can be costly for some municipalities. With the aim of achieving economies of scale, ICs seek to rationalize the supply of local public services and thus to concentrate resources on facilities in high-density areas. As a result, low-density municipalities might end up with fewer facilities, increasing the distance to public services for their residents.

I take these two predictions to the data and test whether entering an intermunicipal community leads to more construction and fewer public services in municipalities forced to integrate. I show that both dimensions help explain their resistance, but that urban and rural municipalities face different consequences.

Exploring the loss of autonomy over urban planning, I find that municipalities forced to enter an IC experienced a large increase in construction: the number of building permits delivered on their territory increased on average by 12.5 percent per year after 2010 . Given that control and treated municipalities displayed similar trends prior to the law, this effect can be interpreted as the

\footnotetext{
${ }^{3}$ In light of the recent literature on the issues associated with the staggered adoption design, I also use an alternative estimation procedure developed by de Chaisemartin and D'Haultfoeuille (2020).

${ }^{4}$ Due to local opposition to construction, higher-level governance has been advocated as a way to overcome housing regulations and increase construction (Rusk, 1995; OECD, 2012; Glaeser, 2014; Glaeser and Gyourko, 2018). This typically triggers strong resistance from municipalities. For instance, Orfield (1997) describes the fierce opposition of municipalities in Minnesota against the transfer of urban planning policies to the Metropolitan Area level. In France, we say that a mayor who builds will lose the next election ("maires batisseurs, maires battus").
} 
causal impact of their integration. ${ }^{5}$ To investigate further whether such an effect can explain their resistance, I turn to municipalities that voluntarily joined an IC before the law and find that they did not experience a significant change in their housing supply following their integration. Hence, only municipalities that did not want to enter an IC experienced a significant rise in construction. This differential impact supports the view that municipalities that had refused to integrate did so to avoid a rise in housing supply.

Further heterogeneity analyses show that the increase in building permits is driven by municipalities in which the demand for housing is high and that are already densely built up. In contrast, the impact on housing is not stronger for municipalities surrounded by neighboring municipalities that are more different from them, in terms of income, socio-demographic characteristics, or political preferences, or for municipalities with a higher share of homeowners. These findings suggest that resistance is not driven by residents' fear of greater population heterogeneity, or by homeowners' fear of a housing price decline. Instead, they suggest that municipalities that wanted to keep control over their housing supply are mainly urban municipalities whose NIMBY residents, whether homeowners or renters, seek to avoid further increases in density to preserve their quality of life.

Additional results suggest that integration did not lead to a significant drop in housing prices. I provide an interpretation for this null effect that is based on demand spillovers from nearby municipalities and is consistent with new construction taking place in high-demand municipalities. I also show that the increase in construction is neither preceded nor followed by an increase in economic activity, providing additional evidence that the rise in housing supply is due to a change in regulation after integration, rather than to a change in economic conditions. This also suggests that the disutility associated with new construction is not compensated for by economic gains.

I then assess the consequences of integration on local public services. I gathered data on two different public services transferred to the community level after integration: daycare services and public libraries. The results suggest that, in the average year after 2010, rural municipalities forced to integrate ended up with 20 to 30 percent fewer daycare spots and public libraries, compared to rural control municipalities. Urban municipalities, however, did not experience any decline in local public services. These results suggest that, while urban municipalities resisted integration to prevent further construction, rural municipalities resisted to avoid losing local public services. I provide additional evidence that the impact comes from their loss of control over the location of facilities and from ICs concentrating resources in more densely populated areas: rural municipalities forced to integrate did not experience any change in the number of schools, the location of which is decided nationally and thus not directly affected by intermunicipal cooperation.

\footnotetext{
${ }^{5}$ I show that all main results are robust in magnitude and significance to using propensity score matching, varying the control group, using higher-level clustering, and including time-varying controls at the municipality level.
} 
Finally, I investigate the benefits of integration in order to assess what resisting municipalities were willing to give up by not integrating. By enhancing cooperation and enabling municipalities to pool resources, integration is likely to improve large-scale public services. Specifically, it might help neighboring municipalities build larger and more efficient public transport networks. Moreover, ICs are likely to generate extra fiscal revenues through a decrease in tax competition and thanks to the additional grants provided by the government to ICs. In line with these predictions, I find that municipalities that were forced to enter an IC became twice as likely to have access to public transport. They also experienced an increase of 14.5 percent per year in the fiscal resources available per resident, driven by additional state transfers and an increase in tax revenues.

Crucially, those benefits are similar to those experienced by municipalities that voluntarily integrated prior to the law. While resisting municipalities experienced costs that other municipalities did not face, they entered ICs generating at least as much revenue and they benefited equally from an increased access to public transport. This suggests that they did not resist due to lower benefits, but to avoid the costs associated with increased construction for urban municipalities and with the loss of public services for rural municipalities. Although resisting municipalities are quite similar to municipalities that integrated voluntarily, based on socio-demographic, land-use, and political characteristics, they tend to be smaller than their neighbors and thus to end up with less bargaining power once integrated. All together, this suggests that municipalities resisted integration knowing that they would not be able to prevent their neighbors from imposing new construction on them or decreasing their access to public services.

The last part of the paper provides additional evidence supporting this interpretation. I first show that the costs experienced by resisting municipalities are unlikely to be driven by the fact that they entered an IC later on and were forced to do so, which could have triggered punishment by already integrated neighbors for having resisted so long. In particular, the impact is similar whether resisting municipalities entered longstanding communities, recently created ones, or even newly created ICs, suggesting that they would have experienced the same effects had they integrated earlier. Second, looking at ICs' composition at the end of the period of integration, in 2014, I provide evidence that resisting municipalities have, on average, a lower share of seats on the intermunicipal council and are more likely to end up in ICs that encompass a large municipality. They are thus the ones losing the most bargaining power upon integration, making them less able to fight ICs' decisions and more likely to bear the costs of integration.

Overall, this paper provides new evidence that municipalities' opposition to consolidation is driven by local consequences of integration, beyond ideological or political considerations. As most forms of cooperation among local jurisdictions imply sharing urban planning policies and public services, these results may help explain resistance against integration beyond the French case, as long as the decision process involves some jurisdictions losing more power than others. 
These findings could also help policymakers design better compensation schemes to implement consolidation policies more effectively. In particular, it is important to take into account that rural and urban municipalities do not face the same costs of integration.

\subsection{Contribution to the literature}

In the first half of the nineteenth century, Alexis de Tocqueville described the US federal system as a way of "combining the different advantages which result from the magnitude and the littleness of nations" (Tocqueville, 1945). In their seminal works on decentralization, Tiebout (1956) and Oates (1972) emphasized that the provision of public good at the local level reflects the population preferences more adequately than provision at the national level. Ultimately, the tradeoff was formalized in Alesina and Spolaore (2003) and Bolton and Roland (1997), in which the efficiency gains of large jurisdictions are weighted against the costs associated with heterogeneity and with the loss of local control. Additionally, Alesina and Spolaore (2003) predict that political agents will tend to choose a higher number of jurisdictions than optimal, as the ones bearing the costs of size do not internalize the aggregate benefits of belonging to a larger jurisdiction. Identifying the costs that prevent aggregation is the focus of this paper.

Studies of the (un)willingness to consolidate have analyzed which types of municipality choose to integrate (see Bel and Warner (2016) for a review). Using structural or spatial models, they stress the role of expected change in fiscal revenues, expected distance to public services, and neighbors' characteristics (Alesina et al., 2004; Gordon and Knight, 2009; Saarimaa and Tukiainen, 2014; Weese, 2015; Bel and Warner, 2016; Di Porto and Paty, 2018). Relying on surveys, Sorensen (2006) and Bergholz and Bischoff (2018) show, respectively, that politicians' reported opposition to integration is driven by expected losses in revenues and decision-making power. ${ }^{6}$ Instead of estimating the preference or modeling the choice to cooperate, this paper provides new evidence on the factors explaining resistance by focusing on the actual consequences of integration.

So far, the literature has mainly measured the impact of intermunicipal cooperation at the aggregate level to assess whether it leads to efficiency gains, as hoped by central governments. The results are mixed (see Bel and Warner (2015) and Bel and Sebo (2019) for a review). Although Reingewertz (2012), Blesse and Baskaran (2016), and Cobban (2019) find some evidence of efficiency gains in Israel, Germany, and Ontario, there is no evidence of cost savings in France, Denmark, the Netherlands, or Italy (Frère et al., 2014; Blom-Hansen et al., 2016; Allers and De Greef, 2018; Luca and Modrego, 2020). ${ }^{7}$ While intermunicipal cooperation might not achieve its

\footnotetext{
${ }^{6}$ Looking at secession instead and using referendum data in Canada, Lapointe (2018) show that income and language differences affect voters' preferences concerning municipal borders.

${ }^{7}$ In contrast to Luca and Modrego (2020), Ferraresi and Migali (2018) find that intermunicipal communities (Unioni di Comuni) lead to a reduction in public expenditures in the Emilia Romagna region of Italy.
} 
goal of reducing the cost of public goods, it does seem to reduce tax competition. In France, several studies find that the voluntary integration into intermunicipal communities led to higher tax rates and tax revenues (Carbonnier, 2013; Charlot et al., 2015; Breuillé et al., 2018).

Beyond the overall impact of cooperation, a few recent papers have used geo-coded data to investigate the distributional impact of mergers on voter turnout (Horiuchi et al., 2015; Lapointe, 2018), local public sector jobs (Harjunen et al., 2019) and night-light intensity (Pickering et al., 2020; Egger et al., 2021). Looking at mergers makes it particularly challenging to study local effects. First, the set of outcomes is limited, as data are typically collected at the post-merger level. Second, most mergers are voluntary, providing little insight on the impact for municipalities that did not want to merge and are the most likely to bear the costs of consolidation. ${ }^{8}$

In contrast, my setting of forced cooperation enables me to make three important contributions to the literature. First, exploiting the 2010 law, I can assess the causal impact of integration on municipalities that refused to cooperate to better understand their resistance. Second, I can investigate the local consequences of integration on a large set of outcomes, including housing, economic activity, local public services, public transport, and fiscal revenues. Third, given the large number of French municipalities, I can perform heterogeneity analysis along several dimensions to shed light on the mechanisms and show that different types of municipality face different costs of integration.

In particular, while the regulation of construction is one of the most important functions of local government, this paper is the first to study the impact of intermunicipal cooperation on housing. I provide novel evidence that NIMBYism helps explain urban municipalities' reluctance to integrate and to share urban planning policies. These results are consistent with survey evidence showing that residents, whether renters or homeowners, oppose nearby constructions (Hankinson, 2018), which they consider nothing but a bother (Glaeser, 2014). My findings also show that transferring urban planning to a higher level—allowing outsiders and would-be residents to participate in the decision making - reduces local housing restrictions. This is in line with evidence in the US showing that municipalities with ward-based representatives impose more zoning restrictions than those with at-large representatives (Clingermayer, 1994; Mast, 2020). These results are particularly policy-relevant in light of the growing literature stressing the overall negative impact of local regulation on productivity, intergenerational mobility, and greenhouse gas emissions through urban sprawl (Glaeser and Maré, 2001; Glaeser and Kahn, 2010; Jones and Kammen, 2013; Chetty et al., 2016; Ganong and Shoag, 2017; Glaeser and Gyourko, 2018; Hsieh and Moretti, 2019; Duranton and Puga, 2019).

The remainder of the paper is organized as follows. Section 2 presents the institutional frame-

\footnotetext{
${ }^{8}$ Two recent papers provide evidence of the local impacts of jurisdiction size in alternative settings. Wilner (2021) focuses on the 2016 merger of French regions to assess the impact of higher-level centralization on life satisfaction. Dahis and Szerman (2021) focus on administrative splits instead of mergers and find that rural Brazilian municipalities that successfully split experienced some improvements in public service delivery.
} 
work and the data. Section 3 describes the empirical strategy and provides descriptive statistics on resisting municipalities. I present the main results on housing supply in Section 4 and on local public services in Section 5. Section 6 studies the benefits of integration. Section 7 discusses the interpretation and mechanisms. Section 8 concludes.

\section{Institutional background and data}

\subsection{Intermunicipal cooperation in France}

France is divided into about 36,000 municipalities with an average size of 1,800 inhabitants. Municipalities are the lowest of three tiers of local government and account for 11 percent of total public spending. They are responsible for local urban planning, social housing, the provision of primary schools, ${ }^{9}$ daycare services, municipal roads, public transport, and social, sports, and cultural facilities. Municipalities' revenues come mainly from local taxation (54 percent) and state transfers ( 23 percent). They raise four local taxes: the local business tax paid by firms and accounting for 45 percent of local tax revenues, the housing tax paid by all residents on the cadastral value of their accommodations (whether they are renters or owners), the property tax paid by owners, and the land tax. Each municipality is governed by a municipal council chaired by the mayor. Elections for municipal councilors take place every six years.

In the 1970s, the French government intended to pass a law that would have reduced the number of municipalities by 20 percent through mergers. Mayors massively blocked the reform and only a few mergers took place, reducing the number of municipalities by only 3 percent. Following this failure, the government decided to pivot toward promoting the creation of a new administrative structure: intermunicipal communities. ${ }^{10}$ When entering an IC, the municipality does not disappear as in mergers; it continues to exist under a new level of local governance. The mayor and municipal council stay in place, but the municipality has to share some public services with the other municipalities that are part of the same community.

By law, intermunicipal communities are in charge of "territory and economic development";

\footnotetext{
${ }^{9}$ Municipalities' responsibilities in the education sector are very limited. They are only responsible for the equipment of primary schools and for the organization of extra curricular activities. Decisions over the location of the schools, size of the classrooms, teachers' recruitment and assignment, and learning programs are centralized at the state level. Secondary schools (resp. high schools) are managed at the national and departmental (resp. regional) levels.

${ }^{10}$ In France, intermunicipal communities are called EPCI, for établissement public de coopération intercommunale. France has four types of IC: communautés de communes (CC), communautés d'agglomerations (CA), communautés urbaines (CU), and métropoles - defined mainly by the number of mandatory competences to be transferred to the community and by the size of the member municipalities. The vast majority of municipalities are part of a CC (more than 80 percent), the form of cooperation I describe in this section and the one that gives the most freedom to municipalities in deciding which public services to transfer.
} 
that is, urban planning and the promotion of local businesses. Since the 1980s decentralization laws, French municipalities are in charge of building permits, and must produce a planning and development plan (plan local d'urbanisme). Once a municipality is part of an IC, local planning becomes subject to guidelines set by the community. In the most stringent case, the IC issues a housing plan (plan local d'habitat or PLH) detailing where and how much to build in each member municipality. While the PLH is mandatory only for the largest ICs, many adopt it voluntarily and it covered 65 percent of the French population in 2011. ICs that do not issue a PLH can still set urban planning guidelines through the territorial coherence plan (schéma de cohérence territoriale) or the intermunicipal development plan (plan local d'urbanisme intercommunal).

Municipalities also decide which additional public services to transfer to the IC. The most commonly delegated ones (in 80 to 90 percent of cases) are services for which cooperation is likely to result in economies of scale: waste management, public transport, and social, cultural, and sports facilities. Once the public service is transferred, the IC becomes the sole decision maker and the sole owner of the financial and material resources attached to it.

Finally, an IC's revenues consist of state transfers and local taxes. It can either apply an additional tax rate to the four municipal tax rates or set a single business tax rate while still applying an additional tax rate on the other three. In the latter case, the municipalities lose the right to set their own business tax. Municipalities choose the tax system when creating the community.

The IC is run by a board made up of members of the municipal councils of all participating municipalities. The number of seats held by a municipality on the intermunicipal council is proportional to its population. By law, each municipality has at least one seat and no municipality has more than half of the seats. Once the allocation of seats is decided, each municipal council elects the municipal councilors who will be part of the intermunicipal council. Then, the intermunicipal council elects its president. Decisions over which public services to transfer to the community or over which tax system to adopt require the approval of either (a) two-thirds of the municipal councilors representing more than half of the IC's total population or (b) at least half of the municipal councilors representing more than two-thirds of the population, as well as the approval of all municipal councilors representing more than one-fourth of the IC's population. Then, day-to-day decisions about urban planning or the delivery of public services are made by the intermunicipal council, by majority. Hence, when joining an intermunicipal community, a municipality loses power over policies, the more so the smaller its population compared with the population of the other municipalities in the same IC.

Until 2010, municipalities were free to decide whether or not to create or join an IC. However, the financial incentives to integrate into an IC were high: since the "Chevènement law" in 1999, ICs receive a state transfer on top of the individual transfers to each municipality, which remain unchanged whether the municipality integrates or not. This law marked a turning point: whereas 
half of the municipalities were part of an IC in 1999, 95 percent were by 2010. In 2010, mainland France had 2,575 ICs, each with an average of 13 municipalities and 21,295 inhabitants. Still, 5 percent of the municipalities—about 1,800—remained isolated.

\subsection{The 2010 law}

In December 2010, a new law passed requiring that (1) all municipalities must be part of an intermunicipal community and (2) all intermunicipal communities must contain at least 5,000 inhabitants. This law followed a report issued by the French Court of Auditors indicating that, in general, ICs were too small to achieve economies of scale. The goal of the reform was thus to draw a new map of intermunicipal communities and organize the territory more effectively. ${ }^{11}$

This law forced municipalities that were isolated to enter a community. The only exceptions were Paris and municipalities in three départements around $i^{12}$ as well as a few islands that make up one municipality. The law also forced existing small ICs to merge with other communities in order to comply with the 5,000 threshold. This threshold did not apply to ICs in mountain zones, where municipalities are far from each other. I focus on the first aspect of the law and look at what happened to the municipalities that were not part of an IC before 2010. I call them "resisting municipalities," given that they chose not to join any IC until forced to. ${ }^{13}$

Figure 1 shows the geographic distribution of French municipalities depending on their integration status in 2010. Red indicates that the municipality was still not integrated in 2010; blue indicates that the municipality was already part of an IC. The gray areas are municipalities excluded from the sample, as further explained in Section 3.1. Even if many isolated municipalities are located in the center-north, red municipalities are present in all French regions.

Implementation of the reform took place between 2011 and 2014 and was conducted by the departmental prefect (the state representative in the département). In 2010, municipalities forced to enter an IC shared a border with 1.7 intermunicipal communities on average. Those neighboring more than one IC could choose which to join, but the decision had to be approved by the prefect. When possible and if allowed by the prefect they could also create a new IC with neighboring isolated municipalities. The process had to be finalized by 2014. If a municipality was still isolated

\footnotetext{
${ }^{11}$ The 2010 law also changed the rule for the allocation of seats on the intermunicipal council (which still remains tightly linked to population size), as well as the way municipal councilors are elected (directly by voters during municipal elections). These changes became effective only after the 2014 municipal elections. All municipalities were already part of an IC by then, so the changes affected all municipalities the same way.

${ }^{12}$ Paris and municipalities in three départements around Paris (Hauts-de-Seine, Seine-Saint-Denis, and Val-deMarne) were exempt from this law as they are part of the "Great Paris" Project, which aims at consolidating the Paris metropolitan area.

${ }^{13}$ In particular, it never happened that one of these municipalities tried to integrate before 2010 but was rejected by an IC. More generally, an IC can refuse the entrance of a municipality only under very specific conditions and under the approval of the prefect. In practice, it almost never happened.
} 
in 2013, the prefect could force its integration into the IC she chose. At the end, 77 percent of the isolated municipalities entered an IC between 2011 and 2013 and 23 percent entered in 2014. This timing was greatly affected by the prefects themselves, some having initiated the process sooner after the law than others. The majority of municipalities (73 percent) joined an existing community; the rest created new ICs. As shown in Section 7.1, the consequences of integration do not depend on the number of options the municipality had or on the type of IC it was forced to enter. This is consistent with all the integration options being considered equally undesirable and with resisting municipalities' decision not to join any neighboring ICs prior to the law.

On average, municipalities forced to integrate made up 5.6 percent of the population of the community they joined. In 2014, the average intermunicipal community included 17 municipalities and 28,126 inhabitants.

\subsection{Data}

Municipalities' characteristics. The municipality characteristics I use for the descriptive statistics and for the heterogeneity analysis come from various sources. Municipalities' socio-demographic characteristics are available from censuses conducted by the National Institute of Statistics and Economic Studies (INSEE). INSEE also provides a classification of rural and urban municipalities as well as the composition of French urban areas. Municipalities' geographical coordinates are obtained from the National Geographic Institute (IGN). Household taxable income data aggregated at the municipality level are provided by the Ministry of Finance and extracted from income tax declarations. Municipal and presidential electoral results are obtained from the Ministry of the Interior and mayors' characteristics from the National Directory of Elected Officials (RNE). ICs' municipal composition and the list of mountain-zone municipalities are provided by the General Directorate of Local Authorities (DGCL).

Finally, data on municipalities' land use come from Combes et al. (2021). The share of built land is computed considering all construction, whereas the average height and floor-to-area ratio (FAR) are computed considering only housing construction. To measure the FAR stringency, I follow Combes et al. (2021) and take the 30th percentile of the distribution of realized FARs of all housing buildings in the municipality. I also show the statistics using the median.

Housing building permits. Housing building permits data come from the Ministry of Sustainable Development (sit@del2 database). The dataset contains the number of housing building permits delivered every year in each municipality over 1999-2018. ${ }^{14}$ More precisely, it provides the number of housing units allowed for construction. Hence, if a building of 10 apartments was approved, the dataset registers 10 authorized housing units, even if only one permit was delivered.

\footnotetext{
${ }^{14}$ I focus on ordinary housing, excluding residences providing particular services, such as medical or retirement residences.
} 
The database also indicates whether the unit is a house (single-family home) or an apartment (unit part of a multiple-family home) and whether the construction takes place on empty land or as an extension to an existing building.

Housing prices. Building on Combes et al. (2018) and following INSEE's guidelines (Gouriéroux and Laferrère, 2009; Musiedlak and Vignolles, 2016), I measure housing prices at the municipal level using official transactions records of non-new dwellings and adjusting for housing characteristics. The data are available from the Ministry of Sustainable Development for every even year since 2000, separately for the Parisian region of Île-de-France and for the rest of France. Transaction data are available until 2014 (resp. 2016) for Île-de-France (resp. the rest of the country). To build municipal housing price indices, I regress separately for each year the log of the price per square meter on the characteristics of the dwelling. I then compute the indices as the average of the residuals for each municipality and year, after adding the regression constant. Since I center the explanatory variables, the resulting indices can be interpreted as the price per square meter of a reference dwelling. Appendix D provides further details on the construction of the indices.

Economic activity. I measure firm creation using the number of new establishments created in a municipality during a given year. The data are obtained from INSEE and cover 2007-2018. As an alternative proxy for economic activity, I use the total wages of the municipality's residents over 2002-2016, obtained from the annual declaration of social data (DADS).

Local public services. I gathered novel data on two local public services commonly transferred to the IC level: daycare and municipal libraries. Daycare data come from the Family Allowance Agency (CAF), which gives the number of daycare facilities and the total number of daycare spots available in each municipality for every year over 2007-2018. Data on the location of municipal libraries come from a yearly survey run by the Ministry of Culture from 2009 to 2018. While all French départements ended up participating in the survey, only seven were surveyed in 2009. The analysis of public libraries is thus restricted to those départements.

I also gathered data on public schools, a largely centralized public service which is unlikely to be directly affected by intermunicipal cooperation. I obtained data on the number of preschool (maternelle) and primary schools in each municipality over 2009-2018 from the Ministry of Education. Data on higher-level schools (including secondary schools, high-schools, and universities) come from the Central Education Database (BCS) made available by the Quetelet network for 2004-2018.

Public transport. Information on municipalities' access to public transport comes from the Center for Studies and Expertise on Risk, the Environment, Mobility and Development (CEREMA) which surveys public transport operators every year in all French regions except Île-de-France. Operators report the list of municipalities served by their network. I thus know for each year which municipalities have access to a public transport network. The database includes all regular public 
transport networks that are managed at the municipal or intermunicipal level, accounting for about half of French public transport networks and 90 percent of all public transit trips (the other networks are managed at the departmental or regional level). Specific and temporary transports such as school bus services or transport services during market days are not included in the database. Data are available for every year until 2017, when the survey ended.

Fiscal revenues. I use municipalities' and ICs' annual accounts that are made publicly available by the French Ministry of Economy and Finance (DGFiP) from 2010 to 2018. For years prior to 2010 , the data come from Fabre (2021).

\section{Empirical Strategy}

\subsection{Sample of analysis}

This paper uses a difference-in-differences strategy in order to assess the impact of integration on resisting municipalities. More precisely, I compare, before and after the 2010 law, municipalities that were not part of an intermunicipal community in 2010 - and thus forced to integrate-with municipalities that were already part of an IC in 2010 and thus not affected by the law.

I consider a balanced panel of municipalities and I focus on metropolitan France, excluding overseas territories and Corsica. I also exclude law exceptions: municipalities exempt from the law (Paris, municipalities in the three départements around Paris, and a few islands), and where the law applied differently (municipalities in mountain zones). ${ }^{15}$

My treatment group is made of municipalities that were still isolated in 2010. I distinguish two types of municipality among those already integrated: (a) those that were already integrated by 1999 and thus had entered an IC long before the law and (b) those that integrated between 2000 and 2010 and thus entered an IC closer to the law. To make sure that control municipalities are not affected by their shift in integration status during the period of interest, I restrict the control group to group (a) and focus on the time period around the 2010 law, from 2004 to 2018. ${ }^{16}$ The results are robust in both significance and magnitude to varying the latest date of integration of the control municipalities, from including only municipalities that integrated before 1999 to including all municipalities already integrated in 2010 (see Appendix B1).

\footnotetext{
${ }^{15}$ As noted in Section 2.2, as municipalities in mountain zones are small and far from each other, the 2010 law applied differently. First, the prefect had less leverage to force them to enter an IC, as her decision had to be approved by the local "mountain committee," which slowed down the process. By 2013, only 60 percent of these municipalities were integrated, compared to 77 percent outside of mountain zones. Second, communities in mountain zones were not subject to the 5,000 population threshold, meaning that isolated municipalities were free to create or join smaller ICs.

${ }^{16}$ This definition of the sample excludes the less than 1 percent of municipalities whose integration status changed over 1999-2010: isolated municipalities in 2010 that were part of an IC at some point between 1999 and 2010 as well as municipalities that were part of an IC in 2010 but briefly isolated at some point between 1999 and 2010 . The results remain unchanged if I include them.
} 
The final main sample of analysis is a balanced panel of 16,396 municipalities: 15,097 in the control group and 1,299 in the treatment group ( 8 percent). To illustrate the sample, Figure 2 plots the share of municipalities part of an IC, separately for the control group (blue line) and the treatment group (red line). By construction, all municipalities in the control group belonged to an IC by 1999 and over the whole period. In contrast, no municipality in the treatment group belonged to an IC before 2010. After the law, treated municipalities gradually enter a community and, by 2014, all municipalities from the sample are integrated. ${ }^{17}$ Finally, the gray dotted line displays the integration of the 11,894 municipalities that integrated between 2000 and 2010. While these municipalities are excluded from the main sample of analysis, I will take advantage of their staggered integration to assess the impact of integration on municipalities that voluntarily integrated and compare it with the experience of municipalities forced to integrate (see Section 4.2).

\subsection{Descriptive statistics}

Table 1 provides descriptive statistics on the treatment group in 2010 and compares treated municipalities with municipalities that were already integrated.

The first panel displays socio-demographic characteristics. On average, a treated municipality had 1,640 inhabitants in 2010, versus 1,711 for an integrated municipality. While treated municipalities are slightly denser on average, they exhibit similar population growth between 1999 and 2010 and the share of urban municipalities is quite comparable across the two groups. The population composition of treated municipalities is also similar compared to other municipalities, in terms of age composition, average number of children per family, and share of immigrants and unemployed workers. Treated municipalities have a larger share of executives on average (7.0 vs. 5.3 percent for integrated municipalities). Accordingly, residents are on average richer: the average annual taxable income per capita is 14,064 euros in 2010 in treated municipalities against 12,621 euros in the other municipalities. Note, however, that the standard deviation in the treatment group is large (4,362), indicating that it encompasses both rich and poor municipalities. ${ }^{18}$

As shown in Panel B, treated municipalities' land use is similar to that of integrated municipalities in 2010, suggesting that they do not systematically differ in their housing and land-use regulations. The share of built land in treated municipalities is 0.74 percent on average (against

\footnotetext{
${ }^{17}$ There are only two exceptions: one municipality integrated in 2015 and another in 2017. Both went to court to challenge the decision made by the prefect, but ultimately had to comply with it.

${ }^{18}$ Given that integrated municipalities benefit from additional state transfers allocated to their IC and that they share their tax revenues at the IC level, comparing treated and integrated municipalities' fiscal revenues in 2010 would not accurately reflect their relative wealth. Instead, I compare the 2002 fiscal revenues of resisting municipalities with those of municipalities that integrated voluntarily before 2010 but later than 2002 (the first year for which account data are available). In 2002, the average fiscal revenue of resisting municipalities was 581 euros per capita, compared to 523 for municipalities that voluntarily integrated after 2002. This is consistent with the gap found on residents' income in Table 1 and, as for income, the treatment group displays a large standard deviation (346).
} 
0.73 percent in integrated municipalities), the average height of housing constructions is 1.6 stories for both types of municipality, and their measures of floor-to-area ratio (FAR) stringency are very similar.

Overall, treated municipalities are quite representative-based on observables — of an average French municipality. This is reassuring for the identification strategy, as we would not expect completely different groups to display parallel trends in the outcomes of interest. Moreover, the set of treated municipalities is very diverse, which will enable me to perform heterogeneity analysis and to provide evidence that different types of municipality face different consequences of integration. ${ }^{19}$

The last panel displays municipalities' political characteristics, based on the results of the 2008 municipal and 2007 presidential elections. Treated municipalities are more likely to have a rightwing mayor (62.0 vs. 55.9 percent) but the turnout rate in municipal and presidential elections, the share of voters voting for the far-right in presidential elections, and the probability of having a mayor not affiliated with any party ("NC" for "non classified") are comparable across the two groups. Mayors of treated municipalities are slightly more likely to be women, but they have the same age on average as mayors in other municipalities. Finally, treated municipalities have as much political turnover as any other municipality. The average probability that the mayor is the incumbent and has thus been in place since at least 2001 and the probability that the municipality changed political orientation between 2001 and 2008 are very similar in treated and integrated municipalities (66.1 vs. 62.4 percent and 21.0 vs 22.1 percent, respectively).

The fact that treated municipalities are as likely as others to have elected a new mayor in 2008 suggests that their resistance is unlikely to be driven by mayors' individual interests or political preferences. Instead, it suggests that something structural explains why these municipalities kept refusing to integrate across electoral mandates. ${ }^{20}$ Assessing the actual consequences of integration is thus key to understanding why they resisted integration in the first place.

\subsection{Specification and identification}

I estimate the following specification for all municipalities in the main sample of analysis over 2004-2018:

\footnotetext{
${ }^{19}$ Instead of looking at all integrated municipalities, Appendix Table A1 provides the same statistics as in Table 1 but restricting the second group to the control municipalities used in the main estimation. The t-tests of the differences between the control and treatment groups are displayed in Appendix B3, along with the matching analysis. Appendix Table A2 replicates the first panel of Table 1 using municipalities' characteristics in 1999 instead of 2010. Finally, Appendix Tables A3 and A4 replicate Table A1 for urban and rural municipalities separately. The same patterns emerge in all those tables.

${ }^{20}$ Furthermore, Appendix Tables A22 and A23 show that the costs of integration-the effects on construction and public services - are similar whether the mayor was the incumbent or newly elected.
} 


$$
Y_{m t}=\alpha+\beta 1_{\{t>2010\}} 1_{\left\{\text {treated }_{m}=1\right\}}+\delta_{t}+\theta_{m}+\varepsilon_{m t},
$$

where $m$ stands for the municipality and $t$ for the year. $1_{\{t>2010\}}$ is an indicator variable equal to 1 for years after the reform, starting in 2011. $1_{\left.\text {treated }_{m}=1\right\}}$ is an indicator variable equal to 1 for municipalities that were isolated in 2010 and thus forced to join an IC (treatment group), and 0 for municipalities already integrated by 1999 (control group). $\delta_{t}$ and $\theta_{m}$ are time and municipality fixed effects, respectively. The inclusion of municipality fixed effects controls for any time-invariant unobserved factors; the inclusion of year fixed effects captures changes over time that affect all municipalities the same way. Standard errors are clustered at the municipality level. ${ }^{21}$

Outcomes are standardized in order to give the same weight to municipalities of different sizes. I divide each outcome by the 2010 municipal population and then multiply by 10,000. Hence, $Y_{m t}$ is, for instance, the number of housing building permits delivered in municipality $m$ during year $t$ per 10,000 inhabitants, using the 2010 population. In an alternative specification, I divide the outcome by the current population of year $t$ using the number of households living in the municipality. ${ }^{22}$ The results remain qualitatively unchanged, as further discussed in the main text.

The identification assumption is that absent the law, municipalities in the control and in the treatment groups would have evolved the same way. Under this assumption, the main coefficient of interest $\beta$ captures any deviation from a parallel evolution in the outcome of interest between the treatment and the control groups due to the 2010 law. I outline below the additional analyses I perform to support the identification strategy.

Selection into treatment. The first concern is the selection into treatment: municipalities in the control group chose to integrate early, whereas those in the treatment group chose to remain isolated. The question is whether we can expect those two groups to display parallel trends in the outcomes of interest. Two main aspects of the setting might threaten the validity of the common trend assumption. I address them formally below. First, the fact that treated municipalities resisted integration implies that they differ in some aspects and these differences might affect their trends. Reassuringly, Section 3.2 shows that treated municipalities are quite similar to other municipalities based on socio-demographic, land-use, and political characteristics. Still, in Section 7.2, I also show that, while similar on average, treated municipalities tend to join ICs encompassing larger municipalities and lose more bargaining power upon integration, ultimately explaining why they

\footnotetext{
${ }^{21}$ I also run specifications with standard errors clustered at the IC level, considering municipalities' IC either in 2014 or 2018. While, as expected, the standard errors are generally slightly larger, all main results remain significant at similar levels (see Appendix B2).

${ }^{22}$ The municipal population computed by the annual census is an average over 5 years, with different municipalities being surveyed at different times. The census survey's method makes any census measures challenging to use in a panel. I thus approximate municipalities' size in year $t$ using the number of households computed by the Ministry of Finance based on income tax declarations.
} 
bear the costs of integration. The identification thus rests on the assumption that these differences are orthogonal to the outcomes' trajectories absent treatment. This seems plausible: if having relatively larger neighbors influenced public service and construction trends prior to 2010, we would expect the two groups to differ in 2010 based on socio-demographic and land-use characteristics, which is not the case (Table 1). Instead, I argue that these differences start to matter only once part of an IC, as they make municipalities less able to fight ICs' decisions. Second, one could question whether control municipalities experience different trends because they are part of an intermunicipal community. Removing municipalities that integrated after 1999 alleviates the concern that control municipalities' shifts in integration status affect their trends during the period of interest. Nevertheless, being part of an IC might cause control municipalities to evolve differently across time and to react differently to shocks.

This is ultimately an empirical question and, while the common trend assumption cannot be directly tested, I run several analyses to provide support for it.

First, when presenting the results, I systematically test for the presence of pre-trends by plotting for each outcome the coefficients of the following leads-and-lags regression:

$$
Y_{m t}=\alpha+\sum_{k=2004}^{2018} \beta_{k} 1_{\{t=k\}} 1_{\left\{\text {treated }_{m}=1\right\}}+\delta_{t}+\theta_{m}+\varepsilon_{m t},
$$

where $1_{\{t=k\}}$ is an indicator variable equal to 1 for year $k$. All coefficients are normalized relative to 2010. On top of visually inspecting the pre-trends, I test for the significance of the pre-treatment estimates and for their joint significance.

Second, I estimate the impact of a series of placebo reforms by pretending that treated municipalities were forced to enter an IC before 2010 and excluding the actual treatment period from the estimation (Appendix Figure B4). The results of the placebo exercise are discussed in the main text. $^{23}$

Finally, I show that the main results are robust to using propensity score matching (Appendix B3) and that they are robust to including time-varying controls-namely, municipality size proxied by the number of households and the average household's annual taxable income-as further discussed in the result sections.

Control municipalities affected. We can interpret the estimated $\beta$ of Equation (1) as the causal impact of integration on the treated municipalities, provided that only municipalities in the treatment group are affected by the law. However, some municipalities in the control group might also be impacted - those that are part of an intermunicipal community into which a treated municipality entered, as well as those that are part of ICs that fall below the 5,000-inhabitant threshold and

\footnotetext{
${ }^{23}$ I cannot run the placebo tests on daycare and public libraries, given the few pre-treatment periods I have in the data. This analysis is thus restricted to the number of building permits, fiscal revenues, and public transport.
} 
therefore had to enter a larger IC or whose IC had to merge with another one. Appendix B5 reports the main results using several alternative control groups: excluding control municipalities whose IC received a treated municipality; excluding all control municipalities whose IC changed between 1999 and 2014 as a result of the 2010 law; excluding all control municipalities sharing a common border with a treated municipality to address potential spillovers; excluding all the aforementioned control municipalities. The effects are very similar across these samples, supporting the fact that the estimated effects capture the impact on the treated municipalities only.

\section{Impact on housing supply}

\subsection{Impact on municipalities forced to integrate}

I estimate the impact of integration on the number of housing building permits delivered in municipalities forced to enter an IC. The outcome is the number of housing units allowed for construction in a given year per 10,000 inhabitants (using the 2010 population).

Figure 3 plots the coefficients of the leads-and-lags regression. Vertical lines represent the 95-percent-confidence intervals. First, no coefficient before 2010 is significant and all coefficients prior to the law are close to 0 in magnitude. The F-stat for the joint significance of the pre-reform estimates is 0.74 ( $p$-value 0.617 ). In line with the absence of pre-trends, none of the placebo reforms have a significant effect on housing supply (Appendix Figure B4). Instead, after the 2010 law, we observe a large increase in the building permits delivered in treated municipalities compared to control municipalities. The increase starts in 2012, reflecting the fact that most municipalities forced to integrate joined an IC after 2011. Moreover, when splitting the treatment group according to the exact year municipalities entered an IC, we see that the increase starts right after their integration (Appendix Figure A1). This is consistent with the effect capturing the impact of integration rather than of other potential factors affecting the two groups differently after 2010 .

Table 2 provides the formal estimate. On average, the number of building permits increased by 8.1 per year per 10,000 inhabitants after 2010 in treated municipalities compared to control municipalities, an effect significant at the 1-percent level. ${ }^{24}$ As, on average, resisting municipalities were delivering 64.8 building permits per year per 10,000 inhabitants before 2010, their integration led to a yearly increase of 12.5 percent. The impact is similar in magnitude when dividing the outcome by the number of households in year $t$ instead of the population in 2010 (13.1 percent) and robust to controlling for municipality size and for household annual income in year $t$ (Appendix Table A5). This further suggests that resisting municipalities experienced an increase in building

\footnotetext{
${ }^{24}$ The size of the impact is very similar when using propensity score matching (7.2) and the estimate remains significant at the 1-percent level (see Appendix Table B3.3).
} 
permits per current capita, in line with the impact coming from a change in housing regulations. Moreover, the fact that the impact lasts over the whole post-treatment period (Figure 3) and is similar for municipalities that integrated just after the law or a few years later (Appendix Figure A1) suggests that the increase in construction is unlikely to come from a temporary adjustment but rather reflects a more permanent change in regulations.

Finally, as shown in Columns 2 and 3, the increase is mainly driven by new construction: the number of building permits to build new housing units on empty land increased by 6.8 on average, while the number of building permits to add units to existing building increased by only 1.3. This result shows that resisting municipalities had to expand their share of built land once integrated, which is consistent with municipalities losing control over both housing supply and land-use policies. As nothing prevented them from building more prior to the law, this rise in construction is unlikely to reflect their preferences; it is best interpreted as a consequence of their loss of autonomy. 25

\subsection{Comparison with municipalities that voluntarily integrated}

I now investigate the impact of integration on municipalities that joined an IC voluntarily prior to the law. If the increase in housing supply explains why municipalities forced to integrate resisted, we should see a differential impact for municipalities that instead chose to integrate.

I consider municipalities that were previously excluded from the main sample of analysis: those that joined an IC between 2000 and 2010. ${ }^{26}$ I apply the same geographical restrictions as for the main sample of analysis (see Section 3.1), resulting in a balanced panel of 11,894 municipalities. To estimate the impact of their voluntary integration, I take advantage of the fact that they entered an IC at different times. Formally, I use a staggered adoption design, in which the date of the treatment is the year when the municipality first joined an IC. I run the analysis over the period from 1999 to 2018: in 1999, no municipality in this sample is part of an IC, whereas they all are starting in 2010. I observe municipalities up to 11 years prior to the integration (for municipalities integrating in 2010) and up to 18 years after the integration (for those integrating in 2000). I estimate the following dynamic specification:

\footnotetext{
${ }^{25}$ These effects are unlikely to come from a change in the benefits associated with new construction. If anything, the fact that the housing tax revenues are shared at the IC level after integration should make municipalities even less likely to start new construction. Moreover, if a change of incentives explains the results, we should see similar effects for municipalities that chose to integrate voluntarily prior to the law. Instead, as shown in the next section, municipalities that joined an IC voluntarily prior to the law did not experience the same increase in construction.

${ }^{26}$ I focus on municipalities that joined an IC voluntarily starting in 2000 for two reasons. First, the municipal composition of French ICs is only available from 1999, meaning that we do not know in which year municipalities that integrated earlier entered an IC. Second, the structure of ICs changed following the Chevènement law in 1999. Hence municipalities that integrated voluntarily after 1999 entered ICs closer in characteristics to the ICs that resisting municipalities entered, making the comparison more relevant.
} 


$$
Y_{m t}=\sum_{d=-5}^{d=5} \beta_{d} 1_{\left\{t=t_{m 0}+d\right\}}+\gamma_{1} 1_{\left\{t<t_{m 0}-5\right\}}+\gamma_{2} 1_{\left\{t>t_{m 0}+5\right\}}+\delta_{t}+\theta_{m}+\varepsilon_{m t},
$$

where the year of integration of municipality $m$ is denoted $t_{m 0}$, and $d$ indexes time-to-integration (negative before integration and positive after). The $\beta_{d} \mathrm{~s}$ measure the difference between municipalities that are part of an IC and those not already part of a community, for each of the five years preceding and following the integration. $\gamma_{1}$ (resp. $\gamma_{2}$ ) estimates the effect for being more than five years before (resp. after) the integration. All coefficients are normalized relative to the year preceding the integration $(d=-1)$. I include time and municipality fixed effects; standard errors are clustered at the municipality level.

In light of the recent literature on the issues associated with event study designs (e.g., de Chaisemartin and D'Haultfoeuille, 2020; Borusyak et al., 2021; Goodman-Bacon, 2021), I also use an alternative estimation procedure developed by de Chaisemartin and D'Haultfoeuille (2020). By using "not-yet-switchers" as controls, the authors provide new estimators that are robust to heterogeneous treatment effects across groups and over time. ${ }^{27}$

Figure 4 plots the coefficients, taking as outcome the number of housing building permits delivered per year per 10,000 inhabitants ${ }^{28}$ and applying the same scale as in Figure 3 . The lefthand graph shows what I obtain using the regular staggered adoption design (referred to as method 1) and the right-hand graph what I obtain using de Chaisemartin and D'Haultfoeuille (2020)'s method (referred to as method 2).

In both graphs, only one coefficient is statistically significant in the post-treatment period. The impact of integration is close to 0 except in the fourth year after integration, when the number of building permits increases by 4 to 8 depending on the method. The effect vanishes the year after and remains nonsignificant afterwards. These results contrast with the experience of municipalities forced to integrate, namely a large increase in construction starting right after their integration and continuing over the entire post-treatment period (Figure 1 and Appendix Figure A1). ${ }^{29}$

Hence, only municipalities that did not want to enter an IC experienced a significant rise in construction. This differential impact supports the view that treated municipalities opposed inte-

\footnotetext{
${ }^{27}$ For more details on de Chaisemartin and D'Haultfoeuille (2020)'s method for staggered adoption design, see Section 5.2 of their paper. Note that this method allows me to compute the estimated effect of being a given number of years before or after the treatment, but not to compute the estimated effect of being more than 5 years before or after the date of the treatment. Both estimates are thus absent in the right-hand graph in Figure 4.

${ }^{28}$ Because I consider municipalities integrating from 2000, I divide the outcome by the 1999 population instead of the 2010 population.

${ }^{29}$ This difference is unlikely to be driven by the fact that the two types of municipality integrated in different periods and thus in different economic climates. In the first specification, I include all years from 1999 to 2018, meaning that I also measure the impact of voluntary integration on the number of building permits delivered after 2010, in the same period as for resisting municipalities. Moreover, the results are similar when focusing on municipalities that voluntarily integrated after 2004, closer to the integration date of the ones forced to integrate (Appendix Figure A2).
} 
gration to avoid a rise in housing supply. It also suggests that mayors' decision to resist was driven by the actual consequences of integration, beyond purely ideological or political considerations. Section 7 discusses further the differential impact between resisting municipalities and those that voluntarily integrated and provides additional evidence supporting this interpretation.

\subsection{Heterogeneity analysis}

As stressed by the literature on housing restrictions, several stories can explain why municipalities would oppose new construction, depending on their characteristics. First, construction in high-demand and densely built places limits the space available, which can trigger resistance from residents who do not want new buildings in their backyards (Saiz, 2010; Hilber and Robert-Nicoud, 2013). Second, new construction might increase the population's heterogeneity in municipalities surrounded by different neighbors (Rolleston, 1987; Bates and Santerre, 1994). Third, through its effect on housing prices, new constructions might decrease the value of residents' assets in municipalities with a large share of homeowners (Fischel, 2001; Ortalo-Magné and Prat, 2014).

To determine which story best explains municipalities' opposition to construction, I explore which types of municipalities are driving the impact on housing supply. I use the same specification as in Section 4.1 and perform heterogeneity analyses along several municipality characteristics measured in 2010, prior to the law. The results presented here are obtained by splitting the full sample at the median value of the heterogeneity variable. For each heterogeneity analysis, Appendix $C$ reports the results from the estimation of Equation (1), in which I add interaction terms with the continuous heterogeneity variable. The corresponding coefficient gives the change in the treatment effect coming from a one-standard-deviation increase in the heterogeneity variable.

\section{NIMBYism: "Not in My BackYard"}

If NIMBYism explains resistance, we should see that the impact on construction is stronger in high-demand and densely built municipalities, where residents' concern over density is higher. Indeed, attractive locations will have a larger share of developed land and residents will therefore be more likely to oppose new construction so as to prevent further increases in housing density (Gyourko and Molloy, 2015).

I proxy municipalities' attractiveness by their location in the urban area. Consistent with the monocentric model, ${ }^{30}$ the demand for housing in French municipalities is the highest closer to the local center of employment and thus closer to the core of the urban area (Combes et al., 2018).

\footnotetext{
${ }^{30}$ The monocentric model predicts that the housing demand is the highest in the center (Alonso, 1964). This is consistent with most housing markets in developed countries, with the notable exception of the US, where the more desirable places are usually in the suburbs (see, for instance, Jackson, 1987).
} 
Accordingly, municipalities that are part of an urban area also have a higher share of built land. ${ }^{31}$ As shown in Table 3 and Appendix Figure A3, the impact on housing supply is driven by treated municipalities that are part of an urban area: after integration, they experienced an average increase of 10.5 in the number of building permits delivered per year per 10,000 inhabitants, an effect significant at the 1-percent level, while municipalities outside any urban area experienced an average increase of only 3.1, which is not significant (Columns 2 and 3). The increase is largest for municipalities in the core (24.5 or 38.3 percent per year, Column 4) and a shorter Euclidean distance to the core is associated with a stronger effect of integration on housing supply (Appendix Table C1). Using residents' income as an alternative measures of attractiveness, I also find that the impact on construction is higher the richer the municipality (Appendix Tables A6 and C2). ${ }^{32}$

Focusing on municipalities inside an urban area, I further show that the effect is even larger for those that are relatively more densely built and thus where new construction most reduces the space available (Appendix Table A8 and Figure A4). Although the coefficients for urban municipalities are noisier-they make up 30.5 percent of the sample-the increase after 2010 is larger in magnitude: the number of building permits increased by 15.5 per year (23.6 percent, Column 2) versus 9.9 in rural municipalities (15.7 percent, Column 3). ${ }^{33}$ Similarly, when splitting the sample according to the number of housing units per square kilometer in 2010, the impact is larger for municipalities above the median (13.9 vs. 9.3, Columns 5 and 4). Appendix Table C3 indicates that a one-standard-deviation increase in housing density increases the treatment effect by 8.5 - or more than half — compared with the impact on housing for an average treated municipality in the urban area.

Finally, the differential impact between more or less dense municipalities is unlikely to be explained by the fact that these municipalities enter different types of ICs. As shown in Appendix Table A9, the impact is twice as large for urban municipalities as for rural municipalities, even when considering only municipalities ending up in ICs required by law to issue the most stringent housing plans ("CA" and "CU"; see Section 2.1). Taken together, these results suggest that munici-

\footnotetext{
${ }^{31}$ Close to the definition of American metropolitan areas, a French urban area is defined as a group of neighboring municipalities encompassing an urban core (urban unit) providing at least 5,000 jobs, and by rural districts or urban units (urban periphery) among which at least 40 percent of the employed resident population works in the core or in the municipalities attracted by this core. I use the 2010 urban area breakdown and consider both large (providing at least 10,000 jobs) and medium (providing between 5,000 and 10,000 jobs) urban areas. The results are left unchanged when using the 1999 breakdown instead. In 2010, France counted 372 urban areas, encompassing two thirds of the municipalities and 85 percent of the population. The average share of built land in municipalities that are part of an urban area is 1.1 percent, versus 0.4 percent for municipalities outside any urban area.

${ }^{32}$ Due to income sorting, residents' income is positively correlated with the probability that a municipality is part of an urban area. To alleviate the concern that the income heterogeneity results are solely driven by this correlation, Appendix Table A7 replicates Table A6 considering only municipalities that are part of an urban area. As for the full sample, the impact is twice as large for municipalities above the income median.

${ }^{33}$ Based on international standards, an urban municipality is a municipality belonging to an urban unit, defined as a continuously built up zone (no cut of more than 200 meters between two constructions) with at least 2,000 inhabitants.
} 
palities that opposed integration to keep control over their housing supply are mainly high-demand urban municipalities trying to avoid new construction in their backyards.

\section{Neighbors' characteristics}

Alternatively, municipalities might oppose new construction to avoid different people coming in, particularly poorer households and/or minorities.

First, while the data do not specify whether or not the building permit is delivered for social housing, the increase in construction is unlikely to come from additional social housing. In France, social housing is concentrated in the largest municipalities (above 3,500 inhabitants), where it is mandatory (Gobillon and Vignolles, 2016). As shown in Appendix Table A10, the impact on housing supply is very stable across municipality size, with municipalities below 1,000 or below 500 inhabitants experiencing a similar rise in construction per capita.

Still, new regular housing could bring different people in. If this is why municipalities opposed construction, we should see a stronger effect for municipalities surrounded by neighboring municipalities that are more different from them. I consider several heterogeneity dimensions: per capita residents' annual taxable income, the share of unemployed workers, and the share of immigrants. For each, I construct a ratio equal to the value for the municipality divided by the average value in neighboring municipalities, weighted by their population. For instance, the immigration ratio indicates whether the proportion of immigrants in a given municipality in 2010 was greater than, less than, or equal to the average proportion in surrounding municipalities. I define surrounding municipalities as all other municipalities from the same département, including but not limited to those from the same IC. The results are robust if I instead define surrounding municipalities as direct neighbors - those sharing a border (Appendix Tables A11 and C5).

Table 4 reports the impact on housing supply depending on whether the municipality is above or below the median value of the ratio. If municipalities were trying to prevent poorer people from coming in, we should see a stronger effect the richer the municipality is compared with its neighbors and thus the higher the income ratio. Instead, the impact is very similar for municipalities below and above the median (8.0 and 7.4, Columns 2 vs. 3). Conversely, if municipalities resisted because they expected more immigrants or unemployed workers to come, we should see that the effect is larger the smaller the municipality's share of immigrants or unemployed compared with those of its neighbors and thus the smaller the ratios. Instead, the impact is larger for municipalities above the median (Columns 4 to 7 ). ${ }^{34}$ The effect is even surprisingly large for municipalities above the unemployment ratio median (Column 7). However, the estimate obtained by interacting the treatment variable with the unemployment ratio is small and not significant, indicating that this

\footnotetext{
${ }^{34}$ The effects are similar if I consider non-European immigration only (Appendix Table A12).
} 
result should not be overinterpreted. Similarly, the interactions with the income and immigrant ratios provide small and nonsignificant estimates (Appendix Table C4).

Next, I consider two measures capturing political heterogeneity. I first look at whether, in 2010, the mayor had the same political orientation as the member of parliament elected by the municipality's legislative district, indicating whether or not the municipality is politically aligned with the median voter of its district. ${ }^{35}$ Second, I consider the absolute value of the difference between the share of voters in the municipality and the share of voters in surrounding municipalities who voted for the right-wing candidate in the second round of the 2007 presidential election, in which a candidate from the right faced a candidate from the left. As shown in Appendix Table A13, the impact on construction is not stronger when the municipality is less politically aligned with its neighbors. The effect is similar whether or not the mayor has the same orientation as the member of parliament, and even a bit larger when she does (8.7 vs. 7.2, Columns 2 and 3). While the impact is slightly larger for municipalities above the vote-share-difference median (10.0 vs. 6.0, Columns 5 and 4), the estimates are instead very close when considering only direct neighbors (8.3 vs. 7.9, Columns 7 and 6), and the coefficient corresponding to the interaction between the heterogeneity and treatment variables is small and not significant (Appendix Tables C4 and C5). Overall, this suggests that the impact is not driven by municipalities whose neighbors are more different in terms of income, immigration, unemployment, or political preferences.

\section{Homeowners}

Finally, if homeowners' fear of a housing price decline explains why municipalities resisted integration, we should see that the impact on construction is higher the larger the municipality's share of homeowners. Instead, the effect is not stronger for treated municipalities above the median (Table 5) and the interaction between the treatment variable and the share of homeowners is negative and not significant (Appendix Table C6). To account for the fact that homeownership is negatively correlated with housing density, Appendix Table A14 reproduces the same analysis restricting the sample to urban municipalities. As for the full sample, the impact is equally strong for urban municipalities above and below the median.

These findings are consistent with the lack of empirical evidence supporting the hypothesis that housing regulations are stronger in places with a higher rate of home ownership (e.g., Brueckner, 1998; Glaeser and Ward, 2009; Hilber and Robert-Nicoud, 2013). They also show that resistance is not driven by homeowners only, in line with recent evidence showing that renters can express as much NIMBYism as homeowners, particularly in high-demand places (Hankinson, 2018).

\footnotetext{
${ }^{35}$ The last parliamentary election before 2010 took place in 2007. At that time, metropolitan France had 551 legislative districts (circonscriptions), each encompassing 128 municipalities on average. In 2010, 57 percent of the mayors had the same political orientation as their member of parliament (63 percent in the treatment group).
} 


\subsection{Impact on housing prices and economic activity}

\section{Housing Prices}

To investigate the actual impact of integration on municipalities' housing prices, I built indices based on official housing transactions, which can be interpreted as the price per square meter of a reference dwelling. As data on housing transactions for the Parisian region of Île-de-France and for the rest of France come from different databases, I present the results for the two parts of France separately (see Appendix D for more details). Since housing prices are arguably forward looking, we can expect them to reflect any changes in expectations about housing value shortly after the 2010 reform.

While the increase in construction in resisting municipalities is likely to affect housing prices throughout the local housing market, my goal is to assess whether resisting municipalities had to face a drop in housing prices after integration, which could account for their resistance. I thus run the analysis at the municipal level and I consider a balanced sample of municipalities, restricting the analysis to those in which at least one transaction took place every even year. This results in a sample of 459 municipalities in the Parisian region and 6,756 in the rest of France (44.0 percent of the initial sample in total). Considering instead all municipalities with at least one transaction during the period of interest almost doubles the sample size and leaves the results unchanged (Appendix Figure D1). Given that municipalities that are part of an urban area have more housing transactions, municipalities driving the impact on construction are overrepresented: municipalities part of an urban area (resp. urban core) make up 76.7 percent of the sample (resp. 23.8 percent) versus 61.6 percent (resp. 11.7 percent) of the full sample.

Figure 5 shows a small decrease in housing prices in 2014 for treated municipalities in the Parisian region, but the estimated impact is not significant and is small in magnitude (-56 euros per square meter, or 2.3 percent). The decrease is even smaller for the rest of France, suggesting that overall, forced integration had no significant impact on housing prices. While there are some early pre-trends for the rest of France, the post-treatment effect remains close to 0 when considering the unbalanced panel, for which the pre-trends are no longer significant (Appendix Figure D1). Moreover, the same conclusions hold when using an alternative version of the indices in which I include a larger set of housing characteristics in the hedonic regressions and when restricting the analysis to municipalities inside the urban area (Appendix Figures D2 and D3).

These results are consistent with high-demand places driving the impact on construction. As stressed by Lin and Wachter (2020), when housing constraints are relaxed at the local level, we can expect both a direct and an indirect effect on prices: the drop in prices coming from the increased supply affects the reallocation choice of households, depressing the demand in nearby municipalities and increasing the demand in the municipality in which regulations have been relaxed. This 
spillover effect is larger the more attractive the municipality. It can compensate for the direct effect, leading to an overall null impact on prices.

\section{Economic Activity}

I explore whether the increase in building permits is associated with a rise in economic activity, which could mitigate the disutility associated with more construction. I first proxy economic activity by firm creation and assess the impact of integration on the number of new establishments created per 10,000 inhabitants in municipalities forced to integrate. I then measure the impact of integration on residents' total wages, divided by the number of inhabitants.

The point estimates are close to 0 and nonsignificant for both outcomes, whether we look at the full sample (Figure 6) or only at municipalities that are part of an urban area (Appendix Figure A5). These null effects provide additional evidence that the rise in construction is caused by a change in housing regulations after integration, rather than by a change in economic conditions. It also suggests that, at least in the medium run, the increase in construction in residents' backyards is not compensated for by greater economic activity.

\section{Impact on local public services}

In order to achieve economies of scale, ICs seek to rationalize the offer of local public services and thus tend to concentrate resources on a subset of public service facilities. In particular, they are likely to concentrate resources on facilities located in central and densely populated areas, closing facilities or preventing new ones from opening in other areas. As a result, low-density municipalities may lose local public services after entering an IC, which then increases the distance to public services for their residents. The loss of local public services is an important source of discontent, as evidenced by the recent demonstrations and blockades of the yellow vests movement in France, which was tightly linked to the loss of public service facilities in peripheral places (Algan et al., 2020; Boyer et al., 2020).

I gathered local data on two different public services transferred to the IC after integration: child daycare and public libraries. I explore the impact on the number of daycare spots available and on the number of public libraries located in municipalities forced to integrate, per 10,000 inhabitants (using the 2010 population). The data are less comprehensive than the data on building permits. First, data on daycare and libraries start in 2007 and 2009, respectively, which does not leave enough time prior to the law to compare the main results with the effects of integration for municipalities that voluntarily integrated before 2010. Moreover, while data on daycare are 
available for the whole territory, data on libraries are available for only seven départements. ${ }^{36}$ Still, the results go in the same direction for both daycare and libraries, strengthening the conclusions we can draw about the effects of integration on local public services in resisting municipalities.

To test the main prediction - that integration decreases public services in low-density placesFigure 7 presents the results separately for rural and urban municipalities (see Appendix Figure A6 for the impact on the full sample). The decreasing trends for rural municipalities indicate that rural municipalities forced to integrate ended up with fewer public services after the law, compared to rural control municipalities. We see no such decline for urban municipalities and, if anything, the trend is even slightly increasing after the law.

Table 6 provides the estimates for the full sample and separately for rural (Columns 2 and 5) and urban municipalities (Columns 3 and 6). In line with the graphical evidence, the coefficient for rural municipalities is negative and significant at the 5-percent level for both public services, whereas the coefficient for urban municipalities is either positive or close to 0 and not significant. In the average year after 2010, rural municipalities forced to integrate had 1.0 fewer daycare spot and 1.2 fewer public libraries per 10,000 inhabitants, compared to rural control municipalities (a decrease of 27.7 and 23.6 percent, respectively). The number of daycare facilities follows a similar pattern, suggesting that the loss of entire daycare facilities is what is driving the decrease in the number of daycare spots (Appendix Figure A7 and Table A15). Interestingly, the resulting effect on the gap in public good provision between rural control and treated municipalities differs for the two public services. On the one hand, rural municipalities forced to integrate already had fewer daycare spots per capita in 2010, meaning that their integration further increased the gap with rural control municipalities. On the other, they had more public libraries per capita, meaning that their integration brought them closer to rural control municipalities. ${ }^{37}$

The decrease in public services remains significant and the effect size is of similar magnitude when dividing the outcomes by the number of households in year $t$ rather than by the 2010 population and when controlling for municipalities' size and residents' revenues (Appendix Table A16). This suggests that the impact is not driven by a differential change in the population of rural treated and control municipalities after 2010. Instead, these results are consistent with the loss of public services being driven by decisions made at the IC level to concentrate resources in denser municipalities, explaining rural municipalities' resistance to integration in the first place.

To provide further support for this interpretation, I assess the impact of integration on public

\footnotetext{
${ }^{36}$ The seven départements are in different parts of the country: Aisne (in the north of France), Finistère (west), Drôme (southeast), Gironde and Dordogne (southwest), and Essonne and Val d'Oise (center north). They make up 9 percent of the municipalities in the main sample of analysis.

${ }^{37}$ In 2010, rural resisting municipalities had on average 4.0 daycare spots per 10,000 inhabitants, compared to 6.5 for rural control municipalities, while having the same average number of children (see Table 1). In contrast, rural resisting municipalities had on average 6.7 public libraries per 10,000 inhabitants, compared to 4.5 for rural control municipalities.
} 
schools. If the impact on daycare and libraries is driven by the loss of control over public services, we should not find the same pattern for public services that are unlikely to be directly affected by integration. I look at the number of preschools (maternelles) and primary schools in the municipality and then at the number of higher-level schools, including secondary schools, high schools, and universities. The former are managed both at the national and municipal levels, but municipalities' role is limited (see Section 2.1). The latter are managed at the national and departmental or regional levels. Unlike the case of daycare and public libraries, integration does not lead to a decrease in the number of public schools in rural municipalities forced to integrate and the point estimates are close to 0 (Appendix Figure A8).

\section{Evidence on the benefits of integration}

Results so far suggest that urban municipalities resisted cooperation to avoid an increase in construction, while rural municipalities resisted cooperation to avoid losing local public services. In this section, I investigate the impact of integration on two additional dimensions on which cooperation is likely to provide some benefits: public transport and fiscal revenues. I first assess the impact for municipalities forced to integrate to see what they were ready to give up by not integrating. I then compare the effect with what municipalities that integrated voluntarily experienced. This enables me to see whether, on top of incurring the costs of integration, resisting municipalities also benefited differently from the gains of cooperation.

\subsection{Impact on public transport}

By enhancing cooperation and enabling municipalities to pool resources, integration is likely to help neighboring municipalities build larger and more efficient public transport networks. As a result, joining an IC might increase a municipality's probability of being connected. I estimate the impact of integration on an indicator variable equal to 1 if the municipality is connected to a public transport network at some point during the year (there is at least one public transport route operating in the municipality) and 0 if the municipality is not connected (there is no public transport route). This analysis excludes municipalities in Île-de-France, for which data on public transport are not available.

Figure 8 shows the impact for municipalities forced to integrate. The decreasing pre-trend suggests that before 2010, access to public transport increased more rapidly for control municipalities than for treated municipalities. One plausible explanation is that coordination inside ICs helped control municipalities develop transport networks more rapidly. In contrast, the large increasing trend after 2010 shows that, after the law, access to public transport increased more rapidly for mu- 
nicipalities forced to join an IC. In line with the presence of pre-trends, the coefficients associated with the placebo reforms before 2010 are significant but small and negative, contrasting with the large and positive effect of the true reform (Appendix Figure B4).

Table 7 indicates that resisting municipalities' probability of being connected to a public transport network is 3.2 percentage points higher in the average year after 2010, an effect significant at the 1-percent level. Given that only 2.4 percent of treated municipalities had access to public transport before 2010, their entry into an IC more than doubled their probability of being connected. In 2017, the effect reaches 6.8 percentage points, a nearly three-fold increase. The point estimate is larger for urban than for rural municipalities (10.6 vs. 2.0, Columns 3 and 2), but the magnitude relative to the pre-treatment mean is similar and both estimates are significant at the 1-percent level. The impact is robust in magnitude and statistical significance to using propensity score matching or to adding time-varying controls (Appendix Tables A17 and B3.5).

I then measure the impact of integration on public transport for municipalities that voluntarily joined an IC before 2010, using the same estimation methods as in Section 4.2 (Appendix Figure A9). The results obtained with the regular staggered adoption design suggest that, on average, the probability of having access to public transport is 2 percentage points higher in the years following their integration. Using de Chaisemartin and D'Haultfoeuille (2020)'s method, I find that the impact increases over time and reaches 4 percentage points four years after integration. This is a sizable effect, given that only 3.4 percent of the municipalities that integrated between 2000 and 2010 had access to public transport in 1999. Hence, integration had a large positive effect on public transport for both municipalities that voluntarily joined an IC and those that resisted integration. Moreover, as the share of residents using their cars was the same in both types of municipality in 1999-before any of them integrated-we can conclude that they benefited equally from this increase in public transport. ${ }^{38}$

\subsection{Impact on fiscal revenues}

I study the effect of integration on the resources available to finance municipalities' public services. First, while a municipality's own state transfers do not change after integration, it does benefit from the additional state transfers allotted each year to the IC. Second, the resources coming from tax revenues are likely to be affected. Tax collection at the IC level might decrease tax competition and lead to higher tax revenues compared to what the municipality was collecting on its own. This increase might be either amplified or mitigated depending on whether the municipality joins neighbors with a smaller or larger tax base than its own.

\footnotetext{
${ }^{38}$ Statistics from the 1999 census indicate that 75.3 percent of resisting municipalities' residents were using their cars to go to work compared with 76.7 percent for municipalities that voluntarily integrated between 2000 and 2010.
} 
I compute municipalities' resources as follows. If a municipality is isolated, its fiscal revenues are made up of its own tax revenues and state transfers. If a municipality is part of an IC, I compute its fiscal revenues as the sum of its own fiscal revenues and the total IC's fiscal revenues scaled by the municipality's share of the total IC population. ${ }^{39}$ I then divide the total fiscal revenues by the municipal population in 2010. This outcome measures the resources available per resident, assuming that every resident benefits equally from the IC's spending. While the results of Section 5 suggest otherwise, comparing the impact for municipalities forced to integrate and those that voluntarily integrated sheds light on whether resisting municipalities entered ICs generating lower revenues, which could further explain why they resisted integration in the first place.

As shown in Figure 9, contrasting with the small decreasing trend before 2010, municipalities forced to integrate had a large increase in fiscal revenues after integration. As with public transport, the estimates associated with placebo reforms are small and negative, contrasting with the large and positive effect of the true reform (Appendix Figure B4). Table 8 indicates that, on average, integration increased fiscal revenues by 101.2 euros per capita per year in resisting municipalities, an effect significant at the 1-percent level.

This effect corresponds to a 14.5-percent yearly increase and is of similar magnitude for rural and urban municipalities (15.1 and 13.3 percent, Columns 2 and 3). Transfer and tax revenues increase in similar proportion compared to the pre-treatment means, showing that they contribute equally to the overall impact (Appendix Figure A10 and Table A18). Note that the increase in fiscal revenues can be interpreted as an increase per current capita, given that the magnitude is similar when dividing by the number of households in year $t$ and when controlling for municipalities' size (Appendix Table A19).

Turning to municipalities that decided to join an IC voluntarily prior to the law, Appendix Figure A11 (Panel A) suggests that their fiscal revenues increased by about 80 to 100 euros per capita per year after their integration, or 14.1 to 17.6 percent per year. ${ }^{40}$ As for municipalities forced to integrate, the increase comes from both additional state transfers and higher fiscal revenues (Appendix Figure A11, Panels B and C). The impact is thus similar for resisting municipalities and for those that voluntarily integrated. All together, these results suggest that resisting municipalities did not oppose integration due to lower benefits, but to avoid the local costs of integration.

\footnotetext{
${ }^{39}$ If the IC gives direct transfers to one of the member municipalities-for instance, as part of the "solidarity transfers" to poorer municipalities in the community-I consider these transfers as part of the revenues of that municipality only, but not as part of the total IC revenues shared among all members.

${ }^{40}$ Data on municipalities' and IC's fiscal revenues are available only starting in 2002. I therefore focus the analysis on municipalities that voluntarily integrated between 2003 and 2010. For the regular staggered adoption design, the period of analysis goes from 2002 to 2018, while in using de Chaisemartin and D'Haultfoeuille (2020)'s method the period of analysis goes from 2002 to 2009 (see Section 4.2). To compute the magnitude of the effect, I compare the increase of 80 and 100 euros to the average fiscal revenues in 2002 for municipalities not already integrated.
} 


\section{Interpretation and mechanisms}

\subsection{Interpretation}

While municipalities forced to integrate experienced benefits of integration similar to those of municipalities that voluntarily integrated, they faced an increase in construction and a loss of local public services that the other municipalities did not experience, at least regarding construction. I have interpreted those results as evidence that municipalities resisted integration to avoid those very costs. This interpretation assumes that they correctly anticipated the consequences of integration and that they would have experienced the same costs had they integrated earlier. Alternatively, one could argue that resisting municipalities faced such effects because they integrated later on and were forced to do so. They might have entered ICs better organized and more able to impose costs on them. Moreover, already-integrated municipalities might have decided to punish them for having resisted so long. This would imply that resisting municipalities would not have experienced the same costs had they voluntarily integrated earlier, casting doubt on whether the impacts observed can explain their resistance.

If this alternative interpretation is correct, we should see that the costs of integration are borne by treated municipalities that entered existing ICs after the law, as opposed to treated municipalities that created new ICs after 2010. Similarly, when joining existing communities, we would expect the costs to be lower for those that joined more recently created ICs. Finally, if municipalities are punished for not having integrated the community earlier, we would expect the impact to be lower for resisting municipalities that shared borders with several ICs at the time of the law, as it would be less clear which IC they were avoiding. I assess the impact of integration in each of these situations, focusing on municipalities that are part of an urban area with respect to building permits and focusing on rural municipalities with respect to daycare and public libraries.

As shown in Table 9, compared to the effect for the full sample (10.5, Column 1), the impact on construction remains large and significant at the 1 percent level for treated municipalities that joined a new IC (8.8, Column 1), joined a recently created one (15.6, Column 4), or had a choice of at least two ICs at the time of the law (6.9, Column 5). Turning to public services (Appendix Table A20), the impact for rural municipalities remains negative across all three cases and only loses statistical significance for recent IC (resp. new IC) for daycare services (resp. libraries).

When entering a new or a recently created IC, the integration process of resisting municipalities resembles that of municipalities that integrated early on. Finding similar patterns in such cases supports the view that municipalities that opposed integration would have experienced the same had they integrated earlier and thus that the consequences they faced help explain their resistance. 


\subsection{Mechanism}

The results above further support the view that municipalities forced to integrate opposed cooperation knowing that they would face some costs in terms of housing supply and local public services. This begs the question of how other municipalities were able to avoid these costs?

One possible explanation is that the costs of integration apply only to municipalities with specific characteristics. However, as shown in Section 3.2, resisting municipalities are on average quite similar to municipalities that integrated voluntarily, based on socio-demographic, land-use and political characteristics. Moreover, urban municipalities face the largest increase in construction while only rural municipalities experience a loss of public services, showing that integration costs can apply to different types of municipality.

A more likely explanation is that the resisting municipalities are the ones losing the most autonomy when integrating. This can be the case if such municipalities - although on average similar to the rest of the country - tend to be smaller than their neighbors and thus less able to fight their IC's decisions. As the number of seats a municipality gets in the intermunicipal council is proportional to its population, I measure a municipality's bargaining power as its share of the IC's total population divided by the share of the IC's total population an average municipality from the same IC represents. The greater this ratio, the larger the share of seats the municipality has compared with the average number of seats others get. I look at the composition of ICs in 2014-that is at the end of the period of integration. While the average value of the ratio is 1 by construction, it is only 0.85 for municipalities that were forced to integrate, suggesting that resisting municipalities have a 15 -percent lower bargaining power on average.

A municipality loses even more power when joining an IC encompassing large municipalities that can impose their decisions. Resisting municipalities are also more likely to end up in such situation: 51.2 percent of them are part of an IC encompassing a big city (of more than 5,000 inhabitants) in 2014, versus 42.3 percent for the full sample. ${ }^{41}$ Moreover, in line with the costs being the highest for municipalities losing the most power, Table 10 shows that the impact on construction is larger for resisting municipalities that join an IC encompassing a big city (13.0 vs. 6.1). The results on public services are less conclusive; they go in the expected direction for libraries but not for daycare (Appendix Table A21). This can be explained by the fact that resisting rural municipalities do not need to integrate with a big city to loose a great share of autonomy, given the very low bargaining power they have to start with (average ratio of 0.63 ).

All together, these results suggest that municipalities resisted integration knowing that they would not be able to prevent their neighbors from imposing new construction or decreasing the availability of public services on their territory. This also suggests that the costs identified in this

\footnotetext{
${ }^{41}$ The threshold of 5,000 inhabitants corresponds to the minimum legal size of an IC. Only 5 percent of French municipalities had more than 5,000 inhabitants in 2010 .
} 
paper can explain resistance beyond the specific case of municipalities forced to enter an IC in 2010. In particular, they help explain why the vast majority of French municipalities recently opposed new laws aimed at increasing the size of intermunicipal communities. Such reforms would lead many municipalities to lose bargaining power and thus to suffer from costs they have been able to avoid so far. ${ }^{42}$ Finally, as most forms of cooperation among local jurisdictions imply sharing urban planning policies and public services, these findings may help explain resistance to integration beyond the case of French municipalities, as long as the decision process involves some jurisdictions losing more power than others.

\section{Conclusion}

This paper provides new evidence on the factors explaining municipalities' opposition to consolidation by measuring the local consequences of integration. Exploiting a 2010 reform in France that forced non-integrated municipalities to enter an intermunicipal community, I measure the causal impact of integration on resisting municipalities. Comparing what they faced to the experience of municipalities that had chosen to integrate prior to the law, I infer the local consequences explaining why resisting municipalities opposed integration in the first place.

Using a difference-in-differences strategy, I first find that municipalities forced to integrate experienced an increase of 12.5 percent in the number of building permits delivered per year. On the contrary, municipalities that joined an IC voluntarily had no such significant increase in their housing supply after integration. Only municipalities that did not want to integrate faced a large increase in construction, supporting the view that they refused to integrate to avoid an increase in housing supply. Further heterogeneity analyses show that the impact is mainly driven by highdemand and densely built municipalities, consistent with NIMBYism driving the opposition of urban municipalities against cooperation.

I then assess the impact of integration on local public services. I gathered data at the local level on two different public services transferred to the community level after integration: daycare and public libraries. I find that rural municipalities forced to enter an IC ended up with 20 to 30 percent fewer daycare spots and public libraries after the law, implying that integration increased the distance to public services for their residents.

Finally, I explore the benefits of integration. I find that municipalities that were forced to enter an intermunicipal community became twice as likely to have access to public transport and

\footnotetext{
${ }^{42}$ In 2015, a new law passed requiring that ICs should have at least 15,000 inhabitants by 2017 and requiring municipalities to share more public services. There was widespread complaint from mayors, leading to multiple revisions of the law with additional room for exceptions (e.g., AMF-Cevipof/SciencesPo 2018). In the face of such resistance, the French president announced he might reconsider the law (see for instance: https://www.amf.asso.fr/documents-versune-revision-la-loi-notre-/39240).
} 
experienced a 14.5-percent-per-year increase in the fiscal resources available per resident. Municipalities that voluntarily integrated experienced very similar gains. These results suggest that resisting municipalities did not oppose integration due to lower benefits, but to avoid the local costs of integration.

These results have several policy implications. First, I provide evidence that opposition to integration is driven by actual consequences of integration, beyond political or ideological considerations. These findings could help policymakers implement consolidation policies more effectively. In particular, they could design better compensation schemes, taking into account the fact that rural and urban municipalities do not face the same costs of integration. This likely applies beyond the French context, as local housing regulations and the provision of local public goods are among the most important functions of municipal governments. Moreover, while the form of urban-rural divide described in this paper may be specific to France, the key message is that the loss of control over urban planning is costly for high-demand locations trying to avoid a rise in density, while the loss of power over local public services is costly for low-density places, due to the rationalization process.

Second, this paper stresses the consequences of changing the scale of decision making. I provide causal evidence that transferring housing and zoning policies to a higher level reduces housing regulations. Such a policy could be used to increase housing supply in areas with strong economic growth, where housing regulations keep workers from moving in. These results speak to the case of the US, where regulations have become tighter, arguably due to a shift of power to the micro scale (Hankinson, 2018; Purcell, 2006). Following the rise of neighborhood institutions, residents have become more involved in urban planning decisions (Rohe and Gates, 1985; Angotti, 2011) and evidence suggests that such ward-based decision making leads to more restrictive policies (Clingermayer, 1994; Mast, 2020). To overcome housing regulations - and in line with my own results - urban scholars have instead advocated for a shift of power from the municipalities to the metropolitan areas (Rusk, 1995; Glaeser, 2014; Glaeser and Gyourko, 2018). However, this is politically difficult to implement due to the fierce opposition of municipalities that do not want to lose control over urban planning (e.g., Orfield, 1997).

Finally, by identifying the local consequences of integration, this paper opens the avenue to a comprehensive welfare analysis of consolidation reforms that would take both sides of the tradeoff into account. To assess the overall welfare effect of the 2010 law and of integration policies more generally, one would need to compare the potential aggregate benefits coming from the rationalization of public services and from the increase in construction to the local costs borne by the residents of the low-density municipalities losing public services and by the residents of the high-demand municipalities facing increases in density. 
Figure 1: French municipalities depending on their integration status in 2010

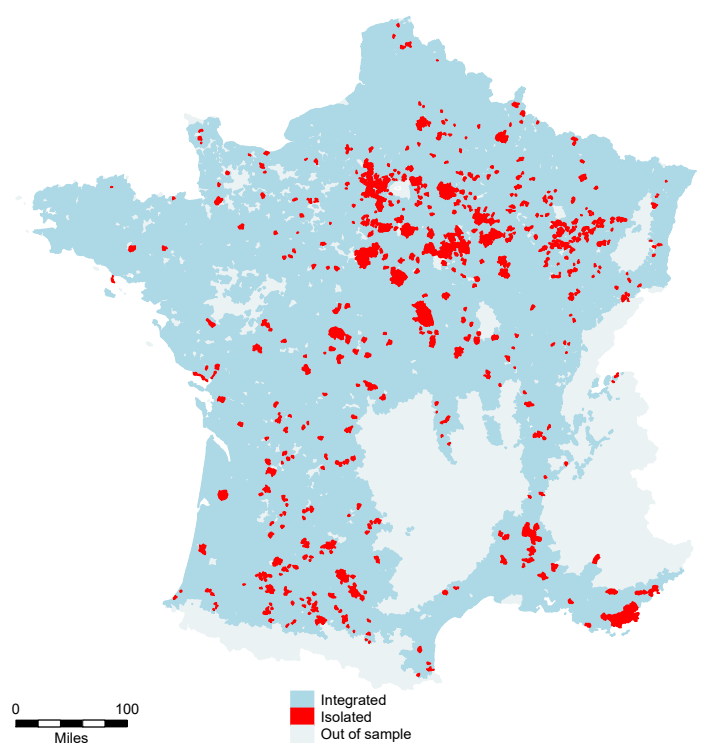

Notes: Municipalities in red were not part of an intermunicipal community in 2010. Municipalities in blue were already integrated. Grey areas represent municipalities excluded from the sample of analysis, as explained in Section 3.1.

Figure 2: Integration status

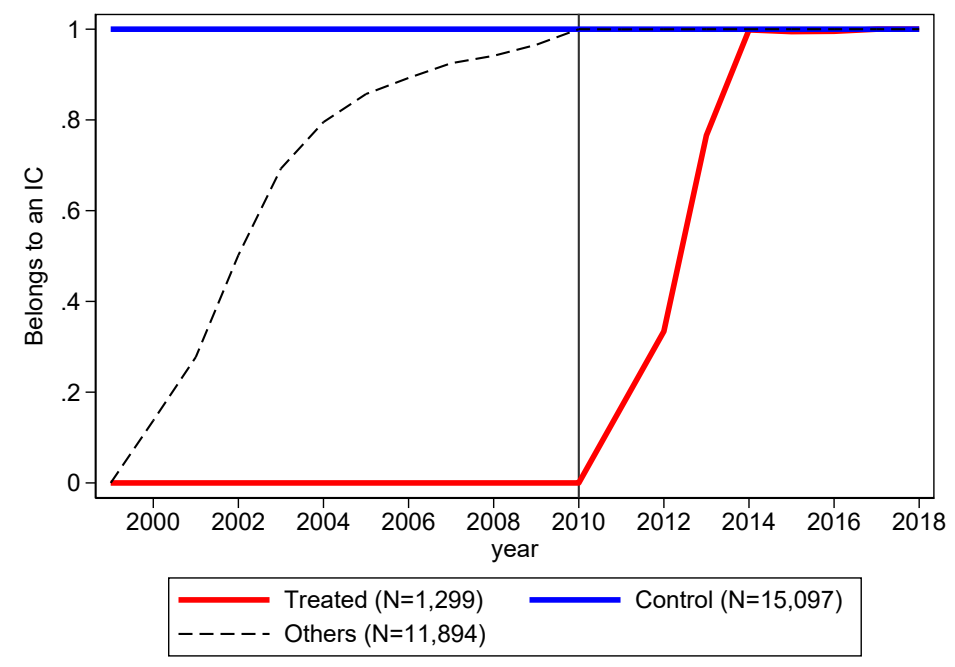

Notes: This graph plots the share of municipalities part of an intermunicipal community separately for the treatment group (red line) and the control group (blue line). The gray dotted line represents municipalities that integrated between 2000 and 2010 and are excluded from the main sample of analysis. 
Figure 3: Impact on housing building permits

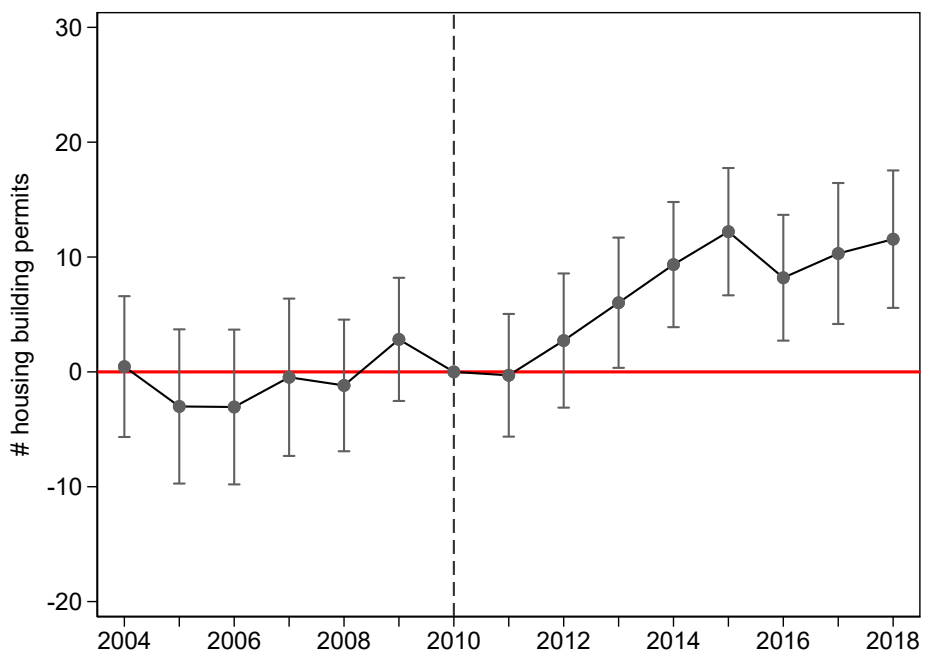

Notes: This graph plots the estimates and 95-percent-confidence intervals from the leads-and-lags regression (see Equation (2)). The outcome is the number of housing building permits delivered in the municipality per year per 10,000 inhabitants (using the 2010 population).

Figure 4: Comparison with municipalities that voluntarily integrated: housing building permits
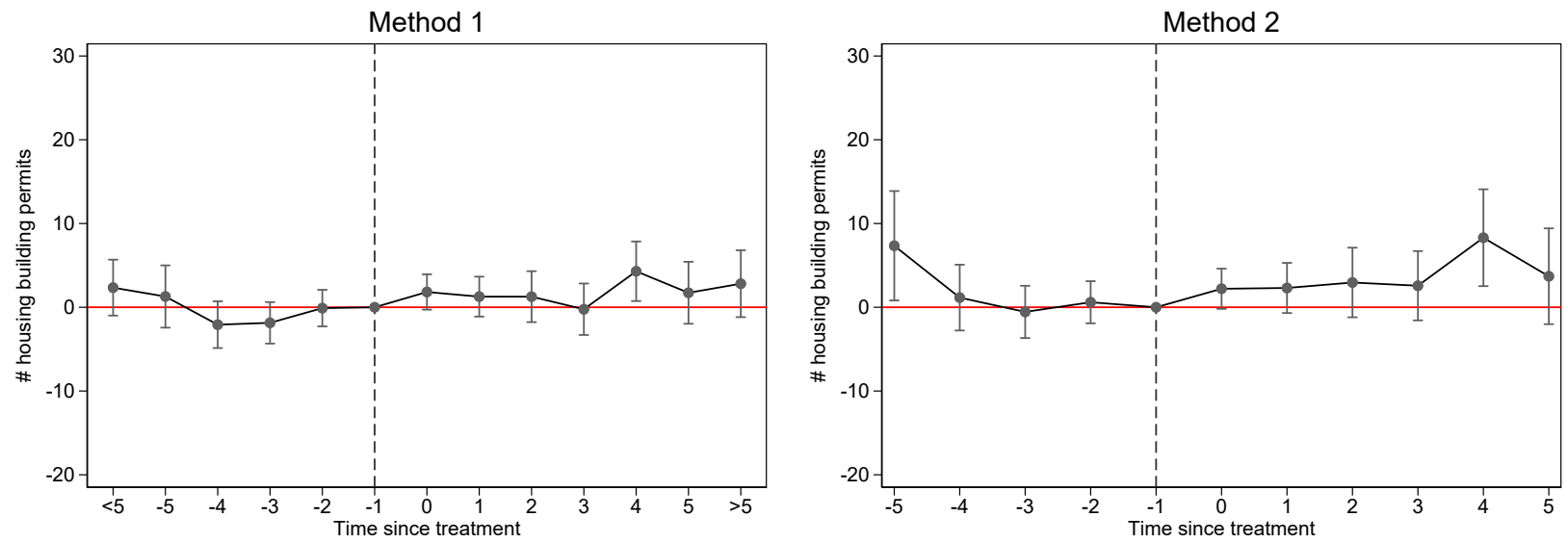

Notes: The outcome is the number of housing building permits delivered in the municipality per year per 10,000 inhabitants (using the 2010 population). The sample is made up of municipalities that voluntarily integrated between 2000 and 2010. The left-hand graph plots the estimates and 95-percent-confidence intervals from a regular staggered adoption design (method 1). The right-hand graph uses de Chaisemartin and D'Haultfoeuille (2020)'s method, implemented using the Stata command did_multiplegt, available on SSC repository (method 2). In method 1, the period of analysis goes from 1999 to 2018, whereas in method 2 it goes from 1999 to 2009. More information on the two methods in Section 4.2. 
Figure 5: Impact on housing prices
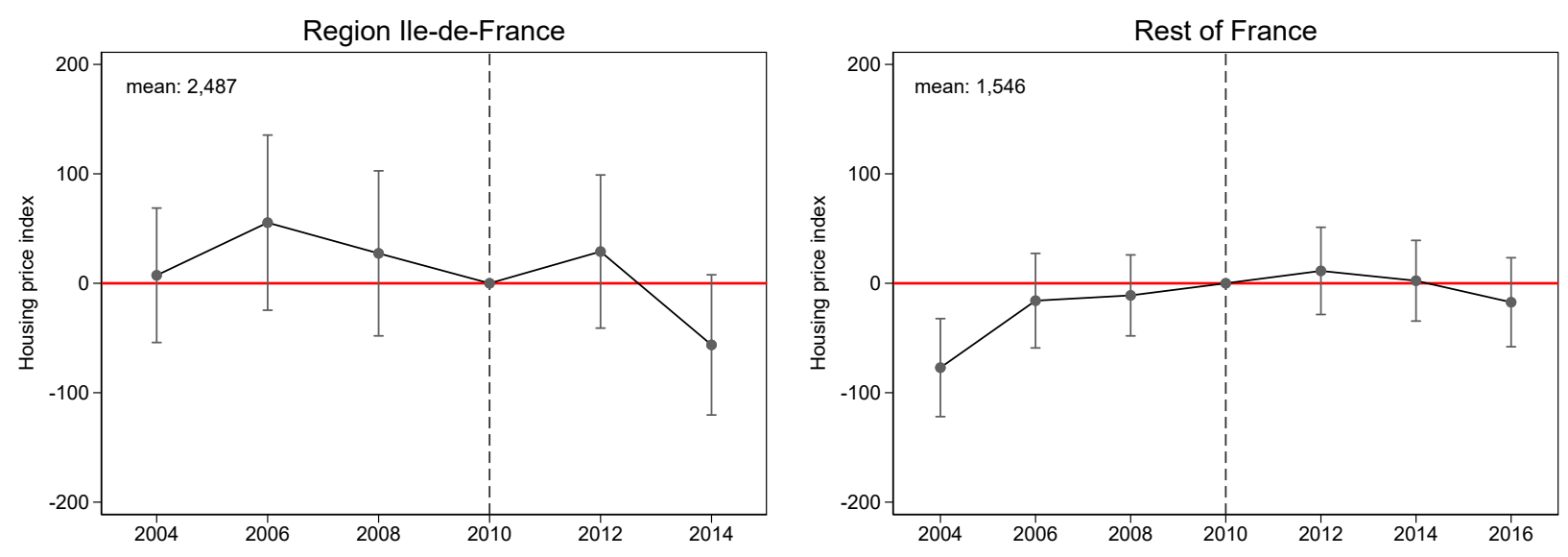

Notes: This graph plots the estimates and 95-percent-confidence intervals from the leads-and-lags regression (see Equation (2)). The outcome is the municipality housing price index giving the price per square meter of a reference dwelling. The sample includes only municipalities in which at least one housing transaction took place each even year over the period studied. The graph on the left-hand side includes only municipalities in the Parisian region of Île-de-France, while the graph on the right-hand side includes all the other municipalities. On each graph, the average price per square meter in the treatment group before 2010 is displayed on the top left corner. 
Figure 6: Impact on economic activity
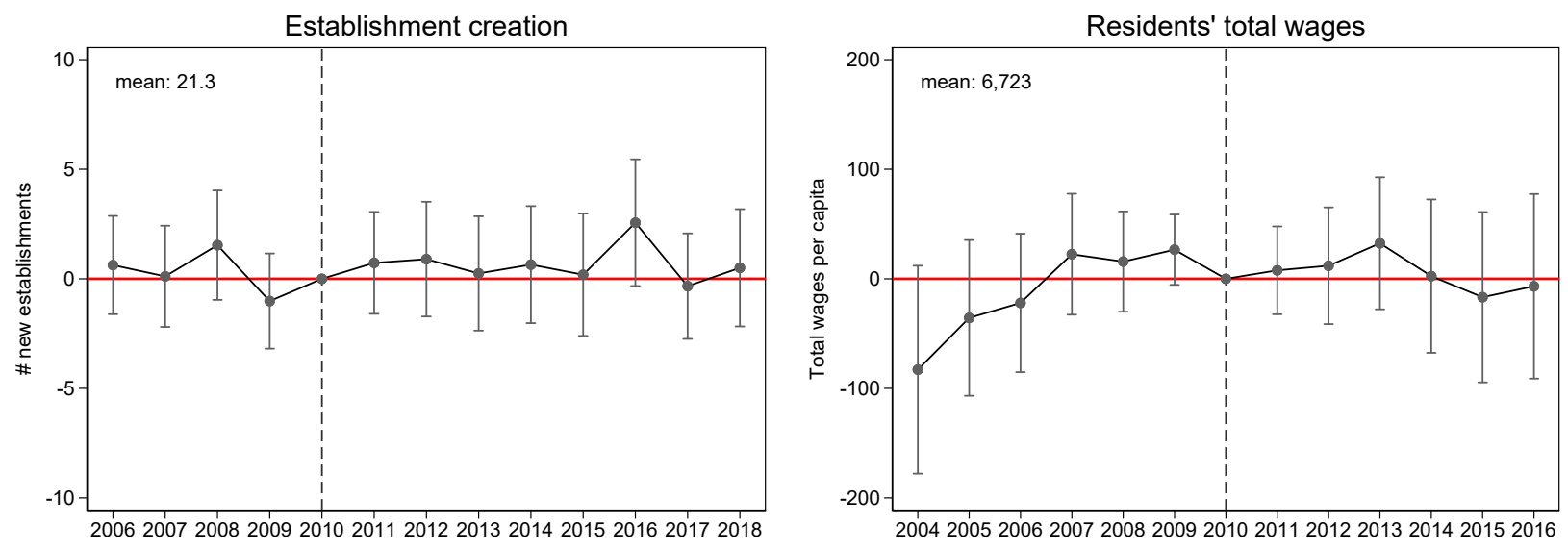

Notes: These graphs plots the estimates and 95-percent-confidence intervals from the leads-and-lags regression (see Equation (2)). On the left-hand graph, the outcome is the number of establishments created in a given year, per 10,000 inhabitants (using the 2010 population). The agricultural sector and the establishments created by individual entrepreneurs are excluded. On the right-hand graph, the outcome is the yearly total wages received by residents, divided by the 2010 population. The total wage computation includes only full-time employed residents. It excludes self-employed workers as well as the agricultural and public sectors. It is missing for the 311 smallest municipalities ( 2 percent of the sample). On both graphs, the average value of the outcome in the treatment group before 2010 is displayed on the top left corner. 
Figure 7: Impact on daycare and public libraries

A. Daycare spots
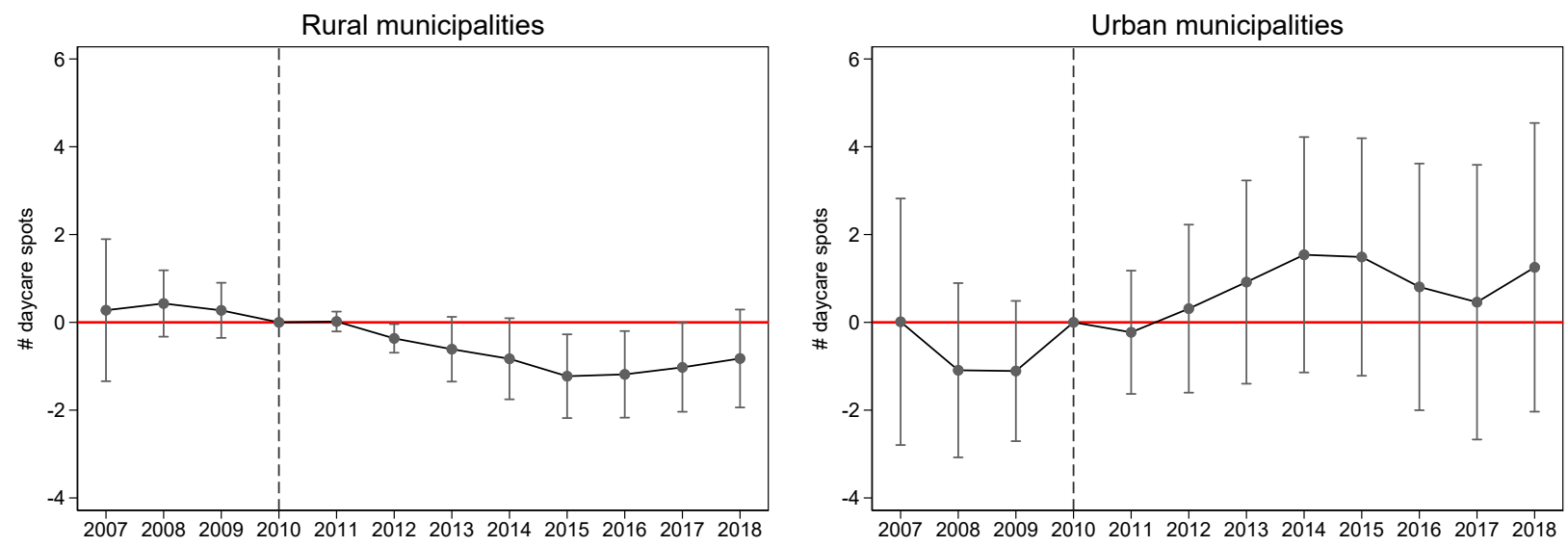

B. Public libraries
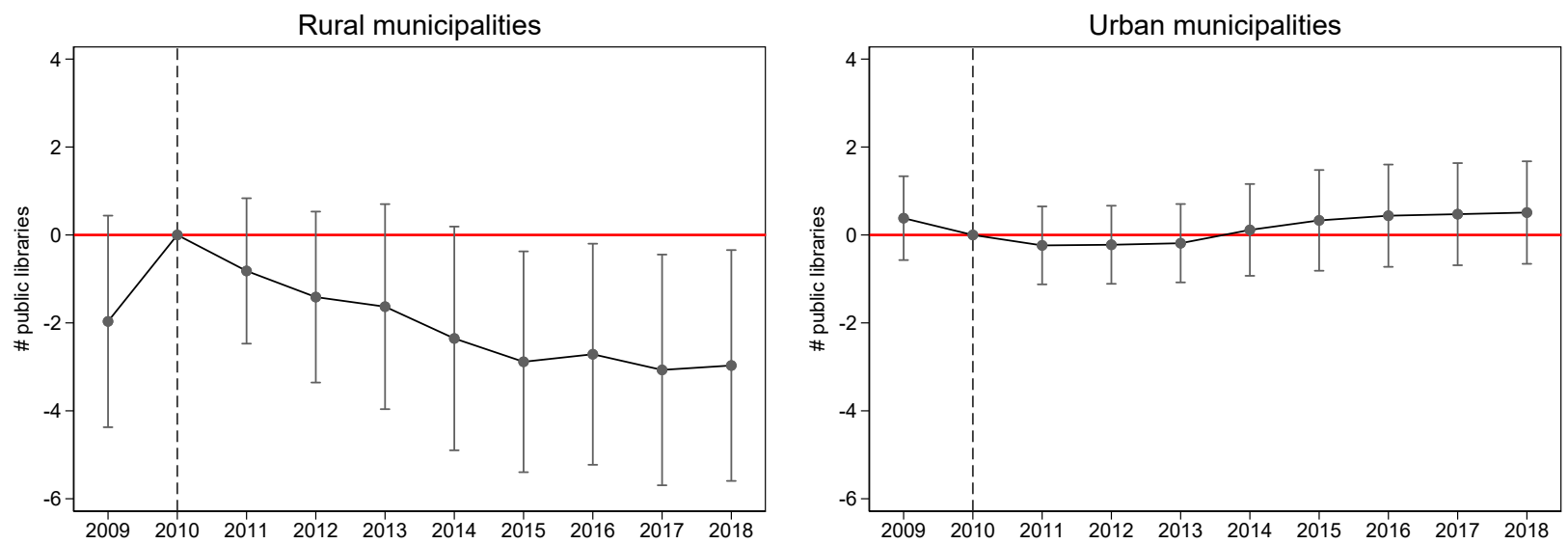

Notes: These graphs plots the estimates and 95-percent-confidence intervals from the leads-and-lags regression (see Equation (2)). In panel A, the outcome is the number of child daycare spots in the municipality per 10,000 inhabitants (using the 2010 population). In panel $\mathrm{B}$, the outcome is the number of public libraries in the municipality per 10,000 inhabitants (using the 2010 population) and the sample is restricted to the 7 départements for which data are available starting in 2009. The graphs on the left-hand side includes only rural municipalities, while the graphs on the right-hand side include only urban municipalities. 
Figure 8: Impact on public transport

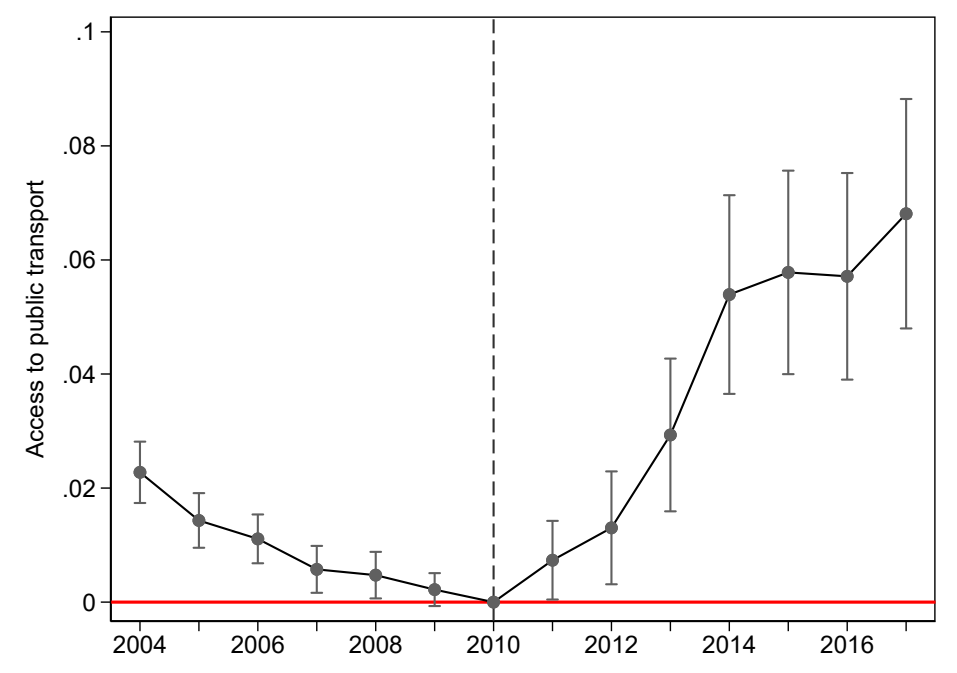

Notes: This graphs plots the estimates and 95-percent-confidence intervals from the leads-and-lags regression (see Equation (2)). The outcome is an indicator variable equal to 1 if the municipality has access to public transport. The sample excludes municipalities in the Parisian region of Île-de-France, for which the data are not available.

Figure 9: Impact on fiscal revenues

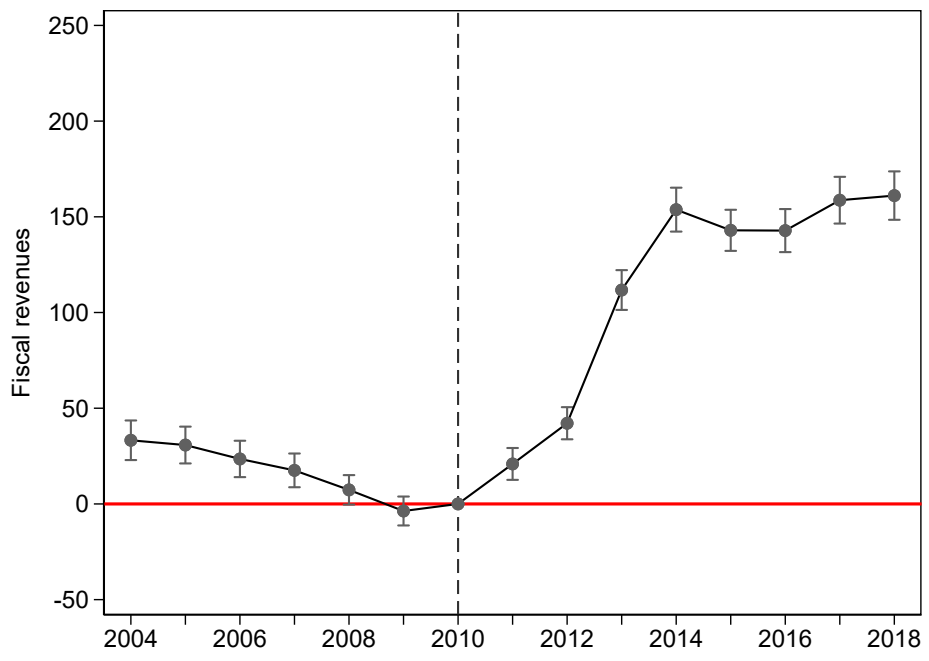

Notes: This graphs plots the estimates and 95-percent-confidence intervals from the leads-and-lags regression (see Equation (2)). The outcome is the municipality's total fiscal revenues per capita, as defined in Section 6.2. I exclude from the analysis the few municipalities for which the data are missing for at least one year over the period 2004-2018 (0.4 percent of the sample). 
Table 1: Descriptive statistics - 2010 (Panels A and B)

\begin{tabular}{|c|c|c|c|c|c|c|c|c|}
\hline & \multicolumn{4}{|c|}{ Treated municipalities $(\mathrm{N}=1,299)$} & \multicolumn{4}{|c|}{ Integrated municipalities $(\mathrm{N}=26,991)$} \\
\hline & mean & sd & $\min$ & $\max$ & mean & $\mathrm{sd}$ & $\min$ & $\max$ \\
\hline Panel A & \multicolumn{8}{|c|}{ Socio-demographic characteristics } \\
\hline population & 1,640 & 4,692 & 16 & 72,939 & 1,711 & 9,606 & 3 & 851,420 \\
\hline$\Delta$ population & 0.102 & 0.160 & -0.397 & 1.385 & 0.100 & 0.152 & -0.500 & 2.692 \\
\hline density & 162.1 & 541.6 & 2.11 & 6,884 & 140.9 & 422.4 & 0.161 & 9,976 \\
\hline urban & 0.204 & 0.403 & 0.000 & 1.000 & 0.209 & 0.406 & 0.000 & 1.000 \\
\hline urban area & 0.637 & 0.481 & 0.000 & 1.000 & 0.610 & 0.488 & 0.000 & 1.000 \\
\hline core urban area & 0.091 & 0.287 & 0.000 & 1.000 & 0.108 & 0.310 & 0.000 & 1.000 \\
\hline immigrants & 0.044 & 0.040 & 0.000 & 0.333 & 0.038 & 0.039 & 0.000 & 0.667 \\
\hline unemployed & 0.082 & 0.039 & 0.000 & 0.571 & 0.087 & 0.040 & 0.000 & 0.429 \\
\hline below $5 \mathrm{y} / \mathrm{o}$ & 0.060 & 0.020 & 0.000 & 0.172 & 0.061 & 0.021 & 0.000 & 0.206 \\
\hline above $65 \mathrm{y} / \mathrm{o}$ & 0.170 & 0.066 & 0.000 & 0.522 & 0.178 & 0.065 & 0.000 & 0.667 \\
\hline av. \# children & 0.907 & 0.245 & 0.000 & 2.000 & 0.892 & 0.228 & 0.000 & 3.000 \\
\hline farmers & 0.036 & 0.053 & 0.000 & 0.444 & 0.038 & 0.052 & 0.000 & 1.000 \\
\hline executives & 0.070 & 0.065 & 0.000 & 0.429 & 0.053 & 0.045 & 0.000 & 0.563 \\
\hline workers & 0.152 & 0.080 & 0.000 & 1.000 & 0.166 & 0.071 & 0.000 & 1.000 \\
\hline retired & 0.280 & 0.101 & 0.000 & 0.800 & 0.288 & 0.098 & 0.000 & 1.000 \\
\hline no diploma & 0.172 & 0.069 & 0.000 & 0.463 & 0.183 & 0.067 & 0.000 & 0.674 \\
\hline baccalaureate & 0.156 & 0.039 & 0.000 & 0.324 & 0.153 & 0.037 & 0.000 & 0.557 \\
\hline high education & 0.088 & 0.071 & 0.000 & 0.507 & 0.073 & 0.046 & 0.000 & 0.542 \\
\hline residents' income & 14,064 & 4,362 & 5,495 & 59,093 & 12,621 & 2,908 & 3,273 & 65,756 \\
\hline Panel B & \multicolumn{8}{|c|}{ Land-use characteristics } \\
\hline share built land (\%) & 0.742 & 1.416 & 0.024 & 15.882 & 0.725 & 1.330 & 0.004 & 25.987 \\
\hline average height & 1.561 & 0.216 & 1.048 & 4.727 & 1.560 & 0.187 & 1.000 & 4.391 \\
\hline FAR (p30) & 0.110 & 0.076 & 0.001 & 0.901 & 0.106 & 0.078 & 0.000 & 1.465 \\
\hline FAR (p50) & 0.171 & 0.116 & 0.003 & 1.812 & 0.169 & 0.118 & 0.003 & 1.901 \\
\hline
\end{tabular}

Notes: Socio-demographic variables come from the 2008 census, which applies to the year 2010 . The variation in the population (line 2) is computed by comparing the 1999 and 2008 censuses. Indicator variables for whether the municipality is urban, part of an urban area, or in the urban core are based on the INSEE 2010 classification. Land-use characteristics come from Combes et al. (2021) and each variable is built considering only construction before 2010 . The share of built land is computed considering all construction, whereas the average height and floor-to-area ratio (FAR) are computed considering only housing construction. The average height gives the average number of housing stories. To measure the FAR stringency, I follow Combes et al. (2021) and take the 30th percentile of the distribution of realized floor-to-area ratios of all housing buildings in the municipality (FAR p(30)). I also show the statistics using the median (FAR $\mathrm{p}(50))$. 
Table 1 (continued): Descriptive statistics - 2010 (Panel C)

\begin{tabular}{|c|c|c|c|c|c|c|c|c|}
\hline & \multicolumn{4}{|c|}{ Treated municipalities $(\mathrm{N}=1,299)$} & \multicolumn{4}{|c|}{ Integrated municipalities $(\mathrm{N}=26,991)$} \\
\hline & mean & sd & $\min$ & $\max$ & mean & sd & $\min$ & $\max$ \\
\hline Panel C & Politic & l chara & teristics & & & & & \\
\hline turnout municipal & 0.763 & 0.096 & 0.431 & 1.000 & 0.779 & 0.090 & 0.367 & 1.000 \\
\hline turnout presidential & 0.874 & 0.040 & 0.655 & 1.000 & 0.873 & 0.040 & 0.000 & 1.000 \\
\hline voteshare right & 0.602 & 0.107 & 0.152 & 1.000 & 0.563 & 0.105 & 0.106 & 1.000 \\
\hline voteshare far-right & 0.138 & 0.057 & 0.000 & 0.467 & 0.130 & 0.054 & 0.000 & 0.556 \\
\hline right-wing mayor & 0.620 & 0.486 & 0.000 & 1.000 & 0.559 & 0.496 & 0.000 & 1.000 \\
\hline left-wing mayor & 0.267 & 0.443 & 0.000 & 1.000 & 0.337 & 0.473 & 0.000 & 1.000 \\
\hline NC mayor & 0.112 & 0.316 & 0.000 & 1.000 & 0.103 & 0.304 & 0.000 & 1.000 \\
\hline woman mayor & 0.161 & 0.368 & 0.000 & 1.000 & 0.142 & 0.349 & 0.000 & 1.000 \\
\hline age mayor & 57.1 & 9.1 & 25.0 & 87.0 & 56.1 & 8.7 & 18.0 & 88.0 \\
\hline incumbent mayor & 0.661 & 0.474 & 0.000 & 1.000 & 0.624 & 0.484 & 0.000 & 1.000 \\
\hline change orientations & 0.210 & 0.407 & 0.000 & 1.000 & 0.221 & 0.415 & 0.000 & 1.000 \\
\hline
\end{tabular}

Notes: The municipal turnout rate and mayor's characteristics are based on the results of the 2008 municipal elections. The presidential turnout rate and far-right vote share come from the results of the first round of the 2007 presidential elections. The right-wing vote share comes from the results of the second round of the 2007 presidential elections. NC stands for "non classified". 
Table 2: Impact on housing building permits

\begin{tabular}{lccc}
\hline \multirow{2}{*}{ Outcome } & $(1)$ & $(2)$ & $(3)$ \\
& \multicolumn{3}{c}{ Number of building permits } \\
& All & New & Ne00 inhabitants \\
& $8.141^{* * *}$ & $6.810^{* * *}$ & Extensions \\
\hline Treatment & $(1.517)$ & $(1.391)$ & $(0.496)$ \\
& Yes & Yes & Yes \\
\hline Municipality FE & Yes & Yes & Yes \\
Time FE & 245,940 & 245,940 & 245,940 \\
Observations & 64.836 & 53.922 & 10.914 \\
Mean DepVar & 90.844 & 82.793 & 35.660 \\
Sd DepVar & & & \\
\hline
\end{tabular}

Notes: Standard errors are in parentheses and are clustered at the municipality level. ***,**, and * indicate significance at $1 \%, 5 \%$, and $10 \%$ respectively. The mean of the dependent variable gives the average of the outcome variable in the treatment group during the pre-reform period (before 2010). The outcome is the number of housing building permits delivered in the municipality per year per 10,000 inhabitants (using the 2010 population). The last two columns distinguish between two types of building permits: for the construction of a new unit on empty land (Column 2) or for the extension of an existing housing building (Column 3). 
Table 3: Impact on housing supply: Urban area

\begin{tabular}{lcccc}
\hline \multirow{2}{*}{ Outcome } & $(1)$ & $(2)$ & $(3)$ & $(4)$ \\
& \multicolumn{5}{c}{ Number of building permits } \\
& All & Outside & Inside & Core \\
\hline Treatment & $8.141^{* * *}$ & 3.105 & $10.494 * * *$ & $24.471^{* * *}$ \\
& $(1.517)$ & $(2.585)$ & $(1.812)$ & $(5.362)$ \\
\hline Municipality FE & Yes & Yes & Yes & Yes \\
Time FE & Yes & Yes & Yes & Yes \\
Observations & 245,940 & 94,440 & 151,500 & 28,785 \\
Mean DepVar & 64.836 & 66.897 & 63.660 & 63.875 \\
Sd DepVar & 90.844 & 99.952 & 85.197 & 97.750 \\
\hline
\end{tabular}

Notes: Standard errors are in parentheses and are clustered at the municipality level. ***,**, and * indicate significance at $1 \%, 5 \%$, and $10 \%$ respectively. The mean of the dependent variable gives the average of the outcome variable in the treatment group during the pre-reform period (before 2010). The outcome is the number of housing building permits delivered in the municipality per year per 10,000 inhabitants (using the 2010 population). Column 2 (resp. 3) includes only municipalities that are not part (resp. part) of an urban area. Column 4 considers only those in the core of the urban area. The municipal composition of urban areas is based on the INSEE 2010 breakdown and I consider both large (providing at least 10,000 jobs) and medium (providing between 5,000 and 10,000 jobs) urban areas. 
Table 4: Impact on housing supply: Neighbors' characteristics

\begin{tabular}{|c|c|c|c|c|c|c|c|}
\hline \multirow{4}{*}{ Outcome } & (1) & $(2)$ & (3) & (4) & $(5)$ & (6) & (7) \\
\hline & \multicolumn{7}{|c|}{ Number of housing building permits per 10,000 inhabitants } \\
\hline & \multirow[t]{2}{*}{ All } & \multicolumn{2}{|c|}{ Median income ratio } & \multicolumn{2}{|c|}{ Median immigrants ratio } & \multicolumn{2}{|c|}{ Median unemployed ratio } \\
\hline & & Below & Above & Below & Above & Below & Above \\
\hline Treatment & $\begin{array}{c}8.141 * * * \\
(1.517)\end{array}$ & $\begin{array}{c}7.983 * * * \\
(2.144)\end{array}$ & $\begin{array}{c}7.413 * * * \\
(2.090)\end{array}$ & $\begin{array}{c}6.548 * * * \\
(1.883)\end{array}$ & $\begin{array}{c}9.745 * * * \\
(2.405)\end{array}$ & $\begin{array}{l}3.695 * \\
(2.102)\end{array}$ & $\begin{array}{c}12.634 * * * \\
(2.190)\end{array}$ \\
\hline Municipality FE & Yes & Yes & Yes & Yes & Yes & Yes & Yes \\
\hline Time FE & Yes & Yes & Yes & Yes & Yes & Yes & Yes \\
\hline Observations & 245,940 & 122,850 & 122,850 & 122,970 & 122,970 & 122,970 & 122,970 \\
\hline Mean DepVar & 64.836 & 60.787 & 67.524 & 59.883 & 70.129 & 67.563 & 61.949 \\
\hline Sd DepVar & 90.844 & 83.960 & 94.371 & 84.459 & 96.934 & 95.575 & 85.466 \\
\hline
\end{tabular}

Notes: Standard errors are in parentheses and are clustered at the municipality level. ***,**, and * indicate significance at $1 \%, 5 \%$, and $10 \%$ respectively. The mean of the dependent variable gives the average of the outcome variable in the treatment group during the pre-reform period (before 2010). The outcome is the number of housing building permits delivered in the municipality per year per 10,000 inhabitants (using the 2010 population). For each municipality, the ratio divides the value of the heterogeneity variable in the municipality by the average value in the other municipalities from the same département, weighted by their population. Column 2 (resp. 3) includes only municipalities below (resp. above) the median value of the ratio using the per capita residents' annual taxable income. Data on taxable income in 2010 are missing for the 16 smallest municipalities. Column 4 (resp. 5) includes only municipalities below (resp. above) the median value of the ratio using the share of immigrants in 2010. Columns 6 and 7 repeat the same exercise using the share of unemployed workers in 2010. 
Table 5: Impact on housing supply: Share of homeowners

\begin{tabular}{lccc}
\hline \multirow{2}{*}{ Outcome } & $(1)$ & $(2)$ & $(3)$ \\
& Number of housing building permits \\
& All & \multicolumn{2}{c}{ Median \% homeowners } \\
\cline { 2 - 4 } & & Below & Above \\
\hline Treatment & $8.141 * * *$ & $9.263 * * *$ & $7.650 * * *$ \\
& $(1.517)$ & $(2.645)$ & $(1.798)$ \\
\hline Municipality FE & Yes & Yes & Yes \\
Time FE & Yes & Yes & Yes \\
Observations & 245,940 & 122,985 & 122,955 \\
Mean DepVar & 64.836 & 70.803 & 60.789 \\
Sd DepVar & 90.844 & 97.331 & 85.940 \\
\hline
\end{tabular}

Notes: Standard errors are in parentheses and are clustered at the municipality level. ***, **, and * indicate significance at $1 \%, 5 \%$, and $10 \%$ respectively. The mean of the dependent variable gives the average of the outcome variable in the treatment group during the pre-reform period (before 2010). The outcome is the number of housing building permits delivered in the municipality per year per 10,000 inhabitants (using the 2010 population). Column 4 (resp. 5) includes only municipalities below (resp. above) the median value of the share of homeowners in 2010. 
Table 6: Impact on daycare and public libraries

\begin{tabular}{|c|c|c|c|c|c|c|}
\hline \multirow{3}{*}{ Outcome } & (1) & (2) & (3) & (4) & (5) & (6) \\
\hline & \multicolumn{3}{|c|}{ Daycare spots } & \multicolumn{3}{|c|}{ Public libraries } \\
\hline & All & Rural & Urban & All & Rural & Urban \\
\hline \multirow[t]{2}{*}{ Treatment } & -0.616 & $-1.001 * *$ & 1.366 & $-0.913 * *$ & $-1.248 * *$ & -0.039 \\
\hline & $(0.461)$ & $(0.463)$ & (1.292) & $(0.460)$ & (0.620) & $(0.305)$ \\
\hline Mun FE & Yes & Yes & Yes & Yes & Yes & Yes \\
\hline Time FE & Yes & Yes & Yes & Yes & Yes & Yes \\
\hline Obs. & 196,752 & 153,216 & 43,536 & 14,290 & 11,020 & 3,270 \\
\hline Mean & 10.620 & 3.617 & 37.947 & 4.374 & 5.277 & 2.032 \\
\hline $\mathrm{Sd}$ & 38.600 & 31.900 & 48.954 & 9.574 & 10.983 & 3.089 \\
\hline
\end{tabular}

Notes: Standard errors are in parentheses and are clustered at the municipality level. $* * *, * *$, and $*$ indicate significance at $1 \%, 5 \%$, and $10 \%$ respectively. The mean of the dependent variable gives the average of the outcome variable in the treatment group during the pre-reform period (before 2010). In Columns 1 to 3, the outcome is the number of child daycare spots in the municipality per 10,000 inhabitants (using the 2010 population); the period of analysis is 2007-2018. In Columns 4 to 6, the outcome is the number of public libraries in the municipality per 10,000 inhabitants (using the 2010 population); the period of analysis is 2009-2018 and the sample is restricted to the 7 départements for which data are available starting in 2009. Columns 2 and 5 include only rural municipalities, while Column 3 and 6 include only urban municipalities. 
Table 7: Impact on public transport

\begin{tabular}{|c|c|c|c|}
\hline \multirow{3}{*}{ Outcome } & (1) & (2) & (3) \\
\hline & \multicolumn{3}{|c|}{ Access to public transport } \\
\hline & All & Rural & Urban \\
\hline \multirow[t]{2}{*}{ Treatment } & $0.032 * * *$ & $0.020 * * *$ & $0.106^{* * *}$ \\
\hline & $(0.007)$ & $(0.006)$ & $(0.024)$ \\
\hline Municipality FE & Yes & Yes & Yes \\
\hline Time FE & Yes & Yes & Yes \\
\hline Observations & 221,368 & 173,894 & 47,474 \\
\hline Mean DepVar & 0.024 & 0.013 & 0.078 \\
\hline Sd DepVar & 0.152 & 0.115 & 0.269 \\
\hline
\end{tabular}

Notes: Standard errors are in parentheses and are clustered at the municipality level. ***, **, and * indicate significance at $1 \%, 5 \%$, and $10 \%$ respectively. The mean of the dependent variable gives the average of the outcome variable in the treatment group during the pre-reform period (before 2010). The outcome is an indicator variable equal to 1 if the municipality has access to public transport. The sample excludes municipalities in the Parisian region of Île-de-France, for which the data are not available. Column 2 includes only rural municipalities, while Column 3 includes only urban municipalities.

Table 8: Impact on fiscal revenues

\begin{tabular}{|c|c|c|c|}
\hline \multirow{3}{*}{ Outcome } & (1) & (2) & (3) \\
\hline & \multicolumn{3}{|c|}{ Fiscal revenues per capita } \\
\hline & All & Rural & Urban \\
\hline Treatment & $\begin{array}{c}101.2^{* * * *} \\
(4.8)\end{array}$ & $\begin{array}{c}93.1 * * * \\
(5.1)\end{array}$ & $\begin{array}{c}134.7 * * * \\
(12.2)\end{array}$ \\
\hline Municipality FE & Yes & Yes & Yes \\
\hline Time FE & Yes & Yes & Yes \\
\hline Observations & 244,965 & 190,965 & 54,000 \\
\hline Mean DepVar & 698.6 & 617.7 & 1,015 \\
\hline Sd DepVar & 430.0 & 329.1 & 598.6 \\
\hline
\end{tabular}

Notes: Standard errors are in parentheses and are clustered at the municipality level. ***, **, and * indicate significance at $1 \%, 5 \%$, and $10 \%$ respectively. The mean of the dependent variable gives the average of the outcome variable in the treatment group during the pre-reform period (before 2010). The outcome is the municipality's total fiscal revenues per capita, as defined in Section 6.2. I exclude from the analysis the few municipalities for which the data are missing for at least one year over the period 2004-2018 (0.4 percent of the sample). Column 2 includes only rural municipalities, while Column 3 includes only urban municipalities. 
Table 9: Impact on housing depending on the integration process: Urban areas

\begin{tabular}{lccccc}
\hline \multirow{2}{*}{ Outcome } & (1) & $(2)$ & $(3)$ & $(4)$ & $(5)$ \\
& \multicolumn{3}{c}{ Number of building permits per 10,000 inhabitants } \\
& All & New IC & \multicolumn{3}{c}{ Existing IC } \\
\cline { 3 - 6 } & & & All & Recent & $\geq 2$ choices \\
\hline Treatment & $10.494^{* * *}$ & $8.751^{* * *}$ & $11.298^{* * *}$ & $15.634^{* * *}$ & $6.879^{* * *}$ \\
& $(1.812)$ & $(3.207)$ & $(2.116)$ & $(3.472)$ & $(2.549)$ \\
\hline Municipality FE & Yes & Yes & Yes & Yes & Yes \\
Time FE & Yes & Yes & Yes & Yes & Yes \\
Observations & 151,500 & 143,010 & 147,585 & 142,125 & 144,585 \\
Mean DepVar & 63.660 & 63.138 & 63.900 & 58.509 & 67.357 \\
Sd DepVar & 85.197 & 83.922 & 85.788 & 85.666 & 86.968 \\
\hline
\end{tabular}

Notes: Standard errors are in parentheses and are clustered at the municipality level. ***, **, and * indicate significance at $1 \%, 5 \%$, and $10 \%$ respectively. The mean of the dependent variable gives the average of the outcome variable in the treatment group during the pre-reform period (before 2010). The outcome is the number of housing building permits delivered in the municipality per year per 10,000 inhabitants (using the 2010 population). The sample includes only municipalities part of an urban area. Columns 2 (resp. 3) includes only treated municipalities that created a new IC (resp. that joined an existing IC) after the 2010 law. Column 4 includes only treated municipalities that entered a recently created IC (in which all other members integrated after 2000). Column 5 includes only treated municipalities that entered an existing IC and that had the choice between at least two of them in 2010 . 
Table 10: Impact on housing depending on whether the IC encompasses a big city: Urban areas

\begin{tabular}{|c|c|c|c|}
\hline \multirow{3}{*}{ Outcome } & (1) & (2) & (3) \\
\hline & \multicolumn{3}{|c|}{ Number of building permits } \\
\hline & All & No big city & Big city \\
\hline \multirow[t]{2}{*}{ Treatment } & $10.494 * * *$ & $6.093^{* *}$ & $12.961 * * *$ \\
\hline & (1.812) & (2.507) & $(2.453)$ \\
\hline Municipality FE & Yes & Yes & Yes \\
\hline Time FE & Yes & Yes & Yes \\
\hline Observations & 151,500 & 67,860 & 83,625 \\
\hline Mean DepVar & 63.660 & 65.957 & 61.974 \\
\hline Sd DepVar & 85.197 & 87.040 & 83.792 \\
\hline
\end{tabular}

Notes: Standard errors are in parentheses and are clustered at the municipality level. ***, **, and * indicate significance at $1 \%, 5 \%$, and $10 \%$ respectively. The mean of the dependent variable gives the average of the outcome variable in the treatment group during the pre-reform period (before 2010). The outcome is the number of housing building permits delivered in the municipality per year per 10,000 inhabitants (using the 2010 population). The sample includes only municipalities part of an urban area. Column 2 (resp. 3) includes only municipalities that, in 2014, were part of an IC in which all municipalities were below 5,000 inhabitants (resp. encompassing a municipality above 5,000 inhabitants). 


\section{References}

Alesina, Alberto and Enrico Spolaore, "On the number and size of nations," The Quarterly Journal of Economics, 1997, 112 (4), 1027-1056.

_ and _, The size of nations, Cambridge, MA: MIT Press, 2003.

_ , Reza Baqir, and Caroline Hoxby, "Political Jurisdictions in Heterogeneous Communities," Journal of Political Economy, 2004, 112 (2), 348-396.

Algan, Yann, Clément Malgouyres, and Claudia Senik, "Territories, Well-being and Public Policy," French Council of Economic Analysis (CAE), 2020.

Allers, Maarten A. and Jan Antoon De Greef, "Intermunicipal cooperation, public spending and service levels," Local Government Studies, 2018, 44 (1), 127-150.

Alonso, William, Location and land use. Toward a general theory of land rent, Cambridge, MA: Harvard University Press, 1964.

AMF-Cevipof/SciencesPo, "Les maires de France: entre résignation et incertitude," Enquête 2018, 2018.

Angotti, Tom, New York for sale: Community planning confronts global real estate, MIT Press, 2011.

Bates, Laurie J and Rexford E Santerre, "The determinants of restrictive residential zoning: Some empirical findings," Journal of Regional Science, 1994, 34 (2), 253-263.

Bel, Germà and Marianna Sebo, "Does Inter-Municipal Cooperation Really Reduce Delivery Costs? An Empirical Evaluation of the Role of Scale Economies, Transaction Costs, and Governance Arrangements," Urban Affairs Review, 2019, 57 (1), 153-188.

- and Mildred E Warner, "Inter-municipal cooperation and costs: expectations and evidence," Public Administration, 2015, 93 (1), 52-67.

_ and _, "Factors Explaining Inter-municipal Cooperation in Service Delivery: A MetaRegression Analysis," Journal of Economic Policy Reform, 2016, 19 (2), 91-115.

Bergholz, Christian and Ivo Bischoff, "Local council members' view on intermunicipal cooperation: does office-related self-interest matter?," Regional Studies, 2018, 52 (12), 1624-1635.

Blesse, Sebastian and Thushyanthan Baskaran, "Do municipal mergers reduce costs? Evidence from a German federal state," Regional Science and Urban Economics, 2016, 59, 54-74.

Blom-Hansen, Jens, Kurt Houlberg, Soren Serritzlew, and Daniel Treisman, "Jurisdiction Size and Local Government Policy Expenditure: Assessing the Effect of Municipal Amalgamation," American Policital Science Review, 2016, 110 (4), 812-831.

Bolton, Patrick and Gerard Roland, "The Breakup of Nations : A Political Economy Analysis," Quarterly Journal of Economics, 1997, 112 (4), 1057-1090. 
Borusyak, Kirill, Xavier Jaravel, and Jann Spiess, "Revisiting Event Study Designs: Robust and Efficient Estimation,” Working Paper, 2021.

Boyer, Pierre C., Thomas Delemotte, Germain Gauthier, Vincent Rollet, and Benoît Schmutz, "Les déterminants de la mobilisation des Gilets jaunes," Revue Economique, 2020, 71, 109-138.

Breuillé, Marie Laure, Pascale Duran-Vigneron, and Anne Laure Samson, "Inter-municipal cooperation and local taxation," Journal of Urban Economics, 2018, 107 (November), 47-64.

Brueckner, Jan K, "Testing for Strategic Interaction Among Local Governments: The Case of Growth Controls," Journal of Urban Economics, nov 1998, 44 (3), 438-467.

Carbonnier, Clément, "Decentralization and Tax Competition between Asymmetrical Local Governments," Public Finance Review, jul 2013, 41 (4), 391-420.

Charlot, Sylvie, Sonia Paty, and Virginie Piguet, "Does fiscal cooperation increase local tax rates in urban areas?," Regional Studies, 2015, 49 (10), 1706-1721.

Chetty, Raj, Nathaniel Hendren, and Lawrence F Katz, "The Effects of Exposure to Better Neighborhoods on Children: New Evidence from the Moving to Opportunity Experiment," American Economic Review, apr 2016, 106 (4), 855-902.

Clingermayer, James C, "Electoral Representation, Zoning Politics, and the Exclusion of Group Homes," Political Research Quarterly, 1994, 47 (4), 969-984.

Cobban, Timothy W, "Bigger is better: Reducing the cost of local administration by increasing jurisdiction size in Ontario, Canada," Urban Affairs Review, 2019, 55 (2), 462-500.

Combes, Pierre-Philippe, Gilles Duranton, and Laurent Gobillon, "The Costs of Agglomeration : House and Land Prices in French Cities," Review of Economic Studies, 2018, 86 (4), $1556-1589$.

Combes, Pierre Philippe, Gilles Duranton, and Laurent Gobillon, "The production function for housing: Evidence from France," Journal of Political Economy, 2021, 129 (10).

Dahis, Ricardo and Christiane Szerman, "Development via Administrative Redistricting: Evidence from Brazil,” Working Paper, 2021.

de Chaisemartin, Clément and Xavier D'Haultfoeuille, “Two-way fixed effects estimators with heterogeneous treatment effects," American Economic Review, 2020, 110 (9), 2964-96.

De Mello, Luiz and Santiago Lago-Peñas, "Local Government Cooperation for Joint Provision: The Experiences of Brazil and Spain with Inter-Municipal Consortia," in "The Challenge of Local Government Size: Theoretical Perspectives, International Experience, and Policy Reform," Chentelham: Edward Elgar, 2013.

Di Porto, Edoardo and Sonia Paty, "Cooperation among Local Governments to Deliver Public Services," Politics Policy, 2018, 46 (5), 790-820. 
Duranton, Gilles and Diego Puga, "Urban growth and its aggregate implications," NBER Working Paper No. w26591, 2019.

Egger, Peter H, Marko Köthenbürger, and Gabriel Loumeau, "Local Border Reforms and Economic Activity," Journal of Economic Geography, 2021.

Fabre, Brice, "Political Colleagues Matter: The Impact of Multiple Office-Holding on Intergovernmental Grants," Revue Economique, 2021.

Ferraresi, Massimiliano and Giuseppe Migali, "Does intermunicipal cooperation promote efficiency gains? Evidence from Italian municipal unions," Journal of Regional Science, 2018, 58 (5).

Fischel, William A, The Homevoter Hypothesis, Cambridge, MA: Harvard University Press, 2001.

Frère, Quentin, Matthieu Leprince, and Sonia Paty, "The impact of intermunicipal cooperation on local public spending," Urban Studies, 2014, 51 (8), 1741-1760.

Ganong, Peter and Daniel Shoag, "Why has regional income convergence in the U.S. declined?," Journal of Urban Economics, 2017, 102, 76-90.

Glaeser, Edward and Joseph Gyourko, "The economic implications of housing supply," Journal of Economic Perspectives, 2018, 32 (1), 3-30.

Glaeser, Edward L, "Land Use Restrictions and Other Barriers to Growth," Cato Institute, 2014.

- and Bryce A Ward, "The causes and consequences of land use regulation: Evidence from Greater Boston," Journal of Urban Economics, may 2009, 65 (3), 265-278.

_ and David C Maré, “Cities and Skills,” Journal of Labor Economics, 2001, 19 (2), 316-342.

- and Matthew E Kahn, "The greenness of cities: carbon dioxide emissions and urban development," Journal of Urban Economics, 2010, 67 (3), 404-418.

Gobillon, Laurent and Benjamin Vignolles, "Evaluation de l'effet d'une politique spatialisée d'accès au logement : la loi Solidarité et Renouvellement Urbain (SRU)," Revue Economique, 2016, 67 (3), 615-637.

Goodman-Bacon, Andrew, "Difference-in-Differences With Variation in Treatment Timing," Journal of Econometrics, 2021.

Gordon, Nora and Brian Knight, "A spatial merger estimator with an application to school district consolidation," Journal of Public Economics, 2009, 93 (5-6), 752-765.

Gouriéroux, Christian and Anne Laferrère, "Managing hedonic housing price indexes: The French experience," Journal of Housing Economics, 2009, 18 (3), 206-213.

Gyourko, Joseph and Raven Molloy, "Regulation and Housing Supply," in Gilles Duranton, Vernon J Henderson, and William Strange, eds., Handbook of Regional and Urban Economics, Vol. 5b, Amsterdam: Elsevier, 2015, pp. 1289-1337. 
Hankinson, Michael, "When Do Renters Behave Like Homeowners? High Rent, Price Anxiety, and NIMBYism," American Political Science Review, 2018, 112 (3), 473-493.

Harjunen, Oskari, Tuukka Saarimaa, and Janne Tukiainen, "Political representation and effects of municipal mergers," Political Science Research and Methods, 2019, pp. 1-17.

Hilber, Christian A.L and Frédéric Robert-Nicoud, "On the origins of land use regulations: Theory and evidence from US metro areas," Journal of Urban Economics, may 2013, 75, 2943.

Horiuchi, Yusaku, Jun Saito, and Kyohei Yamada, "Removing boundaries, losing connections: Electoral consequences of local government reform in Japan," Journal of East Asian Studies, 2015,15 (1), 99-125.

Hsieh, Chang Tai and Enrico Moretti, "Housing Constraints and Spatial Misallocation," American Economic Journal: Macroeconomics, 2019, 11 (2), 1-39.

Hulst, Rudie, André Van Montfort, Arto Haveri, Jenni Airaksinen, and Josephine Kelly, "Institutional Shifts In Inter-Municipal Service Delivery," Public Organization Review, 2009, 9, 263-285.

Jackson, Kenneth T, Crabgrass frontier: The suburbanization of the United States, Oxford University Press, 1987.

Jones, Christopher and Daniel M Kammen, "Spatial Distribution of U.S. Household Carbon Footprints Reveals Suburbanization Undermines Greenhouse Gas Benefits of Urban Population Density," Environmental Science Technology, 2013, 48 (2), 895-902.

Lapointe, Simon, "Love thy neighbour? The effect of income and language differences on votes for municipal secessions," Regional Science and Urban Economics, 2018, 70, 229-245.

Lidström, Anders, "The Swedish Model under Stress: The Waning of the Egalitarian, Unitary State?," in "Territorial Choice. The Politics of Boundaries and Borders," Houndsmills: Palgrave, 2010, pp. 61-80.

Lin, Desen and Susan Wachter, "Land Use Regulation, Regulatory Spillover and Housing Prices," Working Paper, 2020.

Luca, Davide and Felix Modrego, "Stronger together? Assessing the causal effect of intermunicipal cooperation on the efficiency of small Italian municipalities," Journal of Regional Science, 2020.

Mast, Evan, "Warding Off Development: Local Control, Housing Supply, and NIMBYs," Upjohn Institute Working Paper, 2020.

Mouritzen, Poul Erik, “The Danish Revolution in Local Government: How and Why?," in “Territorial Choice. The Politics of Boundaries and Borders," Houndsmills: Palgrave, 2010, pp. 21-41. 
Musiedlak, Yoann and Benjamin Vignolles, "Les mouvements des prix immobiliers dans l'ancien au cours des années 2000: des marchés locaux différenciées," Document de travail du CGEDD, 2016, (24), 1-40.

Oates, Wallace E, Fiscal Federalism, NY: Harcourt Brace Jovanovich, 1972.

OECD, "Compact City Policies: A Comparative Assessment," OECD Green Growth Studies, 2012.

Orfield, Myron, Metropolitics, Brookings Review, 1997.

Ortalo-Magné, François and Andrea Prat, "On the Political Economy of Urban Growth: Homeownership versus Affordability," American Economic Journal: Microeconomics, feb 2014, 6 (1), 154-181.

Pickering, Steve, Seiki Tanaka, and Kyohei Yamada, "The Impact of Municipal Mergers on Local Public Spending: Evidence from Remote Sensing Data," Journal of East Asian Studies, 2020, 20 (2), 243-266.

Purcell, Mark, "Urban Democracy and the Local Trap,' Urban Studies, 2006, 43 (11), 19211941.

Reingewertz, Yaniv, "Do municipal amalgamations work? Evidence from municipalities in Israel," Journal of Urban Economics, 2012, 72 (2-3), 240-251.

Rohe, William M. and Laurence B. Gates, Planning with neighborhoods, UNC Press Books, 1985.

Rolleston, Barbara Sherman, "Determinants of restrictive suburban zoning: An empirical analysis," Journal of Urban Economics, 1987, 21 (1), 1-21.

Rusk, David, Cities without Suburbs, Washington, DC: Woodrow Wilson Center Press, 1995.

Saarimaa, Tuukka and Janne Tukiainen, "I Don't Care to Belong to Any Club That Will Have Me as a Member: Empirical Analysis of Municipal Mergers," Political Science Research and Methods, 2014, 2 (1), 97-117.

Saiz, Albert, "The Geographic Determinants of Housing Supply," Quarterly Journal of Economics, aug 2010, 125 (3), 1253-1296.

Sorensen, Rune J., "Local Government Consolidations: The Impact of Political Transaction Costs," Public Choice, 2006, 127 (1), 75-95.

Tiebout, Charles M, “A pure theory of local expenditures," Journal of Political Economy, 1956, 64 (5), 416-424.

Tocqueville, Alexis, Democracy in America, NY: Vintage Books Random House: first published $1838,1945$. 
Villa, Juan M, "Simplifying the estimation of difference-in-differences treatment effects," Stata Journal, 2016, 16, 52-71.

Weese, Eric, "Political mergers as coalition formation : An analysis of the Heisei municipal amalgamations," Quantitative Economics, 2015, 6, 257-307.

Wilner, Lionel, "How do citizens perceive centralization reforms? Evidence from the merger of French regions," CREST Working Paper, 2021. 


\section{Appendix (for online publication only)}

A. Additional figures and tables

B. Additional robustness checks $3 \mathbf{3 6}$

C. Housing supply: Heterogeneity analysis $\quad 54$

D. Housing price indices 


\section{A. Additional figures and tables}

Figure A1: Impact on housing depending on the exact year of integration
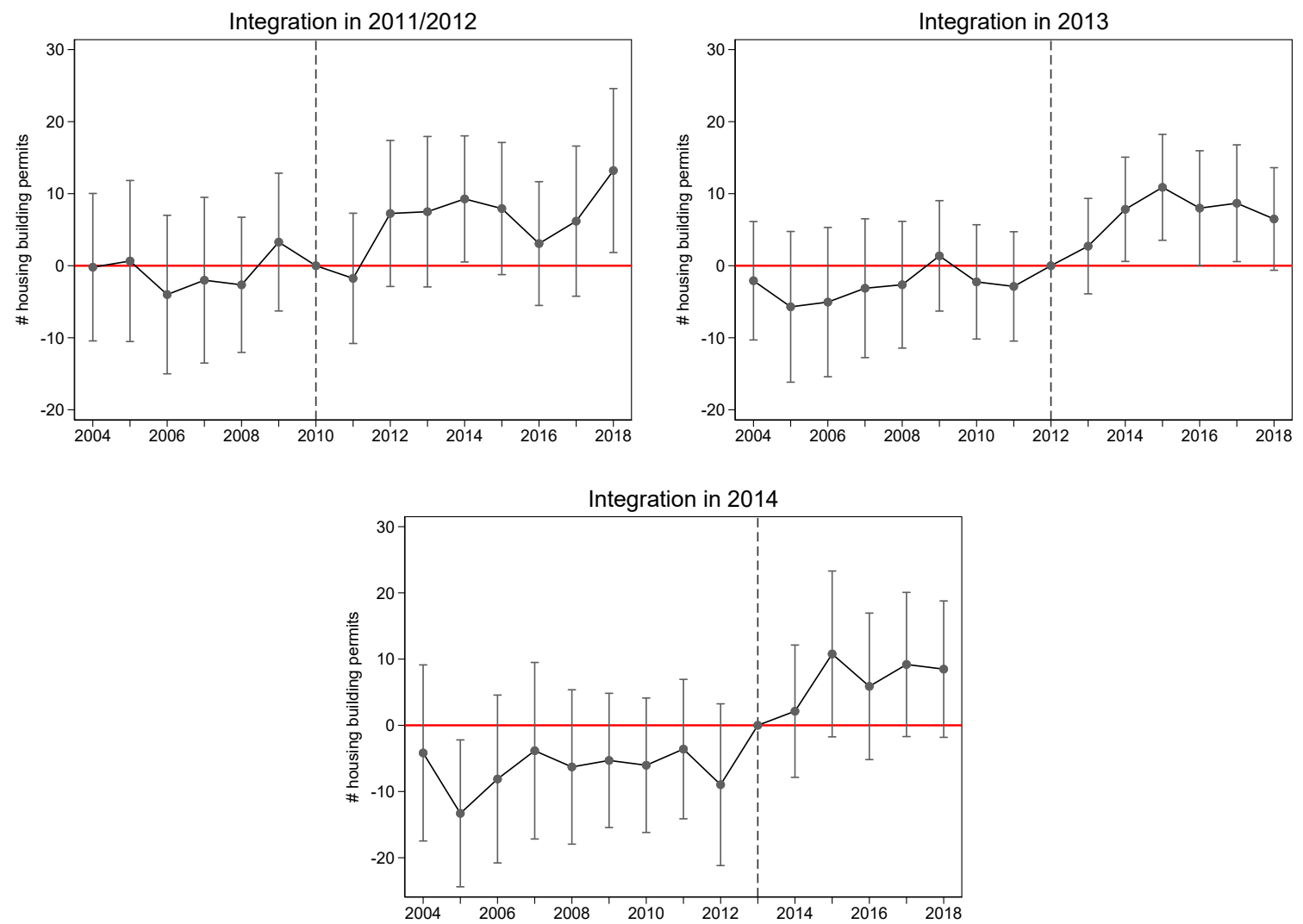

Notes: These graphs plot the estimates and 95-percent-confidence intervals from the leads-and-lags regression, using as outcome the number of housing building permits delivered in the municipality per year per 10,000 inhabitants (using the 2010 population). The first graph includes only treated municipalities that entered an IC in 2011 or 2012 . The second (resp. third) graph includes only treated municipalities that entered an IC in 2013 (resp. 2014). 
Figure A2: Impact on housing for municipalities that voluntarily integrated between 2004 and 2010

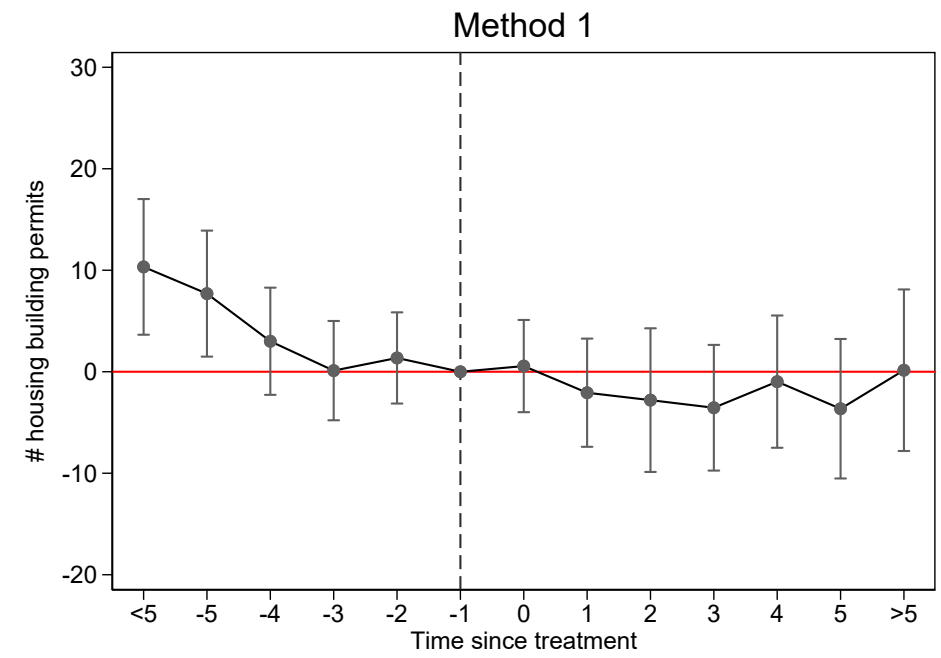

Notes: The outcome is the number of housing building permits delivered in the municipality per year per 10,000 inhabitants (using the 2010 population). The sample is made up of municipalities that voluntarily integrated between 2004 and 2010. The graph plots the estimates and 95-percent-confidence intervals from a regular staggered adoption design (method 1). The period of analysis goes from 1999 to 2018. More information in Section 4.2. 
Figure A3: Impact on housing: Urban area
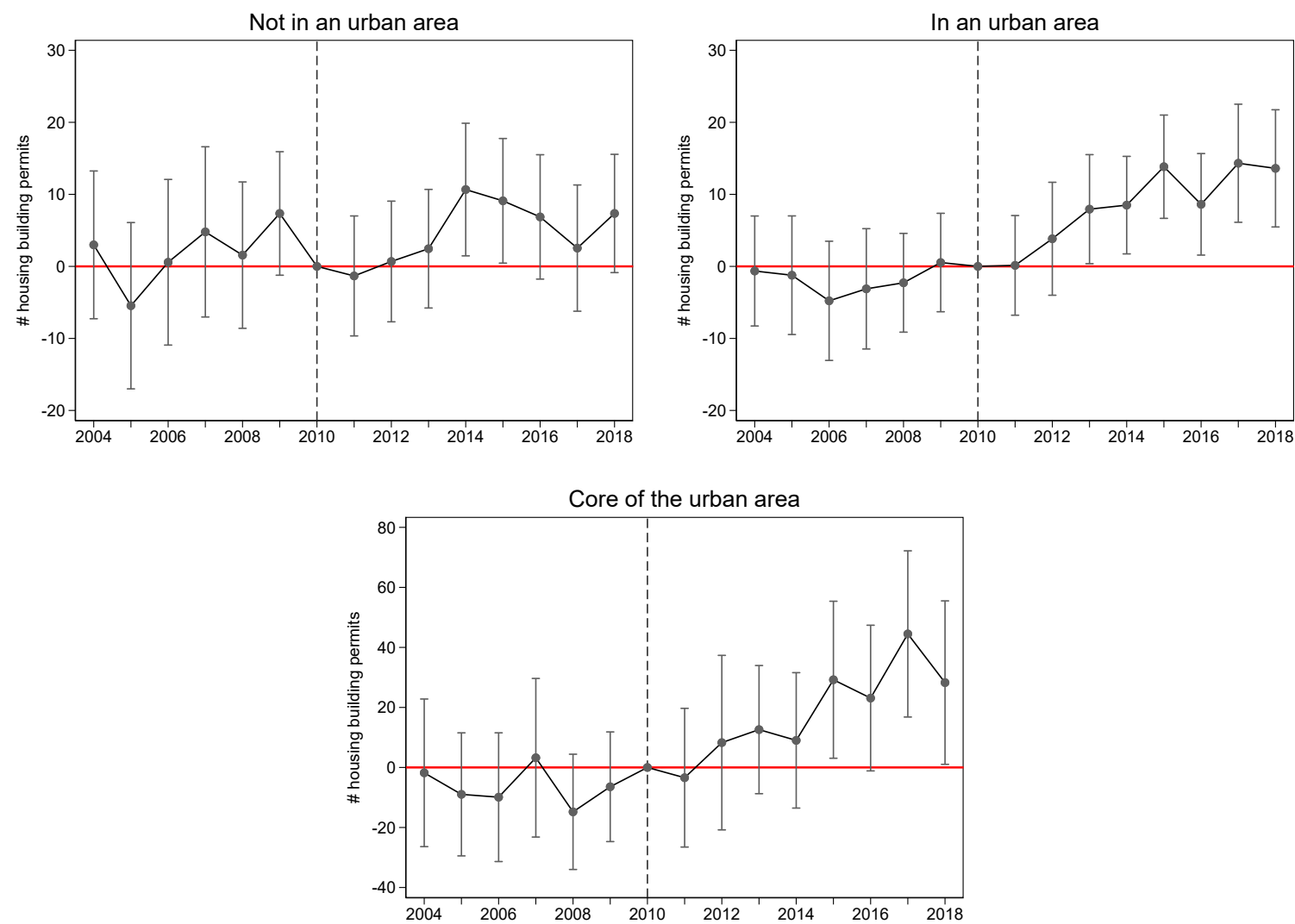

Notes: These graphs plot the estimates and 95-percent-confidence intervals from the leads-and-lags regression, using as outcome the number of housing building permits delivered in the municipality per year per 10,000 inhabitants (using the 2010 population) The first graph includes only municipalities that are not part of an urban area. The second graph includes only municipalities that are part of an urban area. The third graph includes only municipalities in the core of the urban area (using a different scale given the magnitude of the results). 
Figure A4: Impact on housing inside urban areas: Housing density
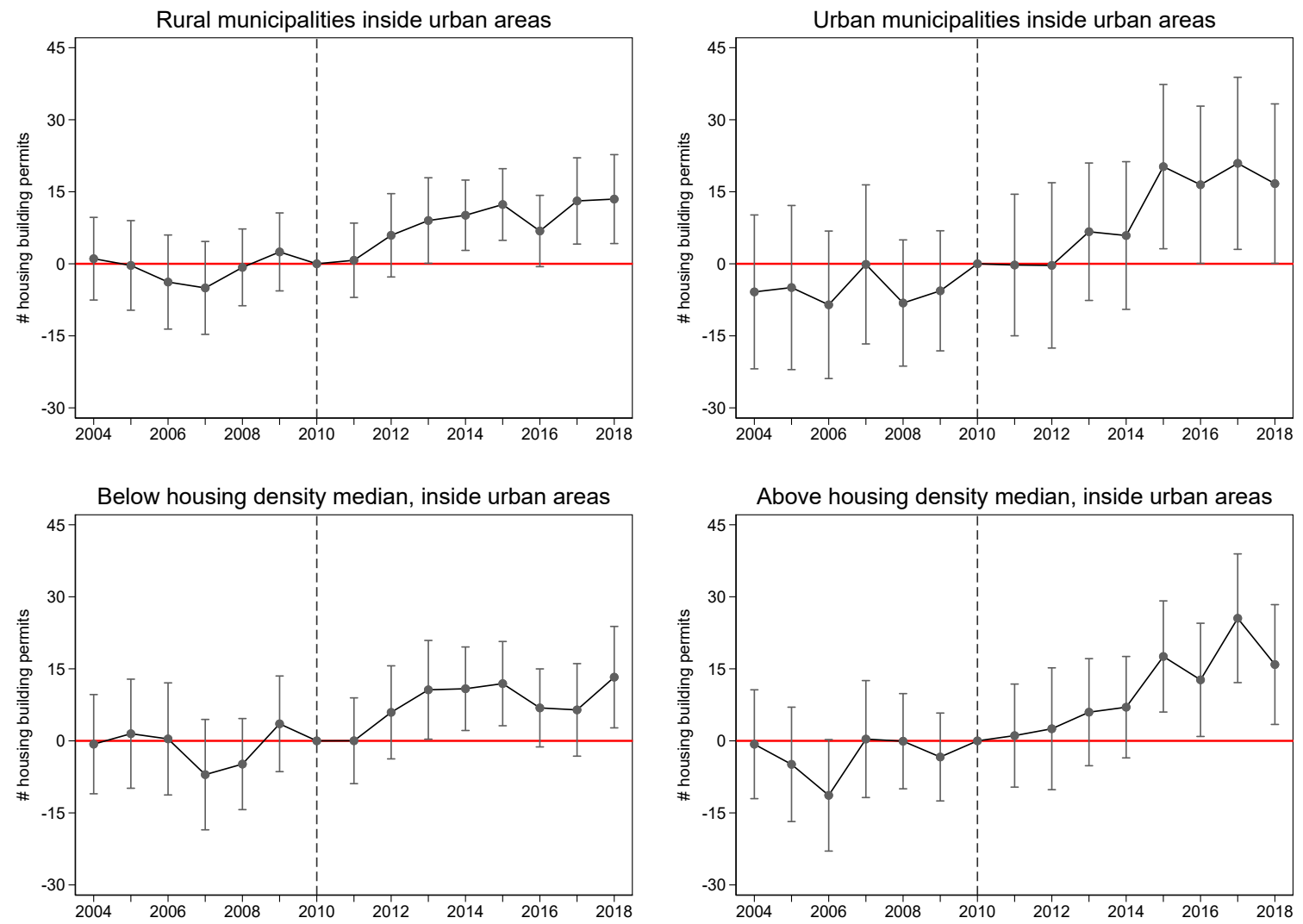

Notes: All graphs focus on municipalities inside an urban area. These graphs plot the estimates and 95-percent-confidence intervals from the leads-and-lags regression, using as outcome the number of housing building permits delivered in the municipality per year per 10,000 inhabitants (using the 2010 population). The first (resp. second) graph includes only rural (resp. urban) municipalities. The third (resp. fourth) graph includes only municipalities with a housing density in 2010 below (resp. above) the median. 
Figure A5: Impact on economic activity: Urban area
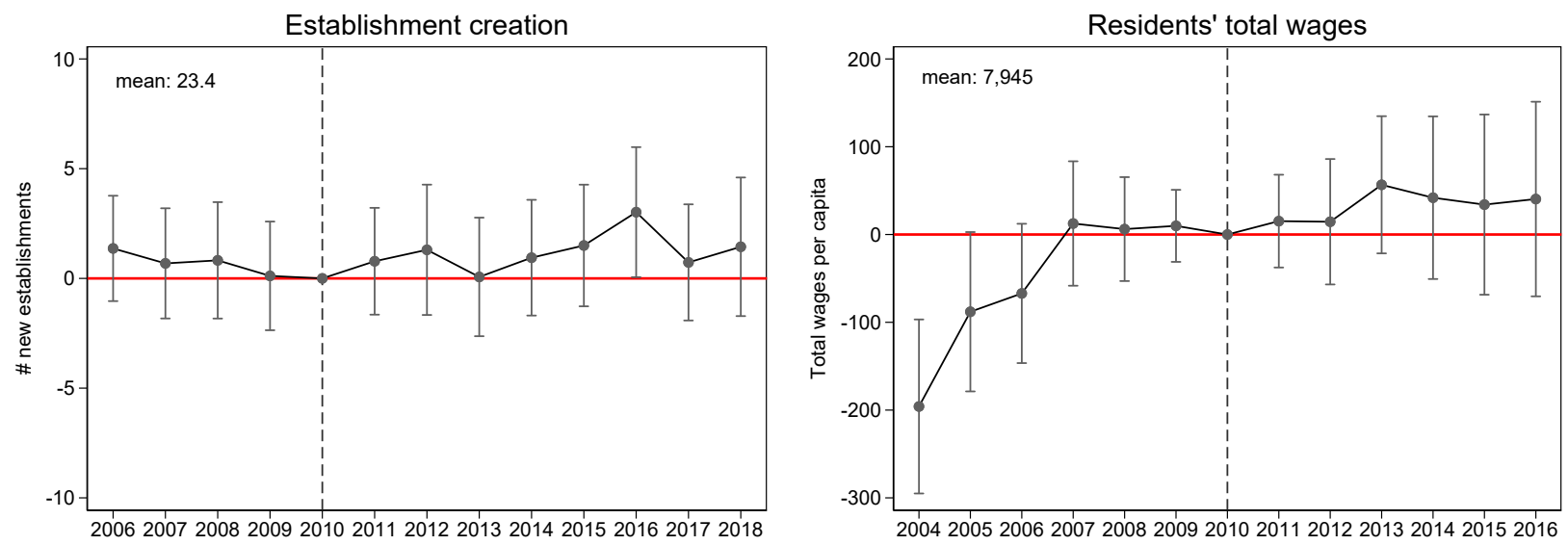

Notes: These graphs plot the estimates and 95-percent-confidence intervals from the leads-and-lags regression. The two graphs focus on municipalities inside an urban area. On the left-hand graph, the outcome is the number of establishments created in a given year, per 10,000 inhabitants (using the 2010 population). The agricultural sector and establishments created by individual entrepreneurs are excluded. On the right-hand graph, the outcome is the yearly total wages received by residents, divided by the 2010 population. The total wage computation includes only full-time employed residents. It excludes self-employed workers as well as the agricultural and public sectors. It is missing for the 311 smallest municipalities ( 2 percent). On both graphs, the average value of the outcome in the treatment group before 2010 is displayed on the top left corner. 
Figure A6: Impact on public services: Full sample
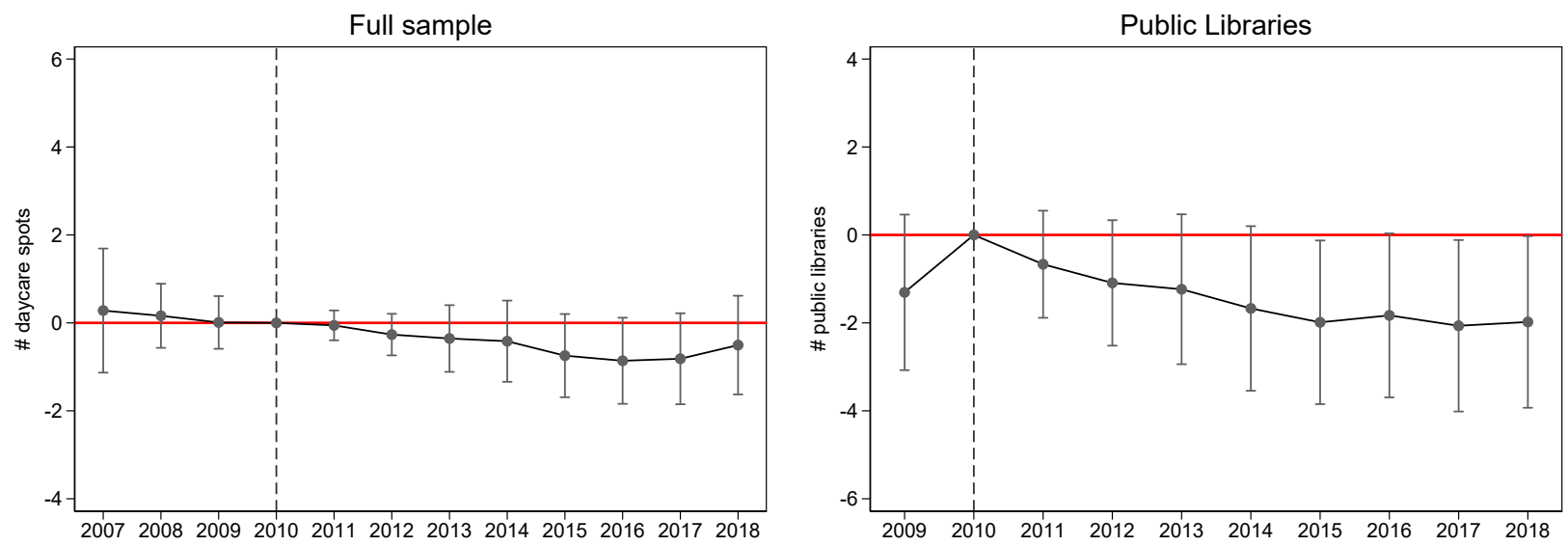

Notes: These graphs plot the estimates and 95-percent-confidence intervals from the leads-and-lags regression. In the left-hand graph, the outcome is the number of child daycare spots in the municipality per 10,000 inhabitants (using the 2010 population). In the right-hand graph, the outcome is the number of public libraries in the municipality per 10,000 inhabitants (using the 2010 population), and the sample is restricted to the 7 départements for which data are available starting in 2009. 
Figure A7: Impact on the number of daycare facilities
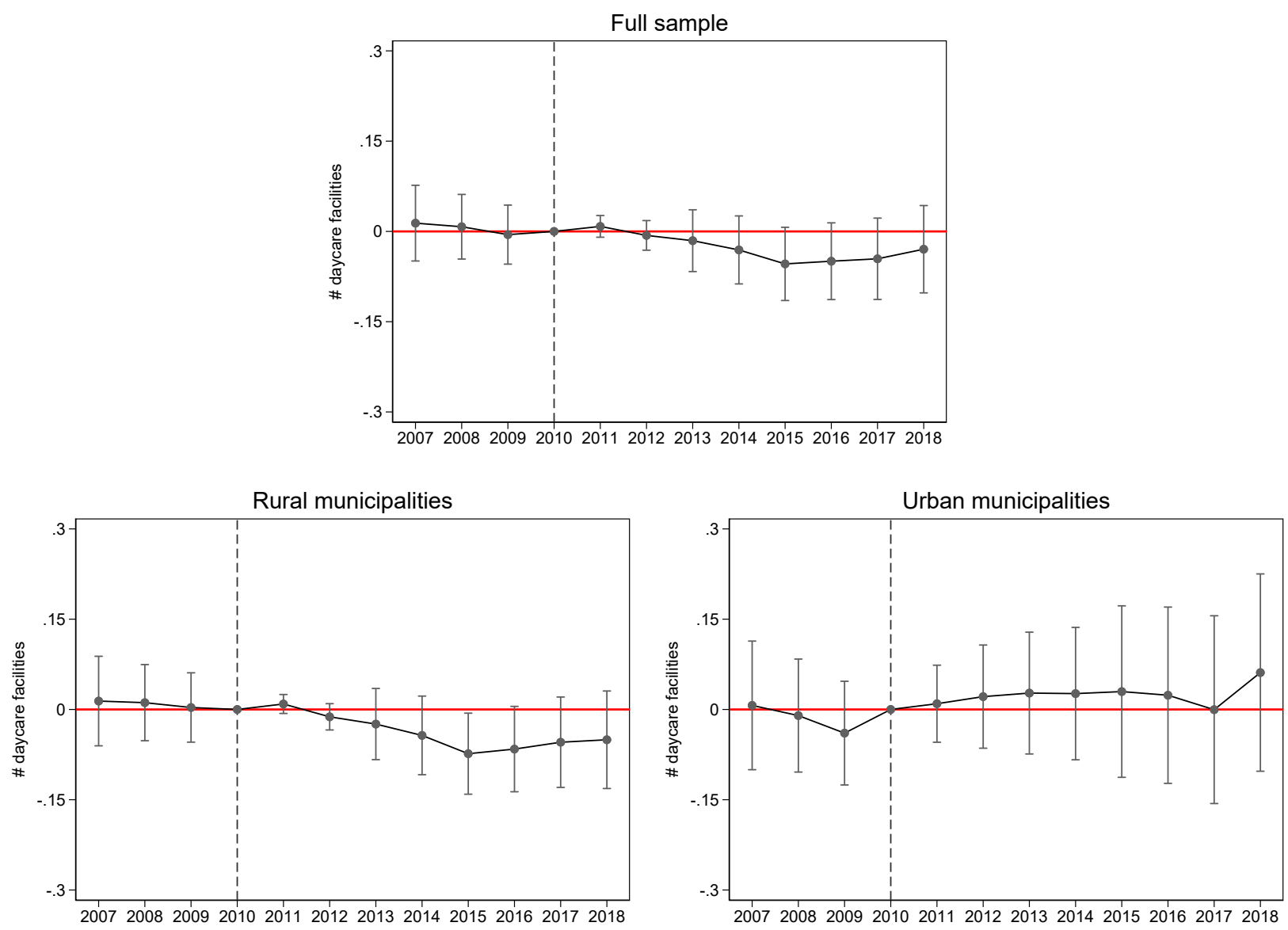

Notes: These graphs plot the estimates and 95-percent-confidence intervals from the leads-and-lags regression. The outcome is the number of daycare facilities in the municipality per 10,000 inhabitants (using the 2010 population). The graph on the bottom left-hand side includes only rural municipalities, while the graph on the bottom right-hand side includes only urban municipalities. 
Figure A8: Impact on public schools: Rural municipalities
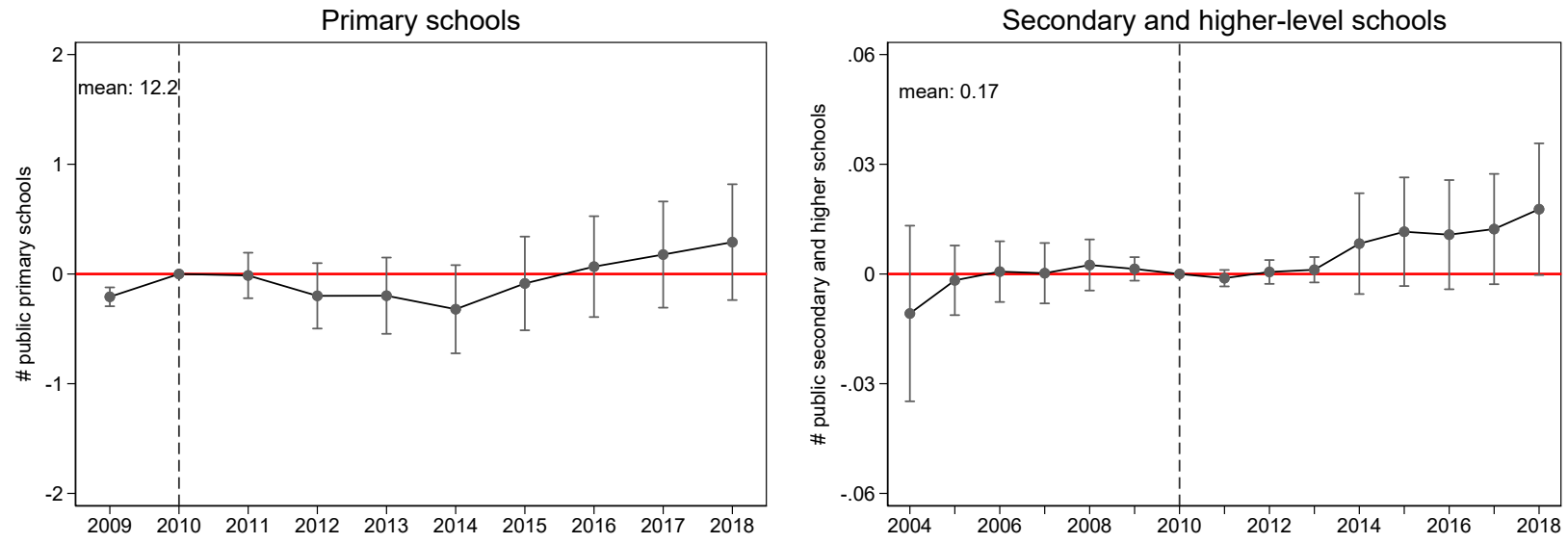

Notes: These graphs plot the estimates and 95-percent-confidence intervals from the leads-and-lags regression. The sample includes only rural municipalities. On the left-hand graph, the outcome is the number of public preschools and primary schools in the municipality, per 10,000 inhabitants (using the 2010 population). On the right-hand graph, the outcome is the number of secondary schools, high schools, and universities in the municipality, per 10,000 inhabitants (using the 2010 population). It includes both fully public schools and private but publicly subsidized schools. On both graphs, the average value of the outcome in the treatment group before 2010 is displayed on the top left corner.

\section{Figure A9: Comparison with municipalities that voluntarily integrated: Transport}
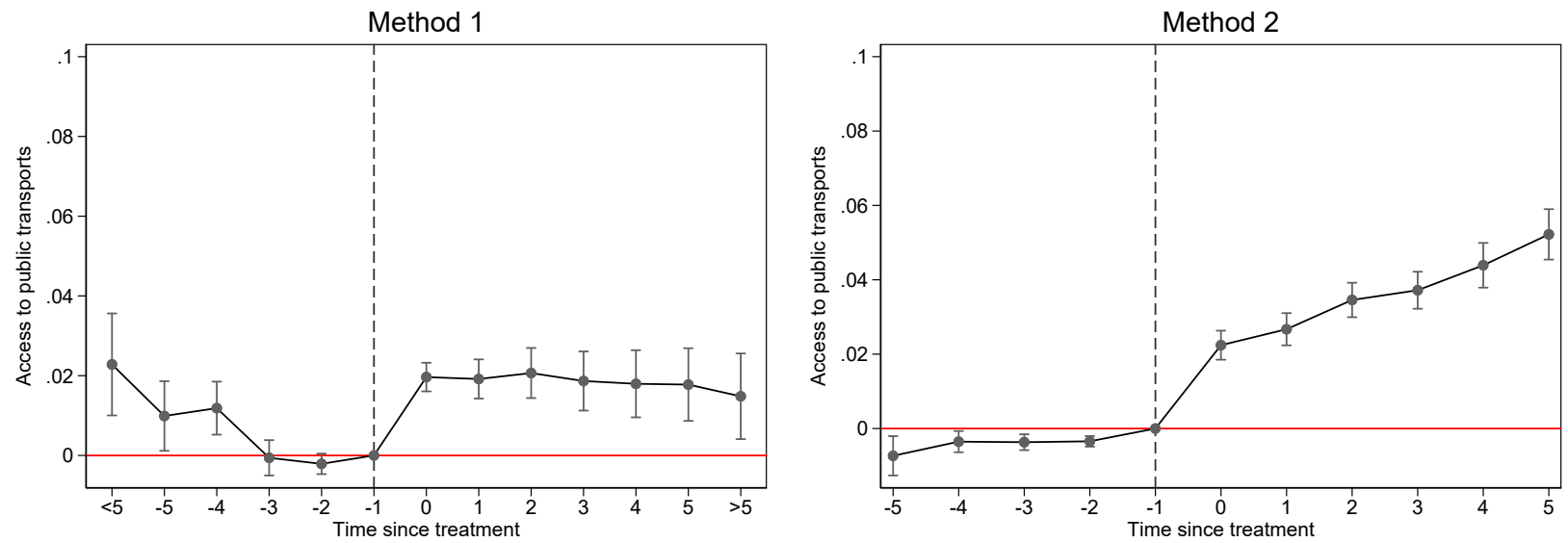

Notes: The outcome is an indicator variable equal to 1 if the municipality has access to public transport. The sample includes only municipalities that voluntarily integrated between 2000 and 2010 and excludes municipalities in the Parisian region of Ille-de-France, for which the data are not available. The left-hand graph plot the estimates and 95-percent-confidence intervals from a regular staggered adoption design (method 1). The right-hand graph uses de Chaisemartin and D'Haultfoeuille (2020)'s method, implemented using the Stata command did_multiplegt, available on SSC repository (method 2). In method 1, the period of analysis goes from 1999 to 2017, whereas, in method 2, it goes from 1999 to 2009. More information on the two methods in Section 4.2. 


\section{Figure A10: Impact on tax revenues and state transfers}
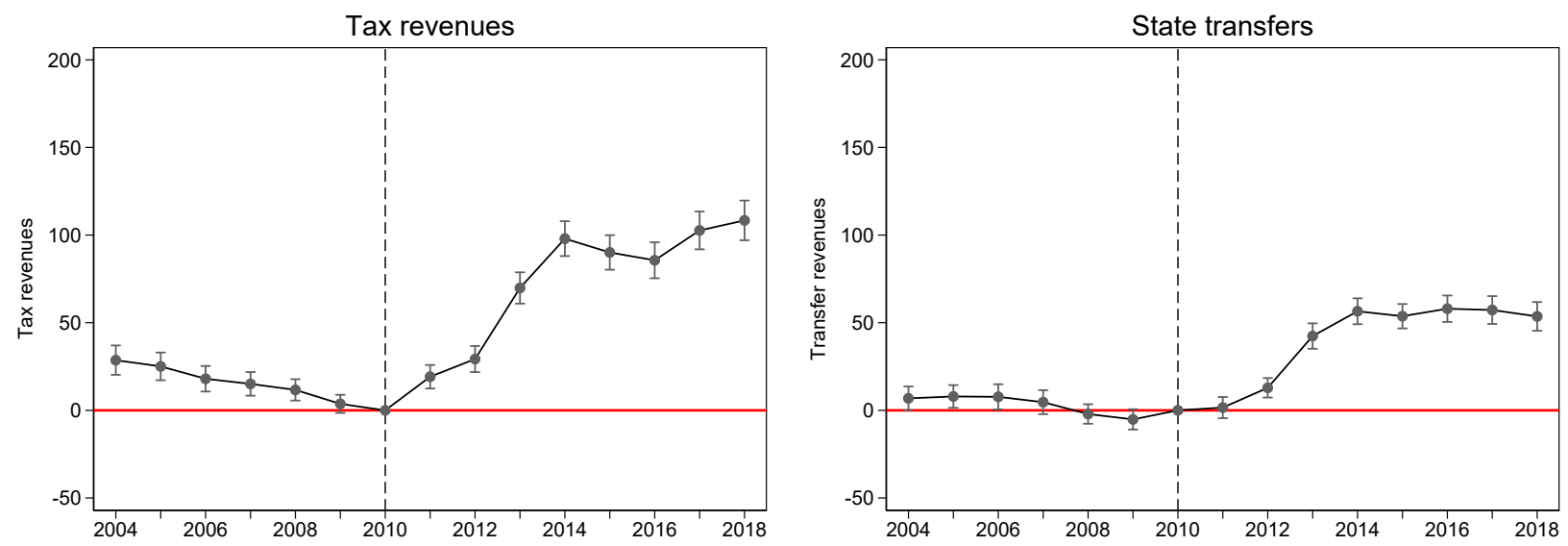

Notes: These graphs plot the estimates and 95-percent-confidence intervals from the leads-and-lags regression. On the left-hand (resp. right-hand) side graph, the outcome is the municipality's tax revenues (resp. state transfers) per capita (using the 2010 population). The outcome construction is described in Section 6.2. I exclude from the analysis the few municipalities for which the data are missing for at least one year over the period 2004-2018 (0.4 percent of the sample). 
Figure A11: Comparison with municipalities that voluntarily integrated: Fiscal revenues
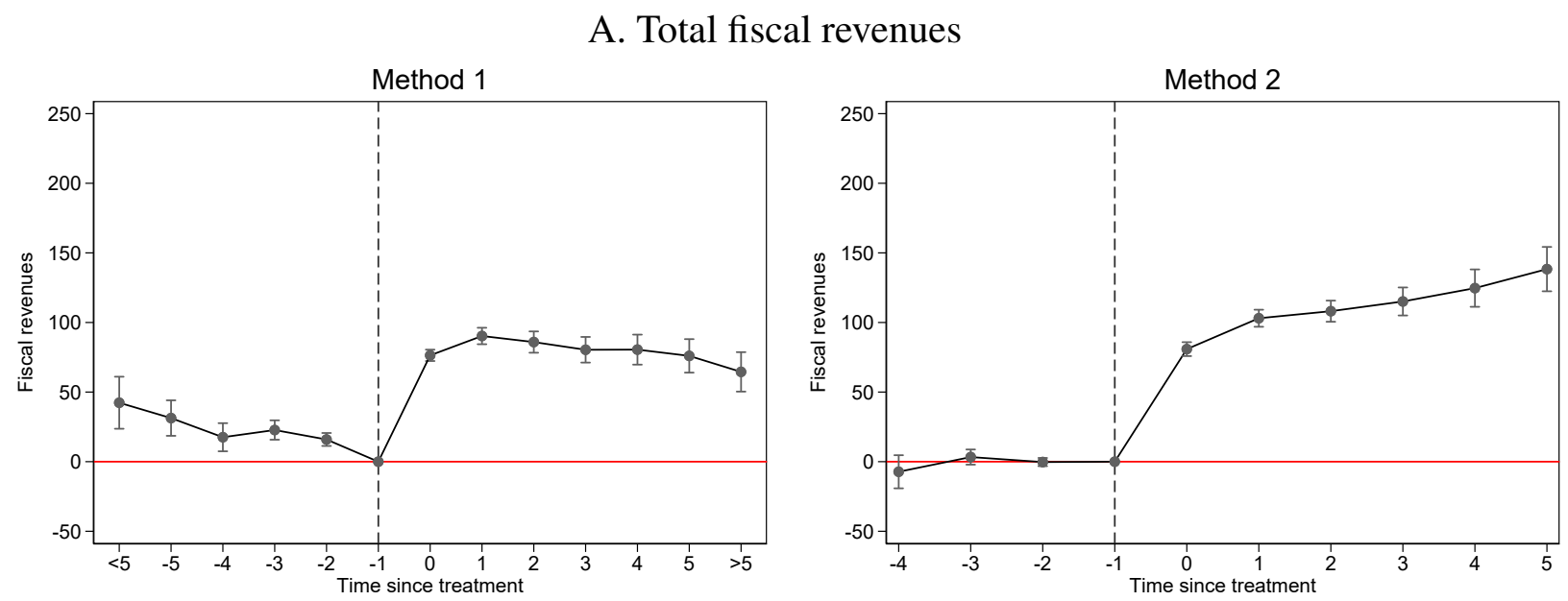

B. Tax revenues
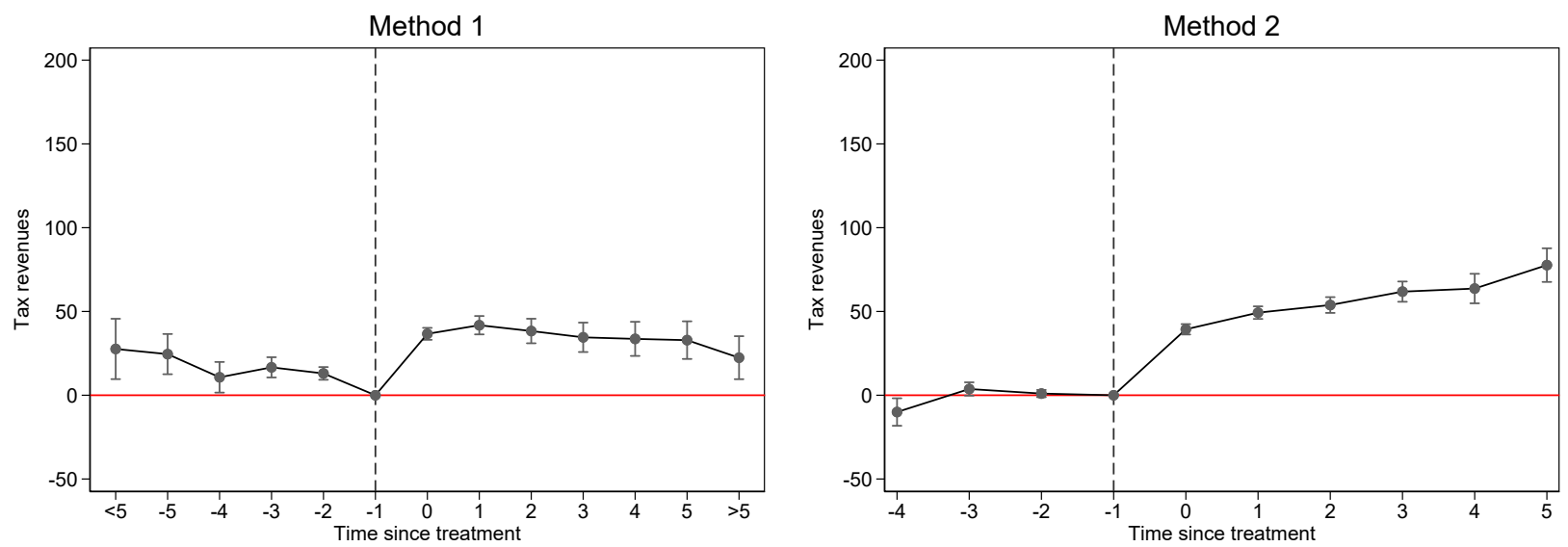

C. State transfers
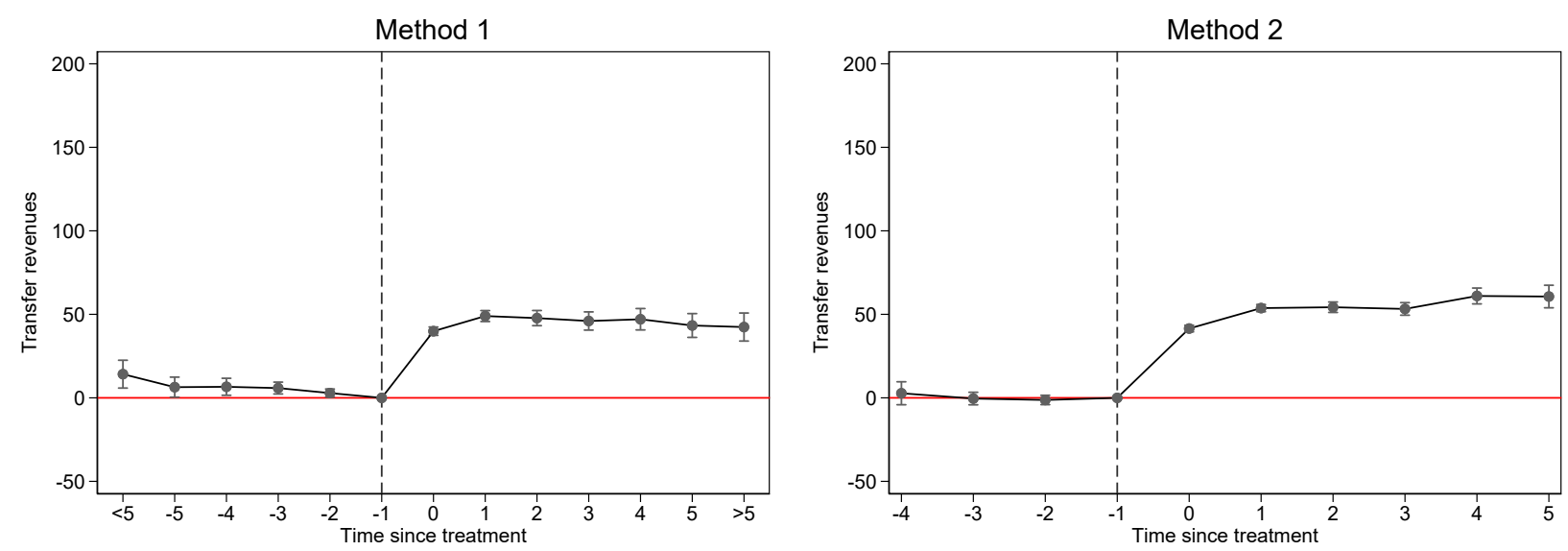

Notes: The sample is made up of municipalities that voluntarily integrated between 2000 and 2010 . The outcome in panel A (resp. B, C) is the municipality's total fiscal revenue (resp. tax revenue, state transfers) per capita, as described in Section 6.2. Data on fiscal revenues are only available starting in 2002. The analysis is thus restricted to municipalities integrating between 2003 and 2010. I exclude from the analysis a few municipalities for which the data are missing for at least one year over the period 2002-2018 (3.5 percent of the sample). Left-hand graphs plot the estimates and 95-percent-confidence intervals from a regular staggered adoption design (method 1). Right-hand graphs use de Chaisemartin and D'Haultfoeuille (2020)'s method (method 2). In method 1, the period of analysis goes from 2002 to 2018, whereas, in method 2, it goes from 2002 to 2009 . The second method goes only back to year -4 for fiscal outcomes. To compute the impact in year -5 , we would need to observe some municipalities both 4 years before and after treatment, which is not possible given the lack of data prior to 2002 . 
Table A1: Descriptive statistics using the control group only - 2010 (Panels A and B)

\begin{tabular}{|c|c|c|c|c|c|c|c|c|}
\hline & \multicolumn{4}{|c|}{ Treated municipalities $(\mathrm{N}=1,299)$} & \multicolumn{4}{|c|}{ Control municipalities $(\mathrm{N}=15,097)$} \\
\hline & mean & sd & $\min$ & $\max$ & mean & sd & $\min$ & $\max$ \\
\hline Panel A & \multicolumn{8}{|c|}{ Socio-demographic characteristics } \\
\hline population & 1,640 & 4,692 & 16 & 72,939 & 1,959 & 11,686 & 7 & 851,420 \\
\hline w/out largest & 1,640 & 4,692 & 16 & 72,939 & 1,574 & 4,139 & 7 & 66,095 \\
\hline$\Delta$ population & 0.102 & 0.160 & -0.397 & 1.385 & 0.100 & 0.149 & -0.500 & 2.692 \\
\hline density & 162.1 & 541.6 & 2.11 & 6,884 & 156.3 & 450.1 & 0.60 & 9,976 \\
\hline urban & 0.204 & 0.403 & 0.000 & 1.000 & 0.223 & 0.416 & 0.000 & 1.000 \\
\hline urban area & 0.637 & 0.481 & 0.000 & 1.000 & 0.614 & 0.487 & 0.000 & 1.000 \\
\hline core urban area & 0.091 & 0.287 & 0.000 & 1.000 & 0.119 & 0.324 & 0.000 & 1.000 \\
\hline immigrants & 0.044 & 0.040 & 0.000 & 0.333 & 0.036 & 0.039 & 0.000 & 0.665 \\
\hline unemployed & 0.082 & 0.039 & 0.000 & 0.571 & 0.088 & 0.040 & 0.000 & 0.417 \\
\hline below 5 y/o & 0.060 & 0.020 & 0.000 & 0.172 & 0.062 & 0.020 & 0.000 & 0.206 \\
\hline above 65 y/o & 0.170 & 0.066 & 0.000 & 0.522 & 0.176 & 0.063 & 0.000 & 0.666 \\
\hline av. \# children & 0.907 & 0.245 & 0.000 & 2.000 & 0.904 & 0.220 & 0.000 & 2.500 \\
\hline farmers & 0.036 & 0.053 & 0.000 & 0.444 & 0.038 & 0.050 & 0.000 & 0.600 \\
\hline executives & 0.070 & 0.065 & 0.000 & 0.429 & 0.052 & 0.043 & 0.000 & 0.563 \\
\hline workers & 0.152 & 0.080 & 0.000 & 1.000 & 0.169 & 0.069 & 0.000 & 0.667 \\
\hline retired & 0.280 & 0.101 & 0.000 & 0.800 & 0.286 & 0.095 & 0.000 & 1.000 \\
\hline no diploma & 0.172 & 0.069 & 0.000 & 0.463 & 0.185 & 0.067 & 0.000 & 0.614 \\
\hline baccalaureate & 0.156 & 0.039 & 0.000 & 0.324 & 0.153 & 0.036 & 0.000 & 0.557 \\
\hline high education & 0.088 & 0.071 & 0.000 & 0.507 & 0.072 & 0.045 & 0.000 & 0.542 \\
\hline residents' income & 14,064 & 4,362 & 5,495 & 59,093 & 12,488 & 2,863 & 3,273 & 65,758 \\
\hline Panel B & \multicolumn{8}{|c|}{ Land-use characteristics } \\
\hline share built land (\%) & 0.742 & 1.416 & 0.024 & 15.882 & 0.791 & 1.411 & 0.006 & 21.892 \\
\hline average height & 1.561 & 0.216 & 1.048 & 4.727 & 1.569 & 0.191 & 1.000 & 4.391 \\
\hline FAR $(\mathrm{p} 30)$ & 0.110 & 0.076 & 0.001 & 0.901 & 0.109 & 0.080 & 0.001 & 0.895 \\
\hline FAR (p50) & 0.171 & 0.116 & 0.003 & 1.812 & 0.173 & 0.121 & 0.004 & 1.901 \\
\hline
\end{tabular}

Notes: Socio-demographic variables come from the 2008 census, which applies to the year 2010. Line 2 removes the 31 municipalities with a population higher than that of the largest treated municipality from the control group. The variation in the population (line 3) is computed by comparing the 1999 and 2008 censuses. Indicator variables for whether the municipality is urban, part of an urban area, or in the urban core are based on the INSEE 2010 classification. Land-use characteristics come from Combes et al. (2021) and each variable is built considering only construction before 2010. The share of built land is computed considering all construction, whereas the average height and floor-to-area ratio (FAR) are computed considering only housing construction. The average height gives the average number of housing stories. To measure the FAR stringency, I follow Combes et al. (2021) and take the 30th percentile of the distribution of realized floor-to-area ratios of all housing buildings in the municipality (FAR p(30)). I also show the statistics using the median (FAR p(50)). 
Table A1 (continued): Descriptive statistics using the control group only - 2010 (Panel C)

\begin{tabular}{|c|c|c|c|c|c|c|c|c|}
\hline & \multicolumn{4}{|c|}{ Treated municipalities $(\mathrm{N}=1,299)$} & \multicolumn{4}{|c|}{ Control municipalities $(\mathrm{N}=15,097)$} \\
\hline & mean & sd & $\min$ & $\max$ & mean & $\mathrm{sd}$ & $\min$ & $\max$ \\
\hline Panel C & \multicolumn{8}{|c|}{ Political characteristics } \\
\hline turnout municipal & 0.763 & 0.096 & 0.431 & 1.000 & 0.774 & 0.090 & 0.367 & 1.000 \\
\hline turnout presidential & 0.874 & 0.040 & 0.655 & 1.000 & 0.872 & 0.039 & 0.600 & 1.000 \\
\hline voteshare right & 0.602 & 0.107 & 0.152 & 1.000 & 0.563 & 0.105 & 0.143 & 1.000 \\
\hline voteshare far-right & 0.138 & 0.057 & 0.000 & 0.467 & 0.128 & 0.054 & 0.000 & 0.519 \\
\hline right-wing mayor & 0.620 & 0.486 & 0.000 & 1.000 & 0.568 & 0.495 & 0.000 & 1.000 \\
\hline left-wing mayor & 0.267 & 0.443 & 0.000 & 1.000 & 0.336 & 0.472 & 0.000 & 1.000 \\
\hline NC mayor & 0.112 & 0.316 & 0.000 & 1.000 & 0.094 & 0.292 & 0.000 & 1.000 \\
\hline woman mayor & 0.161 & 0.368 & 0.000 & 1.000 & 0.138 & 0.345 & 0.000 & 1.000 \\
\hline age mayor & 57.1 & 9.1 & 25.0 & 87.0 & 56.1 & 8.6 & 18.0 & 85.0 \\
\hline incumbent mayor & 0.661 & 0.474 & 0.000 & 1.000 & 0.626 & 0.484 & 0.000 & 1.000 \\
\hline change orientations & 0.210 & 0.407 & 0.000 & 1.000 & 0.212 & 0.409 & 0.000 & 1.000 \\
\hline
\end{tabular}

Notes: The municipal turnout rate and mayor's characteristics are based on the results of the 2008 municipal elections. The presidential turnout rate and far-right vote share come from the results of the first round of the 2007 presidential elections. The right-wing vote share comes from the results of the second round of the 2007 presidential elections. NC stands for "non classified". 
Table A2: Descriptive statistics using municipalities' characteristics in 1999

\begin{tabular}{|c|c|c|c|c|c|c|c|c|}
\hline & \multicolumn{4}{|c|}{ Treated municipalities $(\mathrm{N}=1,299)$} & \multicolumn{4}{|c|}{ Integrated municipalities $(\mathrm{N}=26,991)$} \\
\hline & mean & sd & $\min$ & $\max$ & mean & sd & $\min$ & $\max$ \\
\hline population & $\mathbf{1 , 5 1 1}$ & 4,427 & 18 & 67,406 & 1,615 & 9,170 & 2 & 797,491 \\
\hline density & 150.4 & 518.9 & 1.20 & 6,629 & 133.3 & 413.1 & 0.17 & 10,153 \\
\hline urban & 0.179 & 0.384 & 0.000 & 1.000 & 0.174 & 0.379 & 0.000 & 1.000 \\
\hline urban area & 0.574 & 0.495 & 0.000 & 1.000 & 0.542 & 0.498 & 0.000 & 1.000 \\
\hline core urban area & 0.078 & 0.268 & 0.000 & 1.000 & 0.093 & 0.291 & 0.000 & 1.000 \\
\hline unemployed & 0.101 & 0.046 & 0.000 & 0.345 & 0.105 & 0.048 & 0.000 & 0.500 \\
\hline below 5 y/o & 0.048 & 0.018 & 0.000 & 0.152 & 0.049 & 0.017 & 0.000 & 0.250 \\
\hline above 65 y/o & 0.180 & 0.073 & 0.025 & 0.514 & 0.189 & 0.071 & 0.000 & 0.778 \\
\hline av. \# children & 0.949 & 0.308 & 0.000 & 3.500 & 0.947 & 0.286 & 0.000 & 5.000 \\
\hline farmers & 0.051 & 0.062 & 0.000 & 0.500 & 0.052 & 0.059 & 0.000 & 1.000 \\
\hline executives & 0.053 & 0.056 & 0.000 & 0.429 & 0.038 & 0.036 & 0.000 & 0.500 \\
\hline workers & 0.159 & 0.072 & 0.000 & 0.600 & 0.171 & 0.066 & 0.000 & 0.667 \\
\hline retired & 0.250 & 0.091 & 0.000 & 0.750 & 0.258 & 0.086 & 0.000 & 1.000 \\
\hline no diploma & 0.200 & 0.080 & 0.029 & 0.682 & 0.219 & 0.078 & 0.000 & 0.692 \\
\hline baccalaureate & 0.115 & 0.039 & 0.000 & 0.286 & 0.110 & 0.035 & 0.000 & 0.500 \\
\hline high education & 0.060 & 0.057 & 0.000 & 0.413 & 0.046 & 0.035 & 0.000 & 0.518 \\
\hline residents' income & 8,434 & 3,199 & 2,739 & 30,590 & 7,252 & 1,929 & 1,937 & 38,509 \\
\hline
\end{tabular}

Notes: Data on the municipal population, age, education, and occupational composition come from the 1999 census. The share of immigrants is not available for this census year. Residents' income corresponds to the 2000 taxable income data. 
Table A3: Descriptive statistics - 2010: Urban municipalities (Panels A and B)

\begin{tabular}{|c|c|c|c|c|c|c|c|c|}
\hline & \multicolumn{4}{|c|}{ Treated municipalities $(\mathrm{N}=265)$} & \multicolumn{4}{|c|}{ Integrated municipalities $(\mathrm{N}=5,628)$} \\
\hline & mean & sd & $\min$ & $\max$ & mean & $\mathrm{sd}$ & $\min$ & $\max$ \\
\hline Panel A & \multicolumn{8}{|c|}{ Socio-demographic characteristics } \\
\hline population & 6,199 & 9,001 & 137 & 72,939 & 6,302 & 20,376 & 77 & 85,1420 \\
\hline$\Delta$ population & 0.106 & 0.160 & -0.167 & 1.385 & 0.086 & 0.129 & -0.257 & 2.070 \\
\hline density & 617.9 & $1,081.7$ & 26.2 & $6,883.5$ & 496.5 & 826.6 & 12.4 & $9,976.5$ \\
\hline urban area & 0.838 & 0.369 & 0.000 & 1.000 & 0.852 & 0.355 & 0.000 & 1.000 \\
\hline core urban area & 0.445 & 0.498 & 0.000 & 1.000 & 0.518 & 0.500 & 0.000 & 1.000 \\
\hline immigrants & 0.070 & 0.047 & 0.005 & 0.281 & 0.050 & 0.044 & 0.000 & 0.395 \\
\hline unemployed & 0.092 & 0.036 & 0.013 & 0.237 & 0.099 & 0.041 & 0.000 & 0.296 \\
\hline below 5 y/o & 0.059 & 0.013 & 0.030 & 0.091 & 0.059 & 0.013 & 0.014 & 0.132 \\
\hline above 65 y/o & 0.165 & 0.063 & 0.037 & 0.406 & 0.169 & 0.054 & 0.021 & 0.431 \\
\hline av. \# children & 0.954 & 0.187 & 0.416 & 1.471 & 0.924 & 0.158 & 0.376 & 1.833 \\
\hline farmers & 0.007 & 0.012 & 0.000 & 0.103 & 0.009 & 0.013 & 0.000 & 0.190 \\
\hline executives & 0.099 & 0.069 & 0.000 & 0.319 & 0.070 & 0.044 & 0.000 & 0.340 \\
\hline workers & 0.125 & 0.057 & 0.016 & 0.305 & 0.148 & 0.052 & 0.000 & 0.400 \\
\hline retired & 0.265 & 0.081 & 0.070 & 0.578 & 0.274 & 0.069 & 0.029 & 0.617 \\
\hline no diploma & 0.163 & 0.064 & 0.018 & 0.359 & 0.176 & 0.064 & 0.025 & 0.557 \\
\hline baccalaureate & 0.164 & 0.027 & 0.090 & 0.251 & 0.155 & 0.026 & 0.032 & 0.362 \\
\hline high education & 0.125 & 0.092 & 0.025 & 0.507 & 0.093 & 0.055 & 0.000 & 0.542 \\
\hline residents' income & 16,197 & 4,867 & 8,963 & 40,218 & 13,792 & 3,229 & 6,164 & 57,126 \\
\hline Panel B & \multicolumn{8}{|c|}{ Land-use characteristics } \\
\hline share built land (\%) & 2.377 & 2.474 & 0.247 & 15.882 & 2.183 & 2.274 & 0.122 & 23.943 \\
\hline average height & 1.678 & 0.317 & 1.135 & 4.727 & 1.635 & 0.233 & 1.061 & 4.391 \\
\hline FAR $(p 30)$ & 0.170 & 0.085 & 0.030 & 0.493 & 0.170 & 0.089 & 0.008 & 1.465 \\
\hline FAR (p50) & 0.245 & 0.146 & 0.061 & 1.812 & 0.244 & 0.126 & 0.027 & 1.901 \\
\hline
\end{tabular}

Notes: The sample includes only urban municipalities. Socio-demographic variables come from the 2008 census, which applies to the year 2010. The variation in the population (line 2 ) is computed by comparing the 1999 and 2008 censuses. Indicator variables for whether the municipality is part of an urban area, or in the urban core are based on the INSEE 2010 classification. Land-use characteristics come from Combes et al. (2021) and each variable is built considering only construction before 2010. The share of built land is computed considering all construction, whereas the average height and floor-to-area ratio (FAR) are computed considering only housing construction. The average height gives the average number of housing stories. To measure the FAR stringency, I follow Combes et al. (2021) and take the 30th percentile of the distribution of realized floor-to-area ratios of all housing buildings in the municipality (FAR p(30)). I also show the statistics using the median (FAR p(50)). 
Table A3 (continued): Descriptive statistics - 2010: Urban municipalities (Panel C)

\begin{tabular}{|c|c|c|c|c|c|c|c|c|}
\hline & \multicolumn{4}{|c|}{ Treated municipalities $(\mathrm{N}=265)$} & \multicolumn{4}{|c|}{ Integrated municipalities $(\mathrm{N}=5,628)$} \\
\hline & mean & sd & $\min$ & $\max$ & mean & sd & $\min$ & $\max$ \\
\hline Panel C & \multicolumn{8}{|c|}{ Political characteristics } \\
\hline turnout municipal & 0.677 & 0.086 & 0.431 & 0.883 & 0.696 & 0.084 & 0.367 & 0.985 \\
\hline turnout presidential & 0.869 & 0.032 & 0.761 & 0.943 & 0.863 & 0.036 & 0.724 & 0.993 \\
\hline voteshare right & 0.592 & 0.093 & 0.340 & 0.828 & 0.541 & 0.089 & 0.276 & 0.924 \\
\hline voteshare far-right & 0.115 & 0.039 & 0.034 & 0.224 & 0.119 & 0.043 & 0.020 & 0.380 \\
\hline right-wing mayor & 0.589 & 0.493 & 0.000 & 1.000 & 0.492 & 0.500 & 0.000 & 1.000 \\
\hline left-wing mayor & 0.343 & 0.476 & 0.000 & 1.000 & 0.444 & 0.497 & 0.000 & 1.000 \\
\hline NC mayor & 0.068 & 0.252 & 0.000 & 1.000 & 0.063 & 0.243 & 0.000 & 1.000 \\
\hline woman mayor & 0.140 & 0.347 & 0.000 & 1.000 & 0.109 & 0.312 & 0.000 & 1.000 \\
\hline age mayor & 57.7 & 8.9 & 30.0 & 81.0 & 56.4 & 8.6 & 23.0 & 83.0 \\
\hline incumbent mayor & 0.701 & 0.459 & 0.000 & 1.000 & 0.623 & 0.485 & 0.000 & 1.000 \\
\hline change orientations & 0.170 & 0.377 & 0.000 & 1.000 & 0.203 & 0.403 & 0.000 & 1.000 \\
\hline
\end{tabular}

Notes: The sample includes only urban municipalities. The municipal turnout rate and mayor's characteristics are based on the results of the 2008 municipal elections. The presidential turnout rate and far-right vote share come from the results of the first round of the 2007 presidential elections. The right-wing vote share comes from the results of the second round of the 2007 presidential elections. NC stands for "non classified". 
Table A4: Descriptive statistics - 2010: Rural municipalities (Panels A and B)

\begin{tabular}{|c|c|c|c|c|c|c|c|c|}
\hline & \multicolumn{4}{|c|}{ Treated municipalities $(\mathrm{N}=1,034)$} & \multicolumn{4}{|c|}{ Integrated municipalities $(\mathrm{N}=21,363)$} \\
\hline & mean & sd & $\min$ & $\max$ & mean & sd & $\min$ & $\max$ \\
\hline Panel A & \multicolumn{8}{|c|}{ Socio-demographic characteristics } \\
\hline population & 472 & 469 & 16 & 3,391 & 501 & 491 & 3 & 5,438 \\
\hline$\Delta$ population & 0.101 & 0.160 & -0.397 & 1.279 & 0.104 & 0.157 & -0.500 & 2.692 \\
\hline density & 45.2 & 50.3 & 2.1 & 525.1 & 47.3 & 57.8 & 0.2 & 2,750 \\
\hline urban area & 0.585 & 0.493 & 0.000 & 1.000 & 0.546 & 0.498 & 0.000 & 1.000 \\
\hline immigrants & 0.038 & 0.034 & 0.000 & 0.333 & 0.034 & 0.036 & 0.000 & 0.667 \\
\hline unemployed & 0.080 & 0.040 & 0.000 & 0.571 & 0.084 & 0.040 & 0.000 & 0.429 \\
\hline below 5 y/o & 0.061 & 0.022 & 0.000 & 0.172 & 0.062 & 0.022 & 0.000 & 0.206 \\
\hline above 65 y/o & 0.171 & 0.067 & 0.000 & 0.522 & 0.180 & 0.067 & 0.000 & 0.667 \\
\hline av. \# children & 0.895 & 0.257 & 0.000 & 2.000 & 0.884 & 0.242 & 0.000 & 3.000 \\
\hline farmers & 0.044 & 0.057 & 0.000 & 0.444 & 0.046 & 0.055 & 0.000 & 1.000 \\
\hline executives & 0.063 & 0.062 & 0.000 & 0.429 & 0.048 & 0.044 & 0.000 & 0.563 \\
\hline workers & 0.159 & 0.083 & 0.000 & 1.000 & 0.170 & 0.074 & 0.000 & 1.000 \\
\hline retired & 0.283 & 0.106 & 0.000 & 0.800 & 0.291 & 0.104 & 0.000 & 1.000 \\
\hline no diploma & 0.175 & 0.071 & 0.000 & 0.463 & 0.184 & 0.068 & 0.000 & 0.674 \\
\hline baccalaureate & 0.154 & 0.042 & 0.000 & 0.324 & 0.152 & 0.039 & 0.000 & 0.557 \\
\hline high education & 0.079 & 0.061 & 0.000 & 0.500 & 0.068 & 0.041 & 0.000 & 0.435 \\
\hline residents' income & 13,515 & 4,048 & 5,495 & 59,093 & 12,312 & 2,735 & 3,273 & 65,758 \\
\hline Panel B & \multicolumn{8}{|c|}{ Land-use characteristics } \\
\hline share built land (\%) & 0.323 & 0.308 & 0.024 & 3.631 & 0.341 & 0.408 & 0.004 & 25.987 \\
\hline average height & 1.531 & 0.169 & 1.048 & 2.325 & 1.540 & 0.168 & 1.000 & 3.000 \\
\hline FAR $(\mathrm{p} 30)$ & 0.095 & 0.065 & 0.001 & 0.901 & 0.090 & 0.065 & 0.000 & 0.965 \\
\hline FAR (p50) & 0.152 & 0.099 & 0.003 & 1.614 & 0.150 & 0.108 & 0.003 & 1.790 \\
\hline
\end{tabular}

Notes: The sample includes only rural municipalities. Socio-demographic variables come from the 2008 census, which applies to the year 2010. The variation in the population (line 2) is computed by comparing the 1999 and 2008 censuses. The indicator variable for whether the municipality is part of an urban area is based on the INSEE 2010 classification. Land-use characteristics come from Combes et al. (2021) and each variable is built considering only construction before 2010. The share of built land is computed considering all construction, whereas the average height and floor-to-area ratio (FAR) are computed considering only housing construction. The average height gives the average number of housing stories. To measure the FAR stringency, I follow Combes et al. (2021) and take the 30th percentile of the distribution of realized floor-to-area ratios of all housing buildings in the municipality (FAR p(30)). I also show the statistics using the median (FAR p(50)). 
Table A4 (continued): Descriptive statistics - 2010: Rural municipalities (Panel C)

\begin{tabular}{|c|c|c|c|c|c|c|c|c|}
\hline & \multicolumn{4}{|c|}{ Treated municipalities $(\mathrm{N}=1,034)$} & \multicolumn{4}{|c|}{ Integrated municipalities $(\mathrm{N}=21,363)$} \\
\hline & mean & sd & $\min$ & $\max$ & mean & $\mathrm{sd}$ & $\min$ & $\max$ \\
\hline Panel C & \multicolumn{8}{|c|}{ Political characteristics } \\
\hline turnout municipal & 0.785 & 0.086 & 0.499 & 1.000 & 0.800 & 0.078 & 0.464 & 1.000 \\
\hline turnout presidential & 0.876 & 0.042 & 0.655 & 1.000 & 0.876 & 0.040 & 0.000 & 1.000 \\
\hline voteshare right & 0.604 & 0.111 & 0.152 & 1.000 & 0.569 & 0.108 & 0.106 & 1.000 \\
\hline voteshare far-right & 0.144 & 0.059 & 0.000 & 0.467 & 0.133 & 0.056 & 0.000 & 0.556 \\
\hline right-wing mayor & 0.628 & 0.484 & 0.000 & 1.000 & 0.577 & 0.494 & 0.000 & 1.000 \\
\hline left-wing mayor & 0.248 & 0.432 & 0.000 & 1.000 & 0.309 & 0.462 & 0.000 & 1.000 \\
\hline NC mayor & 0.124 & 0.330 & 0.000 & 1.000 & 0.113 & 0.317 & 0.000 & 1.000 \\
\hline woman mayor & 0.166 & 0.373 & 0.000 & 1.000 & 0.151 & 0.358 & 0.000 & 1.000 \\
\hline age mayor & $\mathbf{5 7 . 0}$ & 9.1 & 25.0 & 87.0 & 56.0 & 8.8 & 18.0 & 88.0 \\
\hline incumbent mayor & 0.651 & 0.477 & 0.000 & 1.000 & 0.624 & 0.484 & 0.000 & 1.000 \\
\hline change orientations & 0.220 & 0.414 & 0.000 & 1.000 & 0.226 & 0.418 & 0.000 & 1.000 \\
\hline
\end{tabular}

Notes: The sample includes only rural municipalities. The municipal turnout rate and mayor's characteristics are based on the results of the 2008 municipal elections. The presidential turnout rate and far-right vote share come from the results of the first round of the 2007 presidential elections. The right-wing vote share comes from the results of the second round of the 2007 presidential elections. NC stands for "non classified". 
Table A5: Impact on housing: Dividing by current population and adding controls

\begin{tabular}{lcccc}
\hline \multirow{4}{*}{ Outcome } & $(1)$ & $(2)$ & $(3)$ & $(4)$ \\
& \multicolumn{4}{c}{ Number of housing building permits } \\
& 2010 population & Current population \\
\hline Treatment & $8.141^{* * *}$ & $7.702^{* * *}$ & $15.980^{* * *}$ & $15.617^{* * *}$ \\
& $(1.517)$ & $(1.521)$ & $(2.878)$ & $(2.883)$ \\
\hline Municipality FE & Yes & Yes & Yes & Yes \\
Time FE & Yes & Yes & Yes & Yes \\
Controls & No & Yes & No & Yes \\
Observations & 245,940 & 228,326 & 228,858 & 228,326 \\
Mean DepVar & 64.836 & 65.006 & 121.936 & 122.265 \\
Sd DepVar & 90.844 & 89.454 & 175.032 & 175.094 \\
\hline
\end{tabular}

Notes: Standard errors are in parentheses and are clustered at the municipality level. ***, **, and * indicate significance at $1 \%, 5 \%$, and $10 \%$ respectively. The outcome is the number of housing building permits delivered in the municipality per year per 10,000 inhabitants. In Columns 1 and 2 (resp. 3 and 4), the outcome is normalized by dividing by the 2010 population (resp. by the number of households in the municipality at year $t$ ). The mean of the dependent variable gives the average of the outcome variable in the treatment group during the pre-reform period (before 2010) and should be used to compare the magnitude of the effect across the two measures. Controls included in Columns 2 and 4 are the number of households in the municipality and the average household's annual taxable income in year $t$. When using the number of households (resp. household's annual taxable income), the sample is restricted to a balanced panel of municipalities for which fiscal data are not missing during the period of analysis, excluding 49 (resp. 87) small municipalities. Household tax declaration data are available up to 2017 so Columns 2, 3, and 4 exclude the year 2018 from the analysis. 
Table A6: Impact on housing: Residents' income

(1)

(2)

(3)

\begin{tabular}{lccc} 
Outcome & \multicolumn{3}{c}{ Number of housing building permits } \\
& All & $\begin{array}{c}\text { Residents' } \\
\text { Below }\end{array}$ & $\begin{array}{c}\text { Above median } \\
\text { Treatment }\end{array}$ \\
& $8.141^{* * *}$ & $4.518 * *$ & $8.114 * * *$ \\
& $(1.517)$ & $(2.173)$ & $(2.024)$ \\
\hline Municipality FE & Yes & Yes & Yes \\
Time FE & Yes & Yes & Yes \\
Observations & 245,940 & 122,850 & 122,850 \\
Mean DepVar & 64.836 & 66.216 & 81.021 \\
Sd DepVar & 90.844 & 87.332 & 102.097 \\
\hline
\end{tabular}

Notes: Standard errors are in parentheses and are clustered at the municipality level. ***, ${ }^{* *}$, and * indicate significance at $1 \%, 5 \%$, and $10 \%$ respectively. The mean of the dependent variable gives the average of the outcome variable in the treatment group during the pre-reform period (before 2010). The outcome is the number of housing building permits delivered in the municipality per year per 10,000 inhabitants (using the 2010 population). Column 2 (resp. 3) includes only municipalities below (resp. above) the median of the per capita residents' annual taxable income in 2010. Data on taxable income in 2010 are missing for the 16 smallest municipalities. 
Table A7: Impact on housing inside urban areas: Residents' income

(1)

(2)

(3)

Outcome Number of housing building permits

All Residents' income median

\begin{tabular}{lccc} 
& & Below & Above \\
\hline Treatment & $10.494 * * *$ & $5.265 *$ & $9.418 * * *$ \\
& $(1.812)$ & $(2.907)$ & $(2.333)$ \\
\hline Municipality FE & Yes & Yes & Yes \\
Time FE & Yes & Yes & Yes \\
Observations & 151,500 & 75,735 & 75,720 \\
Mean DepVar & 63.660 & 70.743 & 80.285 \\
Sd DepVar & 85.197 & 83.777 & 102.510 \\
\hline
\end{tabular}

Notes: The sample includes only municipalities inside an urban area. Standard errors are in parentheses and are clustered at the municipality level. ***, **, and * indicate significance at $1 \%, 5 \%$, and $10 \%$ respectively. The mean of the dependent variable gives the average of the outcome variable in the treatment group during the pre-reform period (before 2010). The outcome is the number of housing building permits delivered in the municipality per year per 10,000 inhabitants (using the 2010 population). Column 2 (resp. 3) includes only municipalities below (resp. above) the median of the per capita residents' annual taxable income in 2010. Data on taxable income in 2010 are missing for the 3 smallest municipalities. 
Table A8: Impact on housing inside urban areas: Housing density

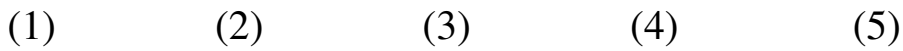

Outcome Number of housing building permits per 10,000 inhabitants

\begin{tabular}{lccccc} 
& All & Rural & Urban & \multicolumn{2}{c}{ Housing density median } \\
\cline { 5 - 6 } & & & & Below & Above \\
\hline Treatment & $10.494 * * *$ & $9.852^{* * *}$ & $15.538 * * *$ & $9.258 * * *$ & $13.895 * * *$ \\
& $(1.812)$ & $(1.967)$ & $(3.755)$ & $(2.230)$ & $(2.759)$ \\
\hline Mun. FE & Yes & Yes & Yes & Yes & Yes \\
Time FE & Yes & Yes & Yes & Yes & Yes \\
Obs. & 151,500 & 105,345 & 46,155 & 75,750 & 75,750 \\
Mean & 63.660 & 62.963 & 65.558 & 64.714 & 62.425 \\
Sd & 85.197 & 82.124 & 93.059 & 85.671 & 84.638 \\
\hline
\end{tabular}

Notes: Standard errors are in parentheses and are clustered at the municipality level. ***, **, and * indicate significance at $1 \%, 5 \%$, and $10 \%$ respectively. The mean of the dependent variable gives the average of the outcome variable in the treatment group during the pre-reform period (before 2010). The outcome is the number of housing building permits delivered in the municipality per year per 10,000 inhabitants (using the 2010 population). The sample includes only municipalities inside an urban area. Columns 2 to 5 add further restrictions: Column 2 (resp. 3) includes only rural (resp. urban) municipalities and Column 4 (resp. 5) includes only municipalities with a housing density in 2010 below (resp. above) the median. 
Table A9: Impact on housing inside urban areas: CA and CU ICs
(1)
(2)
(3)

Outcome Number of housing building permits

\begin{tabular}{lccc} 
& All & Rural & Urban \\
\hline Treatment & $8.853^{* *}$ & 7.831 & $16.928^{* * *}$ \\
& $(4.171)$ & $(5.371)$ & $(6.146)$ \\
\hline Mun. FE & Yes & Yes & Yes \\
Time FE & Yes & Yes & Yes \\
Obs. & 39,180 & 16,260 & 22,920 \\
Mean & 66.201 & 67.800 & 64.264 \\
Sd & 89.274 & 80.366 & 99.046 \\
\hline
\end{tabular}

Notes: Standard errors are in parentheses and are clustered at the municipality level. ***,**, and * indicate significance at $1 \%, 5 \%$, and $10 \%$ respectively. The mean of the dependent variable gives the average of the outcome variable in the treatment group during the pre-reform period (before 2010). The outcome is the number of housing building permits delivered in the municipality per year per 10,000 inhabitants (using the 2010 population). The sample includes only municipalities inside an urban area and that are part of a "CA" or "CU" IC in 2014 (standing for Communauté d'Agglomération and Communauté Urbaine). Column 2 (resp. 3) includes only rural (resp. urban) municipalities.

\section{Table A10: Impact on housing by municipality size}

\begin{tabular}{|c|c|c|c|c|}
\hline \multirow{3}{*}{ Outcome } & (1) & (2) & (3) & (4) \\
\hline & \multicolumn{4}{|c|}{ Number of housing building permits } \\
\hline & All & $<3,500$ & $<1,000$ & $<500$ \\
\hline Treatment & $\begin{array}{c}8.141 * * * \\
(1.517)\end{array}$ & $\begin{array}{c}7.280 * * * \\
(1.531)\end{array}$ & $\begin{array}{c}6.774 * * * \\
(1.687)\end{array}$ & $\begin{array}{c}6.819 * * * \\
(1.964)\end{array}$ \\
\hline Mun. FE & Yes & Yes & Yes & Yes \\
\hline Time FE & Yes & Yes & Yes & Yes \\
\hline Obs. & 245,940 & 223,380 & 174,030 & 123,555 \\
\hline Mean & 64.836 & 64.256 & 62.557 & 61.712 \\
\hline $\mathrm{Sd}$ & 90.844 & 90.398 & 91.500 & 95.589 \\
\hline
\end{tabular}

Notes: Standard errors are in parentheses and are clustered at the municipality level. ***, **, and * indicate significance at $1 \%, 5 \%$, and $10 \%$ respectively. The mean of the dependent variable gives the average of the outcome variable in the treatment group during the pre-reform period (before 2010). The outcome is the number of housing building permits delivered in the municipality per year per 10,000 inhabitants (using the 2010 population). Column 2 (resp. 3, 4) includes only municipalities with less than 3,500 (resp. 1,000, 500) inhabitants in 2010. 
Table A11: Impact on housing: Direct neighbors' characteristics
(1)
(2)
(3)
(4)
(5)
(6)

(7)

\begin{tabular}{|c|c|c|c|c|c|c|c|}
\hline \multirow[t]{3}{*}{ Outcome } & \multicolumn{7}{|c|}{ Number of housing building permits per 10,000 inhabitants } \\
\hline & \multirow[t]{2}{*}{ All } & \multicolumn{2}{|c|}{ Median income ratio } & \multicolumn{2}{|c|}{ Median immigrants ratio } & \multicolumn{2}{|c|}{ Median unemployed ratio } \\
\hline & & Below & Above & Below & Above & Below & Above \\
\hline \multirow[t]{2}{*}{ Treatment } & $8.141 * * *$ & $7.249 * * *$ & $9.348 * * *$ & $6.893 * * *$ & $9.224 * * *$ & $4.362 * *$ & $12.079 * * *$ \\
\hline & $(1.517)$ & $(2.126)$ & $(2.128)$ & (2.118) & $(2.171)$ & $(2.174)$ & $(2.103)$ \\
\hline Municipality FE & Yes & Yes & Yes & Yes & Yes & Yes & Yes \\
\hline Time FE & Yes & Yes & Yes & Yes & Yes & Yes & Yes \\
\hline Observations & 245,940 & 122,850 & 122,850 & 122,970 & 122,970 & 122,970 & 122,970 \\
\hline Mean DepVar & 64.836 & 60.737 & 68.200 & 63.472 & 66.330 & 67.458 & 61.938 \\
\hline Sd DepVar & 90.844 & 84.897 & 94.558 & 87.958 & 93.890 & 95.820 & 84.922 \\
\hline
\end{tabular}

Notes: Standard errors are in parentheses and are clustered at the municipality level. ***, **, and * indicate significance at $1 \%, 5 \%$, and $10 \%$ respectively. The mean of the dependent variable gives the average of the outcome variable in the treatment group during the pre-reform period (before 2010). The outcome is the number of housing building permits delivered in the municipality per year per 10,000 inhabitants (using the 2010 population). For each municipality, the ratio divides the value of the heterogeneity variable in the municipality by the average value for the neighboring municipalities - defined as municipalities sharing a common border-weighted by their population. Column 2 (resp. 3) includes only municipalities below (resp. above) the median value of the ratio using the per capita residents' annual taxable income. Data on taxable income in 2010 are missing for the 16 smallest municipalities. Column 4 (resp. 5) includes only municipalities below (resp. above) the median value of the ratio using the share of immigrants in 2010. Columns 6 and 7 repeat the same exercise using the share of unemployed workers in 2010. 
Table A12: Impact on housing: Neighbors' share of non-European immigrants

(1)

Outcome
(2)

(3)
(4)

\begin{tabular}{|c|c|c|c|c|c|}
\hline & & \\
\hline & \multirow[t]{3}{*}{ All } & \multicolumn{4}{|c|}{ Median non-European immigrants ratio } \\
\hline & & \multicolumn{2}{|c|}{ Département } & \multicolumn{2}{|c|}{ Direct neighbors } \\
\hline & & Below & Above & Below & Above \\
\hline \multirow[t]{2}{*}{ Treatment } & $8.141 * * *$ & $8.359 * * *$ & $8.159 * * *$ & $4.898 * *$ & $11.150 * * *$ \\
\hline & $(1.517)$ & $(1.778)$ & $(2.531)$ & $(2.062)$ & $(2.260)$ \\
\hline Municipality FE & Yes & Yes & Yes & Yes & Yes \\
\hline Time FE & Yes & Yes & Yes & Yes & Yes \\
\hline Observations & 245,940 & 122,970 & 122,970 & 121,440 & 121,425 \\
\hline Mean DepVar & 64.836 & 58.932 & 71.609 & 63.189 & 67.397 \\
\hline Sd DepVar & 90.844 & 84.465 & 97.219 & 88.437 & 92.985 \\
\hline
\end{tabular}

Notes: Standard errors are in parentheses and are clustered at the municipality level. ***, **, and * indicate significance at $1 \%, 5 \%$, and $10 \%$ respectively. The mean of the dependent variable gives the average of the outcome variable in the treatment group during the pre-reform period (before 2010). The outcome is the number of housing building permits delivered in the municipality per year per 10,000 inhabitants (using the 2010 population). For each municipality, the ratio divides the share of non-European immigrants in the municipality by the average share in surrounding municipalities, weighted by their population. Surrounding municipalities are defined either as all the other municipalities from the same département (Columns 2 and 3) or as municipalities sharing a border (Columns 4 and 5). Columns 2 and 4 (resp. 3 and 5) includes only municipalities below (resp. above) the median value of the ratio. The ratio considering direct neighbors (Columns 4 and 5) is missing for 205 municipalities whose neighboring municipalities had zero non-European immigrants. 
Table A13: Impact on housing: Political alignment
(1)
(2)
(3)
(4)
(5)
(6)

(7)

Outcome Number of housing building permits per 10,000 inhabitants

\begin{tabular}{|c|c|c|c|c|c|c|c|}
\hline & \multirow[t]{3}{*}{ All } & \multirow{2}{*}{\multicolumn{2}{|c|}{$\begin{array}{l}\text { Same orientation } \\
\text { as district official }\end{array}$}} & \multicolumn{4}{|c|}{ Vote-share-distance median } \\
\hline & & & & \multicolumn{2}{|c|}{ Département } & \multicolumn{2}{|c|}{ Direct neighbors } \\
\hline & & Yes & No & Below & Above & Below & Above \\
\hline \multirow[t]{2}{*}{ Treatment } & $8.141 * * *$ & $8.699 * * *$ & $7.239 * * *$ & $5.962 * * *$ & $9.951 * * *$ & $7.936 * * *$ & $8.331 * * *$ \\
\hline & $(1.517)$ & $(1.964)$ & $(2.380)$ & $(2.195)$ & $(2.092)$ & $(2.203)$ & $(2.093)$ \\
\hline Mun. FE & Yes & Yes & Yes & Yes & Yes & Yes & Yes \\
\hline Time FE & Yes & Yes & Yes & Yes & Yes & Yes & Yes \\
\hline Obs. & 245,940 & 141,885 & 103,080 & 122,970 & 122,970 & 122,970 & 122,970 \\
\hline Mean & 64.836 & 64.925 & 64.685 & 69.661 & 60.908 & 69.458 & 60.524 \\
\hline $\mathrm{Sd}$ & 90.844 & 91.436 & 89.837 & 94.704 & 87.388 & 94.093 & 87.494 \\
\hline
\end{tabular}

Notes: Standard errors are in parentheses and are clustered at the municipality level. ***, **, and * indicate significance at $1 \%, 5 \%$, and $10 \%$ respectively. The mean of the dependent variable gives the average of the outcome variable in the treatment group during the pre-reform period (before 2010). The outcome is the number of housing building permits delivered in the municipality per year per 10,000 inhabitants (using the 2010 population). Column 2 (resp. 3) includes only municipalities whose mayor had the same orientation (resp. a different orientation) as the member of parliament of their district in 2010. Column 4 (resp. 5) includes only municipalities below (resp. above) the median value of the absolute difference in the rightwing vote share in the 2007 presidential election between the municipality and the other municipalities from the same département. In Columns 6 and 7, surrounding municipalities are defined as direct neighbors. 
Table A14: Impact on housing: Share of homeowners: Urban municipalities

\begin{tabular}{lccc}
\hline \multirow{2}{*}{ Outcome } & $(1)$ & $(2)$ & $(3)$ \\
& Number of housing building permits & All & \multicolumn{2}{c}{ Median \% } & homeowners \\
\cline { 2 - 4 } & & Below & Above \\
\hline Treatment & $13.774 * * *$ & $13.139^{* *}$ & $14.364 * * *$ \\
& $(3.691)$ & $(5.548)$ & $(4.883)$ \\
\hline Municipality FE & Yes & Yes & Yes \\
Time FE & Yes & Yes & Yes \\
Observations & 54,420 & 27,210 & 27,210 \\
Mean DepVar & 69.875 & 74.602 & 65.253 \\
Sd DepVar & 93.921 & 100.447 & 86.876 \\
\hline
\end{tabular}

Notes: Standard errors are in parentheses and are clustered at the municipality level. ***, **, and * indicate significance at $1 \%, 5 \%$, and $10 \%$ respectively. The mean of the dependent variable gives the average of the outcome variable in the treatment group during the pre-reform period (before 2010). The sample includes only urban municipalities. The outcome is the number of housing building permits delivered in the municipality per year per 10,000 inhabitants (using the 2010 population). Column 4 (resp. 5) includes only municipalities below (resp. above) the median value of the share of homeowners in 2010.

Table A15: Impact on the number of daycare facilities

\begin{tabular}{lccc}
\hline \multirow{2}{*}{ Outcome } & $(1)$ & $(2)$ & $(3)$ \\
& Number of daycare facilities \\
& All & Rural & Urban \\
\hline Treatment & -0.032 & -0.046 & 0.036 \\
& $(0.030)$ & $(0.034)$ & $(0.060)$ \\
\hline Municipality FE & Yes & Yes & Yes \\
Time FE & Yes & Yes & Yes \\
Observations & 196,752 & 153,216 & 43,536 \\
Mean DepVar & 0.402 & 0.169 & 1.310 \\
Sd DepVar & 1.453 & 1.267 & 1.749 \\
\hline
\end{tabular}

Notes: Standard errors are in parentheses and are clustered at the municipality level. ***, **, and * indicate significance at $1 \%, 5 \%$, and $10 \%$ respectively. The mean of the dependent variable gives the average of the outcome variable in the treatment group during the pre-reform period (before 2010). The outcome is the number of daycare facilities in the municipality per 10,000 inhabitants (using the 2010 population), and the period of analysis is 2007-2018. Column 2 (resp.3) include only rural (resp. urban) municipalities. 
Table A16: Impact on public services (rural municipalities): Dividing by current population and adding controls

\begin{tabular}{|c|c|c|c|c|c|c|c|c|}
\hline \multirow{3}{*}{ Outcome } & (1) & (2) & (3) & (4) & (5) & (6) & (7) & (8) \\
\hline & \multicolumn{4}{|c|}{ Daycare spots } & \multicolumn{4}{|c|}{ Public Libraries } \\
\hline & \multicolumn{2}{|c|}{2010 population } & \multicolumn{2}{|c|}{ Current population } & \multicolumn{2}{|c|}{2010 population } & \multicolumn{2}{|c|}{ Current populatior } \\
\hline \multirow[t]{2}{*}{ Treatment } & $-1.001 * *$ & $-0.946 * *$ & $-1.854 * *$ & $-1.824 * *$ & $-1.248 * *$ & $-1.180 * *$ & $-2.089 *$ & $-2.107 *$ \\
\hline & $(0.463)$ & $(0.451)$ & $(0.760)$ & $(0.762)$ & $(0.620)$ & $(0.600)$ & $(1.072)$ & $(1.086)$ \\
\hline Mun. FE & Yes & Yes & Yes & Yes & Yes & Yes & Yes & Yes \\
\hline Time FE & Yes & Yes & Yes & Yes & Yes & Yes & Yes & Yes \\
\hline Controls & No & Yes & No & Yes & No & Yes & No & Yes \\
\hline Obs. & 153,216 & 139,502 & 139,909 & 139,502 & 11,020 & 9,819 & 9,864 & 9,819 \\
\hline Mean & 3.617 & 3.673 & 6.991 & 7.025 & 4.374 & 5.342 & 9.657 & 9.775 \\
\hline $\mathrm{Sd}$ & 31.900 & 32.147 & 63.000 & 63.152 & 9.574 & 11.034 & 20.282 & 20.377 \\
\hline
\end{tabular}

Notes: Standard errors are in parentheses and are clustered at the municipality level. ***, **, and * indicate significance at $1 \%, 5 \%$, and $10 \%$ respectively. The sample includes only rural municipalities. In Columns 1 to 3 , the outcome is the number of child daycare spots in the municipality per 10,000 inhabitants (using the 2010 population) and the period of analysis is 2007-2018. In Columns 4 to 6 , the outcome is the number of public libraries in the municipality per 10,000 inhabitants (using the 2010 population), the period of analysis is 2009-2018, and the sample is restricted to the 7 départements for which data are available starting in 2009. In Columns 1, 2, 5, and 6 (resp. 3, 4, 7, and 8) the outcome is normalized by dividing by the 2010 population (resp. by the number of households in the municipality at year $t$ ). The mean of the dependent variable gives the average of the outcome variable in the treatment group during the pre-reform period (before 2010) and should be used to compare the magnitude of the effect across the two measures. Controls included in Columns 2, 4, 6, and 8 are the number of households in the municipality and the average household's annual taxable income in year $t$. When using the number of households (resp. household's annual taxable income), the sample is restricted to a balanced panel of municipalities for which fiscal data are not missing during the period of analysis, excluding 49 (resp. 87) small municipalities. Household tax declaration data are available up to 2017, so all columns except Columns 1 and 5 exclude the year 2018 from the analysis. 
Table A17: Impact on public transport: Adding controls

\begin{tabular}{|c|c|c|}
\hline \multirow{4}{*}{$\begin{array}{l}\text { Outcome } \\
\text { Treatment }\end{array}$} & (1) & (2) \\
\hline & \multicolumn{2}{|c|}{ Public transport } \\
\hline & $0.032 * * *$ & $0.033 * * *$ \\
\hline & $(0.007)$ & $(0.007)$ \\
\hline Municipality FE & Yes & Yes \\
\hline Time FE & Yes & Yes \\
\hline Controls & No & Yes \\
\hline Observations & 221,368 & 220,178 \\
\hline Mean DepVar & 0.024 & 0.024 \\
\hline Sd DepVar & 0.152 & 0.153 \\
\hline
\end{tabular}

Notes: Standard errors are in parentheses and are clustered at the municipality level. ***,**, and * indicate significance at $1 \%, 5 \%$, and $10 \%$ respectively. The mean of the dependent variable gives the average of the outcome variable in the treatment group during the pre-reform period (before 2010). The outcome is an indicator variable equal to 1 if the municipality has access to public transport. The sample excludes municipalities in the Parisian region of Île-de-France, for which the data are not available. Controls included in Column 2 are the number of households in the municipality and the average household's annual taxable income in year $t$. In Column 2, the sample is restricted to a balanced panel of municipalities for which fiscal data are not missing during the period of analysis, excluding 49 (resp. 87) small municipalities. 
Table A18: Impact on tax revenues and state transfers
(1)
(2)
(3)

\begin{tabular}{lccc} 
Outcome & \multicolumn{3}{c}{ Fiscal revenues } \\
& All & Tax & Transfer \\
\hline Treatment & $101.2 * * *$ & $60.8 * * *$ & $39.1 * * *$ \\
& $(4.813)$ & $(4.929)$ & $(2.410)$ \\
\hline Municipality FE & Yes & Yes & Yes \\
Time FE & Yes & Yes & Yes \\
Observations & 244,965 & 244,965 & 244,965 \\
Mean DepVar & 698.6 & 424.4 & 274.2 \\
Sd DepVar & 430.0 & 349.2 & 150.0 \\
\hline
\end{tabular}

Notes: Standard errors are in parentheses and are clustered at the municipality level. ***,**, and * indicate significance at 1\%, 5\%, and 10\% respectively. The mean of the dependent variable gives the average of the outcome variable in the treatment group during the pre-reform period (before 2010). In Column 1, the outcome is the municipality's total fiscal revenues per capita. In Column 2 (resp. 3), the outcome is the municipality's tax revenues (resp. state transfers), per capita. The construction of the outcomes is described in Section 6.2. I exclude from the analysis few municipalities for which the data are missing for at least one year over the period 2004-2018 (0.4 percent of the sample). 
Table A19: Impact on fiscal revenues: Dividing by current population and adding controls

\begin{tabular}{lcccc}
\hline \multirow{4}{*}{ Outcome } & $(1)$ & $(2)$ & $(3)$ & $(4)$ \\
& \multicolumn{4}{c}{ Fiscal revenues per capita } \\
& 2010 population & Current population \\
\hline Treatment & $101.2^{* * * *}$ & $93.8^{* * *}$ & $186.2^{* * *}$ & $180.6^{* * *}$ \\
& $(4.813)$ & $(4.674)$ & $(8.296)$ & $(8.041)$ \\
\hline Municipality FE & Yes & Yes & Yes & Yes \\
Time FE & Yes & Yes & Yes & Yes \\
Controls & No & Yes & No & Yes \\
Observations & 244,965 & 227,416 & 227,948 & 227,416 \\
Mean DepVar & 698.6 & 694.9 & 1,282 & 1,279 \\
Sd DepVar & 430.0 & 423.7 & 731.5 & 721.4 \\
\hline
\end{tabular}

Notes: Standard errors are in parentheses and are clustered at the municipality level. ***, **, and * indicate significance at $1 \%, 5 \%$, and $10 \%$ respectively. The outcome is the municipality's total fiscal revenues per capita, as described in Section 6.2. I exclude from the analysis the few municipalities for which the data are missing for at least one year over the period 2004-2018 (0.4 percent of the sample). In Columns 1 and 2 (resp. 3 and 4) the outcome is normalized by dividing by the 2010 population (resp. by the number of households in the municipality at year $t$ ). The mean of the dependent variable gives the average of the outcome variable in the treatment group during the pre-reform period (before 2010) and should be used to compare the magnitude of the effect across the two measures. Controls included in Columns 2 and 4 are the number of households in the municipality and the average household's annual taxable income in year $t$. When using the number of households (resp. household's annual taxable income), the sample is restricted to a balanced panel of municipalities for which fiscal data are not missing during the period of analysis, excluding 49 (resp. 87) small municipalities. Household tax declaration data are available up to 2018 so Columns 2, 3, and 4 exclude the year 2018 from the analysis. 
Table A20: Impact on public services depending on the integration process: Rural municipalities

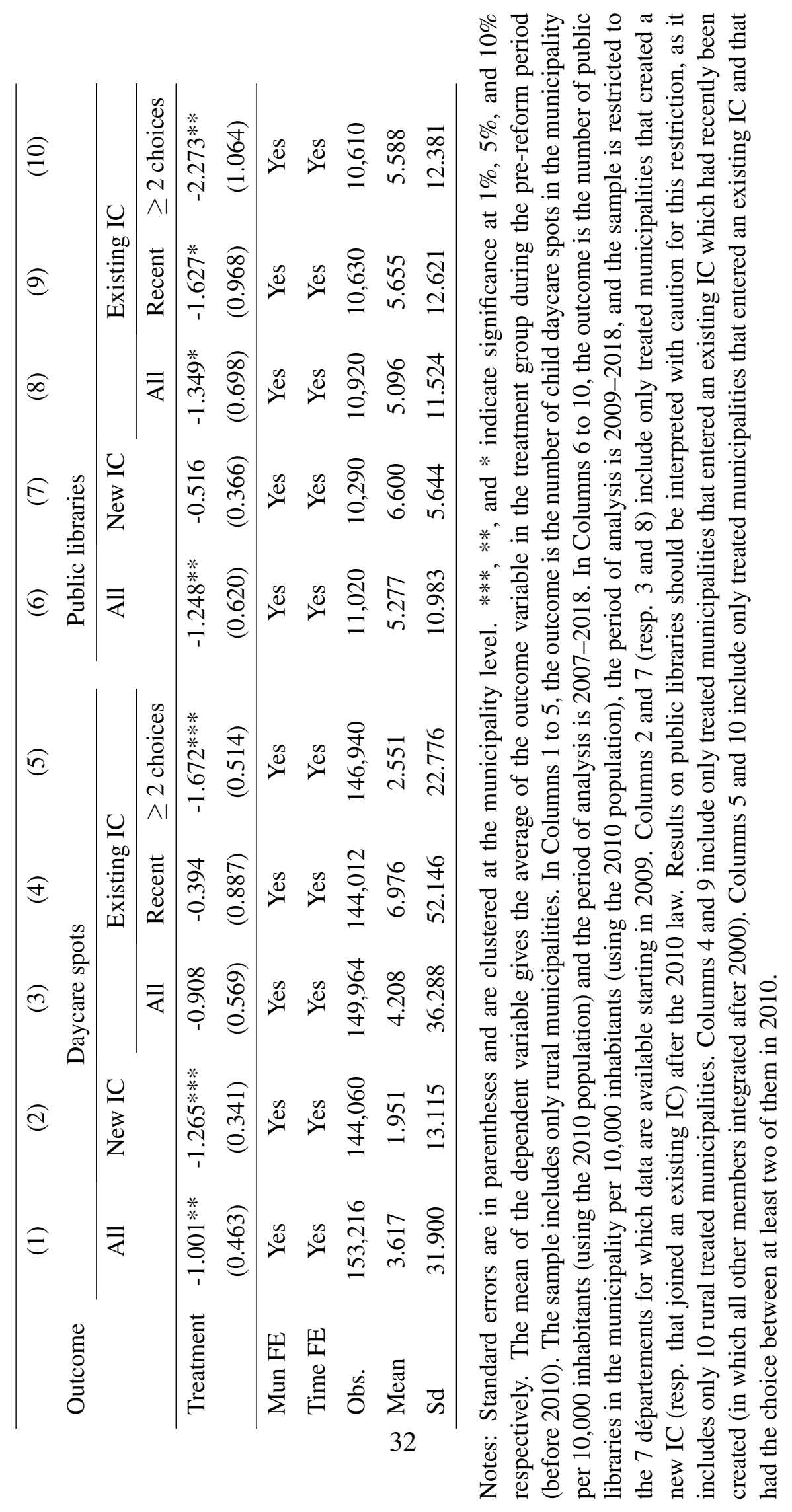


Table A21: Impact on public services depending on whether the IC encompasses big cities: Rural municipalities

\begin{tabular}{|c|c|c|c|c|c|c|}
\hline \multirow{3}{*}{ Outcome } & (1) & (2) & (3) & (4) & (5) & (6) \\
\hline & \multicolumn{3}{|c|}{ Daycare spots } & \multicolumn{3}{|c|}{ Public libraries } \\
\hline & All & No big city & Big city & All & No big city & Big city \\
\hline \multirow{2}{*}{ Treatment } & $-1.001 * *$ & $-1.315^{* * *}$ & -0.637 & $-1.248 * *$ & -1.029 & $-1.474^{*}$ \\
\hline & $(0.463)$ & $(0.394)$ & $(0.934)$ & $(0.620)$ & $(0.831)$ & $(0.890)$ \\
\hline Mun FE & Yes & Yes & Yes & Yes & Yes & Yes \\
\hline Time FE & Yes & Yes & Yes & Yes & Yes & Yes \\
\hline Obs. & 153,216 & 97,884 & 55,308 & 11,020 & 6,850 & 4,170 \\
\hline Mean & 3.617 & 2.200 & 5.502 & 5.277 & 4.857 & 5.615 \\
\hline $\mathrm{Sd}$ & 31.900 & 22.126 & 41.391 & 10.983 & 10.747 & 11.216 \\
\hline
\end{tabular}

Notes: Standard errors are in parentheses and are clustered at the municipality level. ***, **, and * indicate significance at $1 \%, 5 \%$, and $10 \%$ respectively. The mean of the dependent variable gives the average of the outcome variable in the treatment group during the pre-reform period (before 2010). The sample includes only rural municipalities. In Columns 1 to 3 , the outcome is the number of child daycare spots in the municipality per 10,000 inhabitants (using the 2010 population) and the period of analysis is 2007-2018. In Columns 4 to 6, the outcome is the number of public libraries in the municipality per 10,000 inhabitants (using the 2010 population), the period of analysis is 2009-2018, and the sample is restricted to the 7 départements for which data are available starting in 2009. Columns 2 and 5 (resp. 3 and 6) include only municipalities that, in 2014, are part of an IC in which all municipalities are below 5,000 inhabitants (resp. encompassing a municipalities above 5,000 inhabitants). 
Table A22: Impact on housing depending on mayors' incumbency status: Urban areas
(1)
(2)
(3)

\begin{tabular}{lccc} 
Outcome & \multicolumn{3}{c}{ Number of building permits } \\
& All & Incumbent & Not incumbent \\
\hline Treatment & $10.494 * * *$ & $10.883 * * *$ & $10.622 * * *$ \\
& $(1.812)$ & $(2.347)$ & $(2.851)$ \\
\hline Municipality FE & Yes & Yes & Yes \\
Time FE & Yes & Yes & Yes \\
Observations & 151,500 & 93,315 & 55,605 \\
Mean DepVar & 63.660 & 64.866 & 61.206 \\
Sd DepVar & 85.197 & 84.970 & 85.156 \\
\hline
\end{tabular}

Notes: The sample includes only municipalities part of an urban area. Standard errors are in parentheses and are clustered at the municipality level. ***, **, and * indicate significance at $1 \%, 5 \%$, and $10 \%$ respectively. The mean of the dependent variable gives the average of the outcome variable in the treatment group during the pre-reform period (before 2010). The outcome is the number of housing building permits delivered in the municipality per year per 10,000 inhabitants (using the 2010 population). Column 2 (resp. 3) includes only municipalities whose mayor was the incumbent in 2010 and had thus been in place since at least 2001 (resp. was not the incumbent and was thus newly elected in 2008). 
Table A23: Impact on public services depending on mayors' incumbency status: Rural municipalities

\begin{tabular}{|c|c|c|c|c|c|c|}
\hline \multirow{3}{*}{ Outcome } & (1) & (2) & (3) & (4) & (5) & (6) \\
\hline & \multicolumn{3}{|c|}{ Daycare spots } & \multicolumn{3}{|c|}{ Public libraries } \\
\hline & All & Incumbent & Not incumbent & All & Incumbent & Not incumbent \\
\hline \multirow[t]{2}{*}{ Treatment } & $-1.001 * *$ & -0.994 & -0.893 & $-1.248 * *$ & $-1.582 *$ & -0.490 \\
\hline & $(0.463)$ & $(0.650)$ & $(0.603)$ & $(0.620)$ & $(0.898)$ & $(0.417)$ \\
\hline Mun FE & Yes & Yes & Yes & Yes & Yes & Yes \\
\hline Time FE & Yes & Yes & Yes & Yes & Yes & Yes \\
\hline Obs. & 153,216 & 94,536 & 55,800 & 11,020 & 6,750 & 4,060 \\
\hline Mean & 3.617 & 4.183 & 2.713 & 5.277 & 5.381 & 4.147 \\
\hline $\mathrm{Sd}$ & 31.900 & 35.382 & 24.956 & 10.983 & 11.754 & 7.704 \\
\hline
\end{tabular}

Notes: The sample includes only rural municipalities. Standard errors are in parentheses and are clustered at the municipality level. ***,**, and * indicate significance at $1 \%, 5 \%$, and $10 \%$ respectively. The mean of the dependent variable gives the average of the outcome variable in the treatment group during the prereform period (before 2010). In Columns 1 to 3, the outcome is the number of child daycare spots in the municipality per 10,000 inhabitants (using the 2010 population) and the period of analysis is 2007-2018. In Columns 4 to 6, the outcome is the number of public libraries in the municipality per 10,000 inhabitants (using the 2010 population), the period of analysis is 2009-2018, and the sample is restricted to the 7 départements for which data are available starting in 2009. Columns 2 and 5 (resp. 3 and 6) include only municipalities whose mayor was the incumbent in 2010 and had thus been in place since at least 2001 (resp. was not the incumbent and was thus newly elected in 2008). 


\section{B. Additional robustness checks}

In this section, I describe and present additional robustness tests to support the identification strategy. As the negative impact on public services is significant only for rural municipalities, I present the robustness tests on public services for rural municipalities only.

\section{B1. Impact depending on the latest date of integration of the control munici- palities}

For each outcome, I test the robustness of the results to varying the control group depending on the latest date of integration of the control municipalities. In each table below, the first column gives the baseline estimate restricting the control group to municipalities integrated since 1999 . The next columns provide the estimates obtained by considering instead all municipalities integrated since 2002, 2004, 2006, 2008, and 2010, respectively. The last column includes all municipalities already integrated in 2010.

Table B1.1: Housing supply

\begin{tabular}{lcccccc}
\hline & $(1)$ & $(2)$ & $(3)$ & $(4)$ & $(5)$ & $(6)$ \\
Outcome & \multicolumn{5}{c}{ Number of building permits per 10,000 inhabitants } \\
Latest integration & 1999 & 2002 & 2004 & 2006 & 2008 & 2010 \\
\hline Treatment & $8.141^{* * *}$ & $7.865^{* * *}$ & $7.505^{* * *}$ & $7.306^{* * *}$ & $7.318^{* * *}$ & $7.396^{* * *}$ \\
& $(1.517)$ & $(1.496)$ & $(1.490)$ & $(1.489)$ & $(1.488)$ & $(1.487)$ \\
\hline Municipality FE & Yes & Yes & Yes & Yes & Yes & Yes \\
Time FE & Yes & Yes & Yes & Yes & Yes & Yes \\
Observations & 245,940 & 335,685 & 389,325 & 407,010 & 415,815 & 426,495 \\
Mean DepVar & 64.836 & 64.836 & 64.836 & 64.836 & 64.836 & 64.836 \\
Sd DepVar & 90.844 & 90.844 & 90.844 & 90.844 & 90.844 & 90.844 \\
\hline
\end{tabular}

Notes: Standard errors are in parentheses and are clustered at the municipality level. ***, **, and * indicate significance at $1 \%, 5 \%$, and $10 \%$ respectively. The mean of the dependent variable gives the average of the outcome variable in the treatment group during the pre-reform period (before 2010). The outcome is the number of housing building permits delivered in the municipality per year per 10,000 inhabitants (using the 2010 population). Column 1 reproduces the baseline estimate as reported in the paper, using as control group municipalities integrated since 1999. The next columns include in the control group all municipalities integrated since 2002, 2004, 2006, 2008, and 2010, respectively. 
Table B1.2: Daycare: Rural municipalities

(1)

Outcome

\begin{tabular}{lcccccc} 
Latest integration & 1999 & 2002 & 2004 & 2006 & 2008 & 2010 \\
\hline Treatment & $-1.001 * *$ & $-0.969 * *$ & $-1.027 * *$ & $-1.091^{* *}$ & $-1.059^{* *}$ & $-1.019 * *$ \\
& $(0.463)$ & $(0.437)$ & $(0.437)$ & $(0.434)$ & $(0.431)$ & $(0.430)$ \\
\hline Municipality FE & Yes & Yes & Yes & Yes & Yes & Yes \\
Time FE & Yes & Yes & Yes & Yes & Yes & Yes \\
Observations & 153,216 & 210,816 & 245,412 & 256,680 & 262,704 & 270,180 \\
Mean DepVar & 3.617 & 3.617 & 3.617 & 3.617 & 3.617 & 3.617 \\
Sd DepVar & 31.900 & 31.900 & 31.900 & 31.900 & 31.900 & 31.900 \\
\hline
\end{tabular}

Notes: Standard errors are in parentheses and are clustered at the municipality level. ***,**, and * indicate significance at $1 \%, 5 \%$, and $10 \%$ respectively. The mean of the dependent variable gives the average of the outcome variable in the treatment group during the pre-reform period (before 2010). The sample includes only rural municipalities. The outcome is the number of daycare spots in the municipality per 10,000 inhabitants (using the 2010 population) and the period of analysis is 2007-2018. Column 1 reproduces the baseline estimate as reported in the paper, using as a control group municipalities integrated since 1999. The next columns include in the control group all municipalities integrated since 2002, 2004, 2006, 2008, and 2010, respectively. 
Table B1.3: Public libraries: Rural municipalities

(1)

Outcome

\begin{tabular}{lcccccc} 
Latest integration & 1999 & 2002 & 2004 & 2006 & 2008 & 2010 \\
\hline Treatment & $-1.248^{* *}$ & $-1.340^{* *}$ & $-1.475^{* *}$ & $-1.501^{* *}$ & $-1.500^{* *}$ & $-1.483^{* *}$ \\
& $(0.620)$ & $(0.617)$ & $(0.615)$ & $(0.614)$ & $(0.614)$ & $(0.614)$ \\
\hline Municipality FE & Yes & Yes & Yes & Yes & Yes & Yes \\
Time FE & Yes & Yes & Yes & Yes & Yes & Yes \\
Observations & 11,020 & 14,820 & 18,170 & 18,960 & 19,030 & 19,580 \\
Mean DepVar & 5.277 & 5.277 & 5.277 & 5.277 & 5.277 & 5.277 \\
Sd DepVar & 10.983 & 10.983 & 10.983 & 10.983 & 10.983 & 10.983 \\
\hline
\end{tabular}

Notes: Standard errors are in parentheses and are clustered at the municipality level. ***, **, and * indicate significance at $1 \%, 5 \%$, and $10 \%$ respectively. The mean of the dependent variable gives the average of the outcome variable in the treatment group during the pre-reform period (before 2010) The sample includes only rural municipalities. The outcome is the number of public libraries in the municipality per 10,000 inhabitants (using the 2010 population). The period of analysis is 2009-2018 and the sample is restricted to the 7 départements for which data are available starting in 2009. Column 1 reproduces the baseline estimate as reported in the paper, using as a control group municipalities integrated since 1999. The next columns include in the control group all municipalities integrated since 2002, 2004, 2006, 2008, and 2010, respectively. 
Table B1.4: Public transport

(1)

(2)

(3)

(4)

(5)

(6)

Outcome

\begin{tabular}{lcccccc} 
Latest integration & 1999 & 2002 & 2004 & 2006 & 2008 & 2010 \\
\hline Treatment & $0.032 * * *$ & $0.031 * * *$ & $0.031 * * *$ & $0.031 * * *$ & $0.030 * * *$ & $0.030 * * *$ \\
& $(0.007)$ & $(0.007)$ & $(0.007)$ & $(0.007)$ & $(0.007)$ & $(0.007)$ \\
\hline Municipality FE & Yes & Yes & Yes & Yes & Yes & Yes \\
Time FE & Yes & Yes & Yes & Yes & Yes & Yes \\
Observations & 221,368 & 304,178 & 350,938 & 364,994 & 372,918 & 382,088 \\
Mean DepVar & 0.024 & 0.024 & 0.024 & 0.024 & 0.024 & 0.024 \\
Sd DepVar & 0.152 & 0.152 & 0.152 & 0.152 & 0.152 & 0.152 \\
\hline
\end{tabular}

Notes: Standard errors are in parentheses and are clustered at the municipality level. ***,**, and * indicate significance at $1 \%, 5 \%$, and $10 \%$ respectively. The mean of the dependent variable gives the average of the outcome variable in the treatment group during the pre-reform period (before 2010) The outcome is an indicator variable equal to one if the municipality has access to public transport. The sample excludes municipalities in the Parisian region of Île-de-France, for which the data are not available. Column 1 reproduces the baseline estimate as reported in the paper, using as a control group municipalities integrated since 1999. The next columns include in the control group all municipalities integrated since 2002, 2004, 2006, 2008 , and 2010, respectively. 
Table B1.5: Fiscal revenues

\begin{tabular}{lcccccc}
\hline & $(1)$ & $(2)$ & $(3)$ & $(4)$ & $(5)$ & $(6)$ \\
Outcome & & \multicolumn{5}{c}{ Fiscal revenues per capita } \\
Latest integration & 1999 & 2002 & 2004 & 2006 & 2008 & 2010 \\
\hline Treatment & $101.2^{* * *}$ & $102.6^{* * *}$ & $101.0^{* * *}$ & $101.1^{* * *}$ & $100.0^{* * * *}$ & $98.2^{* * * *}$ \\
& $(4.8)$ & $(4.8)$ & $(4.7)$ & $(4.7)$ & $(4.7)$ & $(4.7)$ \\
\hline Municipality FE & Yes & Yes & Yes & Yes & Yes & Yes \\
Time FE & Yes & Yes & Yes & Yes & Yes & Yes \\
Observations & 244,965 & 334,335 & 387,630 & 405,195 & 413,970 & 424,650 \\
Mean DepVar & 698.6 & 698.6 & 698.6 & 698.6 & 698.6 & 698.6 \\
Sd DepVar & 430.0 & 430.0 & 430.0 & 430.0 & 430.0 & 430.0 \\
\hline
\end{tabular}

Notes: Standard errors are in parentheses and are clustered at the municipality level. ***, **, and * indicate significance at $1 \%, 5 \%$, and $10 \%$ respectively. The mean of the dependent variable gives the average of the outcome variable in the treatment group during the pre-reform period (before 2010) The outcome is the municipality's total fiscal revenues per capita, as defined in Section 6.2. I exclude from the analysis the few municipalities for which the data are missing for at least one year over the period 2004-2018 (0.4 percent of the sample). Column 1 reproduces the baseline estimate as reported in the paper, using as a control group municipalities integrated since 1999. The next columns include in the control group all municipalities integrated since 2002, 2004, 2006, 2008, and 2010, respectively. 


\section{B2. Clusters at the IC level}

Table B2.1: Housing supply

\begin{tabular}{|c|c|c|c|}
\hline & (1) & (2) & (3) \\
\hline Outcome & \multicolumn{3}{|c|}{ Number of building permits } \\
\hline Cluster & Municipality & IC 2014 & IC 2018 \\
\hline Treatment & $\begin{array}{c}8.141 * * * \\
(1.517)\end{array}$ & $\begin{array}{c}8.141 * * * \\
(2.250)\end{array}$ & $\begin{array}{c}8.141 * * * \\
(2.344)\end{array}$ \\
\hline Municipality FE & Yes & Yes & Yes \\
\hline Time FE & Yes & Yes & Yes \\
\hline Observations & 245,940 & 245,940 & 245,940 \\
\hline Mean DepVar & 64.836 & 64.836 & 64.836 \\
\hline Sd DepVar & 90.844 & 90.844 & 90.844 \\
\hline
\end{tabular}

Notes: Standard errors are in parentheses. ${ }^{* *}, *^{*}$, and * indicate significance at $1 \%, 5 \%$, and $10 \%$ respectively. In Column 1, standard errors are clustered at the municipality level. In Column 2 (resp. 3), standard errors are clustered at the IC level, considering the IC the municipality belongs to in 2014 (resp. 2018). The mean of the dependent variable gives the average of the outcome variable in the treatment group during the pre-reform period (before 2010). The outcome is the number of housing building permits delivered in the municipality per year per 10,000 inhabitants (using the 2010 population). 
Table B2.2: Local public services: Rural municipalities

\begin{tabular}{|c|c|c|c|c|c|c|}
\hline \multirow{3}{*}{$\begin{array}{l}\text { Outcome } \\
\text { Cluster }\end{array}$} & (1) & (2) & (3) & (4) & (5) & (6) \\
\hline & \multicolumn{3}{|c|}{ Daycare spots } & \multicolumn{3}{|c|}{ Public libraries } \\
\hline & Municipality & IC 2014 & IC 2018 & Municipality & IC 2014 & IC 2018 \\
\hline \multirow[t]{2}{*}{ Treatment } & $-1.001 * *$ & $-1.001 *$ & $-1.001 *$ & $-1.248 * *$ & $-1.248 * *$ & $-1.248 * *$ \\
\hline & $(0.463)$ & $(0.531)$ & $(0.533)$ & $(0.620)$ & $(0.474)$ & $(0.478)$ \\
\hline Mun FE & Yes & Yes & Yes & Yes & Yes & Yes \\
\hline Time FE & Yes & Yes & Yes & Yes & Yes & Yes \\
\hline Obs. & 153,216 & 153,216 & 153,216 & 11,020 & 11,020 & 11,020 \\
\hline Mean & 3.617 & 3.617 & 3.617 & 5.277 & 5.277 & 5.277 \\
\hline $\mathrm{Sd}$ & 31.900 & 31.900 & 31.900 & 10.983 & 10.983 & 10.983 \\
\hline
\end{tabular}

Notes: Standard errors are in parentheses. $*^{* *}, * *$, and $*$ indicate significance at $1 \%, 5 \%$, and $10 \%$ respectively. In Column 1, standard errors are clustered at the municipality level. In Column 2 (resp. 3), standard errors are clustered at the IC level, considering the IC the municipality belongs to in 2014 (resp. 2018). The mean of the dependent variable gives the average of the outcome variable in the treatment group during the pre-reform period (before 2010). In Columns 1 to 3, the outcome is the number of daycare spots in the municipality per 10,000 inhabitants (using the 2010 population) and the period of analysis is 2007-2018. In Columns 4 to 6, the outcome is the number of public libraries in the municipality per 10,000 inhabitants (using the 2010 population), the period of analysis is 2009-2018, and the sample is restricted to the 7 départements for which data are available starting in 2009. 
Table B2.3: Public transport and fiscal revenues

\begin{tabular}{|c|c|c|c|c|c|c|}
\hline \multirow{3}{*}{$\begin{array}{l}\text { Outcome } \\
\text { Cluster }\end{array}$} & (1) & (2) & (3) & (4) & (5) & (6) \\
\hline & \multicolumn{3}{|c|}{ Access to public transport } & \multicolumn{3}{|c|}{ Fiscal revenues per capita } \\
\hline & Municipality & IC 2014 & IC 2018 & Municipality & IC 2014 & IC 2018 \\
\hline \multirow[t]{2}{*}{ Treatment } & $0.032 * * *$ & $0.032 * *$ & $0.032 * * *$ & $101.2 * * *$ & $101.2 * * *$ & $101.2 * * *$ \\
\hline & $(0.007)$ & $(0.013)$ & $(0.012)$ & $(4.813)$ & $(9.073)$ & $(9.027)$ \\
\hline Mun FE & Yes & Yes & Yes & Yes & Yes & Yes \\
\hline Time FE & Yes & Yes & Yes & Yes & Yes & Yes \\
\hline Obs. & 221,368 & 221,368 & 221,368 & 244,965 & 244,965 & 244,965 \\
\hline Mean & 0.024 & 0.024 & 0.024 & 698.6 & 698.6 & 698.6 \\
\hline $\mathrm{Sd}$ & 0.152 & 0.152 & 0.152 & 430.0 & 430.0 & 430.0 \\
\hline
\end{tabular}

Notes: Standard errors are in parentheses. $*^{* *}, * *$, and $*$ indicate significance at $1 \%, 5 \%$, and $10 \%$ respectively. In Column 1, standard errors are clustered at the municipality level. In Column 2 (resp. 3), standard errors are clustered at the IC level, considering the IC the municipality belongs to in 2014 (resp. 2018). The mean of the dependent variable gives the average of the outcome variable in the treatment group during the pre-reform period (before 2010). In Columns 1 to 3, the outcome is an indicator variable equal to 1 if the municipality has access to public transport and the sample excludes municipalities in the Parisian region of Île-de-France, for which the data are not available. In Columns 4 to 6, the outcome is the municipality's total fiscal revenues per capita, as defined in Section 6.2, and I exclude from the analysis the few municipalities for which the data are missing for at least one year over the period 2004-2018 (0.4 percent of the sample). 


\section{B3. Matching}

I test the robustness of the main results to using kernel-based propensity score matching. I use the Stata "diff" package to perform the matching (Villa, 2016) and I match control and treated municipalities based on the socio-demographic characteristics available in the 2008 census, which applies to the year 2010. The variables used are the following: the number of inhabitants; population growth since 1999; population density; whether the municipality is urban; whether it belongs to an urban area; whether it belongs to the core of the urban area; the share of immigrants; the share of unemployed workers; the share of students; the share of the population included in the labor force; the share of the population below 5 years old, between 15 and 64 years old, and above 65 years old; the average number of children per family; the share of the active population being farmers, craftsperson, executives, temporary employed, full-time employed, workers, retired, or others; the share of the population with no diploma, holding a primary school certificate (CEP), holding a secondary education diploma (BEPC), holding a certificate of vocational aptitude (CAP or BEP), holding the baccalaureate, who completed two years after the baccalaureate, or with higher education; and the per capita residents' annual taxable income.

In Tables B3.1 and B3.2, I report the differences between the control and treatment groups along with the t-tests for each variable, with and without using matching, respectively. The next tables provide the estimates. The first column gives the baseline estimate, the second column the estimate obtained using kernel-based propensity score matching, and the third column the estimate using matching on the common support of the propensity score. Given the very small sample for which library data are available, the analysis for public services is restricted to daycare. 
Table B3.1: T-tests without matching

\begin{tabular}{|c|c|c|c|c|}
\hline & Mean treatment & Mean control & Difference (T-C) & $\mathrm{P}$-value \\
\hline population & 1,640 & 1,959 & -319 & $0.048^{* *}$ \\
\hline$\Delta$ population & 0.102 & 0.100 & 0.002 & 0.596 \\
\hline density & 162.0 & 156.3 & 5.8 & 0.709 \\
\hline urban mun & 0.204 & 0.223 & -0.019 & 0.108 \\
\hline urban area & 0.637 & 0.614 & 0.022 & 0.107 \\
\hline core urban area & 0.091 & 0.119 & -0.028 & $0.001 * * *$ \\
\hline immigrants & 0.044 & 0.036 & 0.008 & $0.000^{* * * *}$ \\
\hline unemployed & 0.082 & 0.088 & -0.005 & $0.000^{* * *}$ \\
\hline students & 0.077 & 0.078 & -0.001 & 0.243 \\
\hline labor force & 0.738 & 0.731 & 0.008 & $0.000 * * *$ \\
\hline below 5 y/o & 0.060 & 0.062 & -0.002 & $0.001 * * *$ \\
\hline $15-64$ y/o & 0.639 & 0.633 & 0.006 & $0.000 * * *$ \\
\hline above $65 \mathrm{y} / \mathrm{o}$ & 0.170 & 0.176 & -0.006 & $0.002 * * *$ \\
\hline av. \# children & 0.904 & 0.907 & 0.003 & 0.685 \\
\hline farmers & 0.036 & 0.038 & -0.001 & 0.328 \\
\hline craftsperson & 0.041 & 0.037 & 0.004 & $0.000 * * *$ \\
\hline executives & 0.070 & 0.052 & 0.019 & $0.000 * * *$ \\
\hline part-time employed & 0.133 & 0.125 & 0.008 & $0.000 * * *$ \\
\hline full-time employed & 0.153 & 0.155 & -0.002 & 0.154 \\
\hline workers & 0.152 & 0.169 & -0.017 & $0.000 * * *$ \\
\hline retired & 0.280 & 0.286 & -0.006 & $0.036^{*}$ \\
\hline others & 0.134 & 0.139 & -0.004 & $0.010 * *$ \\
\hline no diploma & 0.172 & 0.185 & -0.013 & $0.000 * * *$ \\
\hline CEP certificate & 0.139 & 0.146 & -0.007 & $0.000 * * *$ \\
\hline BEPC & 0.061 & 0.060 & 0.001 & 0.158 \\
\hline CAP or BEP & 0.271 & 0.279 & -0.007 & $0.000 * * *$ \\
\hline baccalaureate & 0.156 & 0.153 & 0.004 & $0.002 * * *$ \\
\hline $\mathrm{bac}+2$ years & 0.112 & 0.107 & 0.005 & $0.000 * * *$ \\
\hline high education & 0.088 & 0.072 & 0.017 & $0.000 * * *$ \\
\hline residents' income & 14,064 & 12,488 & 1,575 & $0.000^{* * *}$ \\
\hline
\end{tabular}

Notes: Data on the municipal population, age, education, and occupational composition come from the 2008 census, which applies to the year 2010. The variation in the population (line 2) is computed as the variation in the number of inhabitants between the 1999 and 2008 censuses. Indicator variables for whether the municipality is urban, part of an urban area, or located in the urban core are based on the INSEE 2010 classification. $* * *, * *$, and $*$ indicate significance at $1 \%, 5 \%$, and $10 \%$ respectively. 
Table B3.2: T-tests with matching

\begin{tabular}{|c|c|c|c|c|}
\hline & Mean treatment & Mean control & Difference (T-C) & $\mathrm{P}$-value \\
\hline population & 1,640 & 1,579 & 61 & 0.668 \\
\hline$\Delta$ population & 0.102 & 0.104 & -0.002 & 0.731 \\
\hline density & 162.0 & 146.9 & 15.1 & 0.331 \\
\hline urban mun & 0.204 & 0.200 & 0.004 & 0.748 \\
\hline urban area & 0.637 & 0.625 & 0.011 & 0.426 \\
\hline core urban area & 0.091 & 0.092 & -0.001 & 0.913 \\
\hline immigrants & 0.044 & 0.044 & 0.001 & 0.556 \\
\hline unemployed & 0.082 & 0.084 & -0.002 & 0.160 \\
\hline students & 0.077 & 0.077 & 0.001 & 0.388 \\
\hline labor force & 0.738 & 0.737 & 0.002 & 0.356 \\
\hline below 5 y/o & 0.060 & 0.061 & -0.000 & 0.506 \\
\hline $15-64$ y/o & 0.639 & 0.638 & 0.001 & 0.326 \\
\hline above $65 \mathrm{y} / \mathrm{o}$ & 0.170 & 0.172 & -0.002 & 0.315 \\
\hline av. \# children & 0.900 & 0.907 & 0.007 & 0.341 \\
\hline farmers & 0.036 & 0.037 & -0.001 & 0.440 \\
\hline craftsperson & 0.041 & 0.040 & 0.001 & 0.195 \\
\hline executives & 0.070 & 0.064 & 0.006 & $0.001 * * *$ \\
\hline part-time employed & 0.133 & 0.131 & 0.002 & 0.231 \\
\hline full-time employed & 0.153 & 0.154 & -0.001 & 0.559 \\
\hline workers & 0.152 & 0.157 & -0.005 & $0.022 * *$ \\
\hline retired & 0.280 & 0.281 & -0.002 & 0.554 \\
\hline others & 0.134 & 0.135 & -0.001 & 0.686 \\
\hline no diploma & 0.172 & 0.177 & -0.004 & $0.041 * *$ \\
\hline CEP certificate & 0.139 & 0.141 & -0.002 & 0.176 \\
\hline BEPC & 0.061 & 0.060 & 0.000 & 0.680 \\
\hline CAP or BEP & 0.271 & 0.275 & -0.003 & $0.070^{*}$ \\
\hline baccalaureate & 0.156 & 0.155 & 0.001 & 0.367 \\
\hline $\mathrm{bac}+2$ years & 0.112 & 0.110 & 0.002 & $0.088^{*}$ \\
\hline high education & 0.088 & 0.082 & 0.006 & $0.004 * * *$ \\
\hline residents' income & 14,064 & 13,669 & 395 & $0.012^{* * *}$ \\
\hline
\end{tabular}

Notes: Data on the municipal population, age, education, and occupational composition come from the 2008 census, which applies to the year 2010. The variation in the population (line 2) is computed as the variation in the number of inhabitants between the 1999 and 2008 censuses. Indicator variables for whether the municipality is urban, part of an urban area, or located in the urban core are based on the INSEE 2010 classification. $* * *, * *$, and $*$ indicate significance at $1 \%, 5 \%$, and $10 \%$ respectively. 
Table B3.3: Housing

\begin{tabular}{|c|c|c|c|}
\hline & (1) & (2) & (3) \\
\hline Outcome & \multicolumn{3}{|c|}{ Number of building permits } \\
\hline Matching & No & Yes & Common support \\
\hline Treatment & $\begin{array}{c}8.141 * * * \\
(1.517)\end{array}$ & $\begin{array}{c}7.152 * * * \\
(1.634)\end{array}$ & $\begin{array}{c}7.269 * * * \\
(1.624)\end{array}$ \\
\hline Municipality FE & Yes & Yes & Yes \\
\hline Time FE & Yes & Yes & Yes \\
\hline Observations & 245,940 & 245,730 & 245,520 \\
\hline Mean DepVar & 64.836 & 64.836 & 64.836 \\
\hline Sd DepVar & 90.844 & 90.844 & 90.844 \\
\hline
\end{tabular}

Notes: Standard errors are in parentheses and are clustered at the municipality level. ***,**, and * indicate significance at $1 \%, 5 \%$, and $10 \%$ respectively. The mean of the dependent variable gives the average of the outcome variable in the full treatment group during the pre-reform period (before 2010). The outcome is the number of housing building permits delivered in the municipality per year per 10,000 inhabitants (using the 2010 population). In Column 2, the analysis used propensity score matching. Column 3 repeats the same exercise on the common support of the propensity score.

\section{Table B3.4: Daycare: Rural municipalities}

\begin{tabular}{lccc}
\hline & $(1)$ & $(2)$ & $(3)$ \\
Outcome & \multicolumn{3}{c}{ Daycare spots } \\
\cline { 2 - 4 } Matching & No & Yes & Common support \\
\hline Treatment & $-1.001^{* *}$ & -0.776 & -0.776 \\
& $(0.463)$ & $(0.490)$ & $(0.491)$ \\
\hline Mun FE & Yes & Yes & Yes \\
Time FE & Yes & Yes & Yes \\
Obs. & 153,216 & 153,036 & 152,784 \\
Mean & 3.617 & 3.617 & 3.617 \\
Sd & 31.900 & 31.900 & 31.900
\end{tabular}

Notes: Standard errors are in parentheses and are clustered at the municipality level. ***, **, and * indicate significance at $1 \%, 5 \%$, and $10 \%$ respectively. The mean of the dependent variable gives the average of the outcome variable in the full treatment group during the pre-reform period (before 2010). The sample includes only rural municipalities. The outcome is the number of daycare spots in the municipality per 10,000 inhabitants (using the 2010 population) and the period of analysis is 2007-2018. In Column 2, the analysis uses propensity score matching. Column 3 repeats the same exercise on the common support of the propensity score. 
Table B3.5: Public transport and fiscal revenues

(1) (2) (3)

(4)

(5)

(6)

\begin{tabular}{|c|c|c|c|c|c|c|}
\hline \multirow{2}{*}{$\begin{array}{l}\text { Outcome } \\
\text { Matching }\end{array}$} & \multicolumn{3}{|c|}{ Access to public transport } & \multicolumn{3}{|c|}{ Fiscal revenues per capita } \\
\hline & No & Yes & + common support & No & Yes & + common support \\
\hline Treatment & $0.032 * * *$ & $0.032 * * *$ & $0.032 * * *$ & $101.2 * * *$ & $94.85 * * *$ & $94.81 * * *$ \\
\hline & $(0.007)$ & $(0.007)$ & $(0.007)$ & $(4.813)$ & $(5.114)$ & $(5.119)$ \\
\hline Mun FE & Yes & Yes & Yes & Yes & Yes & Yes \\
\hline Time FE & Yes & Yes & Yes & Yes & Yes & Yes \\
\hline Obs. & 221,368 & 221,088 & 220,612 & 244,965 & 244,755 & 244,530 \\
\hline Mean & 0.024 & 0.024 & 0.024 & 698.6 & 698.6 & 698.6 \\
\hline $\mathrm{Sd}$ & 0.152 & 0.152 & 0.152 & 430.0 & 430.0 & 430.0 \\
\hline
\end{tabular}

Notes: Standard errors are in parentheses and are clustered at the municipality level. ***,**, and * indicate significance at $1 \%, 5 \%$, and $10 \%$ respectively. The mean of the dependent variable gives the average of the outcome variable in the full treatment group during the pre-reform period (before 2010). In Columns 1 to 3 , the outcome is an indicator variable equal to 1 if the municipality has access to public transport and the sample excludes municipalities in the Parisian region of Île-de-France, for which the data are not available. In Columns 4 to 6, the outcome is the municipality's total fiscal revenues per capita, as defined in Section 6.2 , and I exclude from the analysis the few municipalities for which the data are missing for at least one year over the period 2004-2018 (0.4 percent of the sample). In Column 2, the analysis uses propensity score matching. Column 3 repeats the same exercise on the common support of the propensity score. 


\section{B4. Placebo tests}

In this section, I test the impact of a series a placebo reforms. I consider only the pre-treatment period from 2004 to 2010 and I run the same specification as the one described in Section 3.3, pretending that the law passed in 2005, 2006, 2007, 2008, or 2009. The graph below provides the estimates obtained for each placebo reform, along with the impact of the true reform (first coefficient on each graph). Unfortunately, I cannot run these placebo tests on daycare and public libraries, given the few pre-treatment periods I have in the data. This analysis is thus restricted to the number of building permits, access to public transport, and fiscal revenues.

As seen Figure B4, no coefficient associated with placebo reforms is significant at the standard level for the number of building permits. For public transport and fiscal revenues, consistent with the presence of decreasing pre-trends (see Section 6), the placebo estimates are significant but negative, which contrasts with the positive effect of the true reform. All in all, these results support the fact that the main results are capturing the impact of the 2010 law rather than the impact of factors that systematically affect treated and control municipalities differently. 
Table B4: Placebo tests
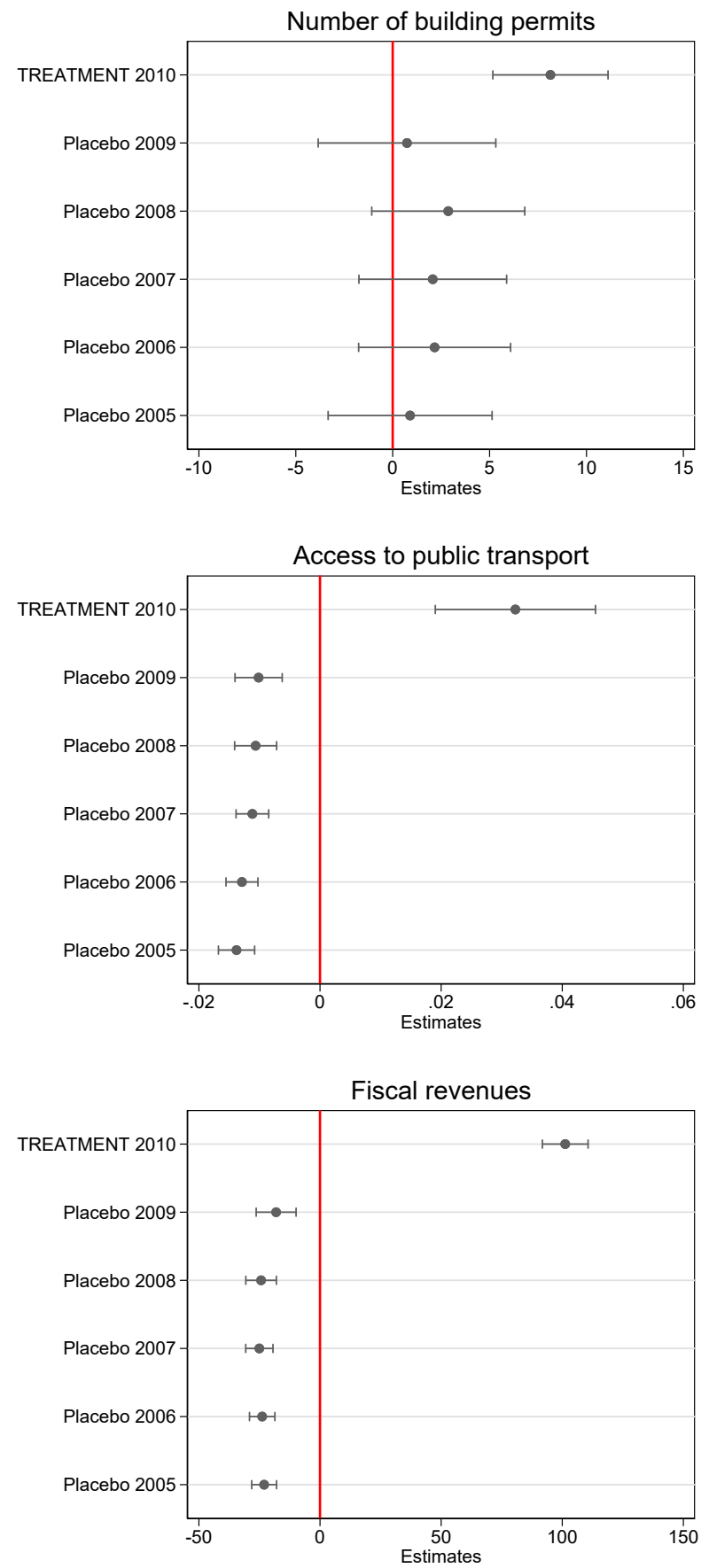

Notes: The figure shows the impact of a series of placebo reforms on the number of building permits, the probability of access to public transport, and fiscal revenues. In each graph, the first coefficient refers to the impact of the 2010 law, while the other estimates give the impact of a placebo reform implemented in 2005, 2006, 2007, 2008, and 2009, respectively. When estimating the impact of the placebo reforms, I include only the pre-treatment period from 2004 to 2010. Horizontal lines are 95-percent-confidence intervals. 


\section{B5. Alternative control groups}

Table B5.1: Housing supply

\begin{tabular}{lccccc}
\hline & $(1)$ & $(2)$ & $(3)$ & $(4)$ & $(5)$ \\
Outcome & \multicolumn{2}{c}{ Number of building permits per 10,000 inhabitants } \\
Control group & Group 1 & Group 2 & Group 3 & Group 4 & Group 5 \\
\hline Treatment & $8.141^{* * *}$ & $8.547 * * *$ & $11.249 * * *$ & $8.511 * * *$ & $11.557 * * *$ \\
& $(1.517)$ & $(1.537)$ & $(1.637)$ & $(1.524)$ & $(1.638)$ \\
\hline Municipality FE & Yes & Yes & Yes & Yes & Yes \\
Time FE & Yes & Yes & Yes & Yes & Yes \\
Observations & 245,940 & 190,410 & 75,825 & 224,310 & 74,040 \\
Mean DepVar & 64.836 & 64.836 & 64.836 & 64.836 & 64.836 \\
Sd DepVar & 90.844 & 90.844 & 90.844 & 90.844 & 90.844 \\
\hline
\end{tabular}

Notes: Standard errors are in parentheses and are clustered at the municipality level. ***, **, and * indicate significance at $1 \%, 5 \%$, and $10 \%$ respectively. The mean of the dependent variable gives the average of the outcome variable in the treatment group during the pre-reform period (before 2010). The outcome is the number of housing building permits delivered in the municipality per year per 10,000 inhabitants (using the 2010 population). In Column 1, the control group is the one used in the baseline estimation, including all municipalities integrated since 1999 (Group 1). In Column 2, I exclude from the control group all municipalities that were part of an IC that received a treated municipality as a result of the 2010 law (Group 2). In Column 3, I exclude more generally all control municipalities whose IC had changed since 1999 and until 2014, as a result of the 2010 law (Group 3). In Column 4, I exclude control municipalities that share a border with a treated municipality (Group 4). In Column 5, I exclude both control municipalities whose ICs changed and neighbors (Group 5). 
Table B5.2: Local public services: Rural municipalities

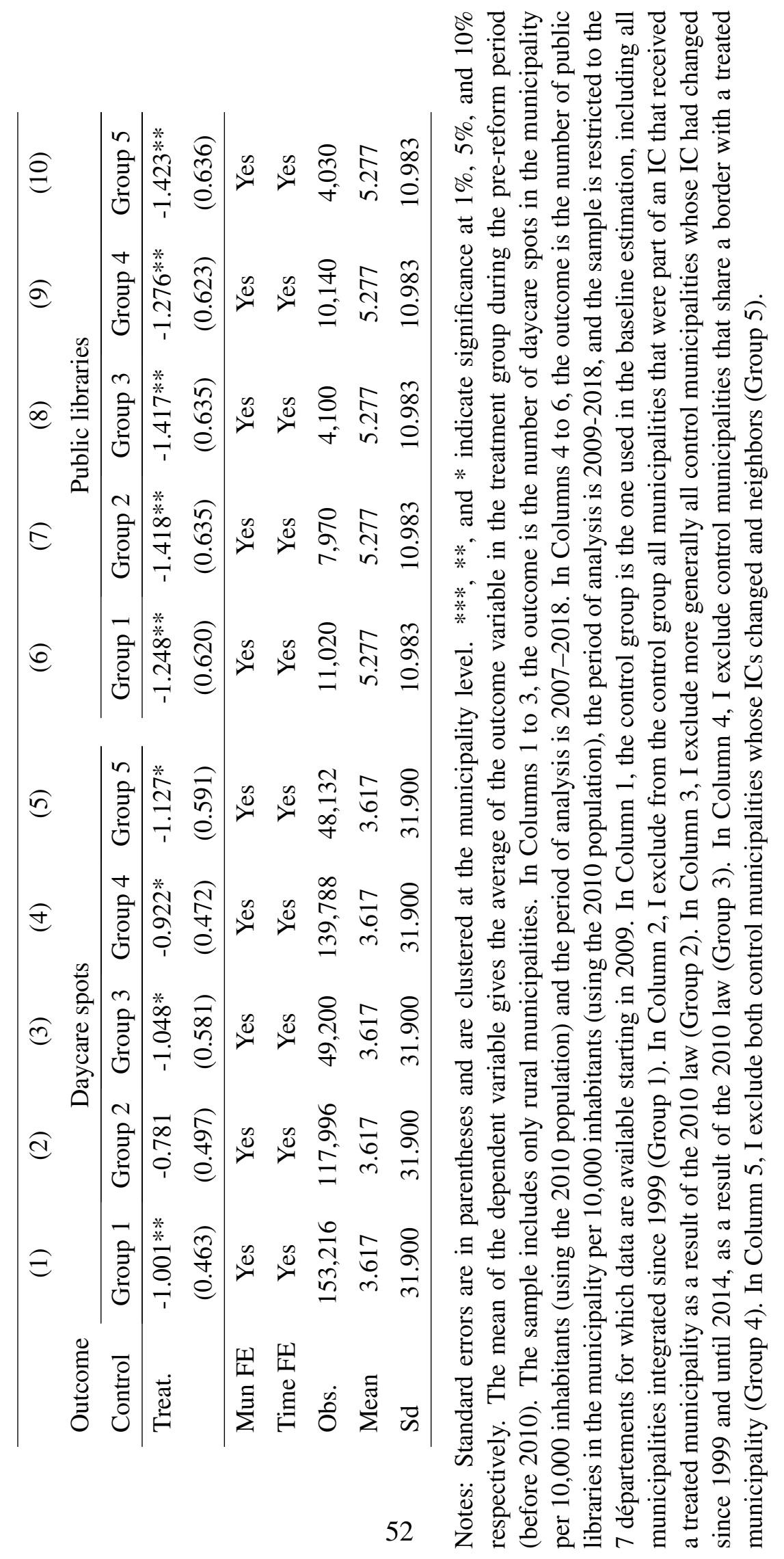


Table B5.3: Public transport and fiscal revenues

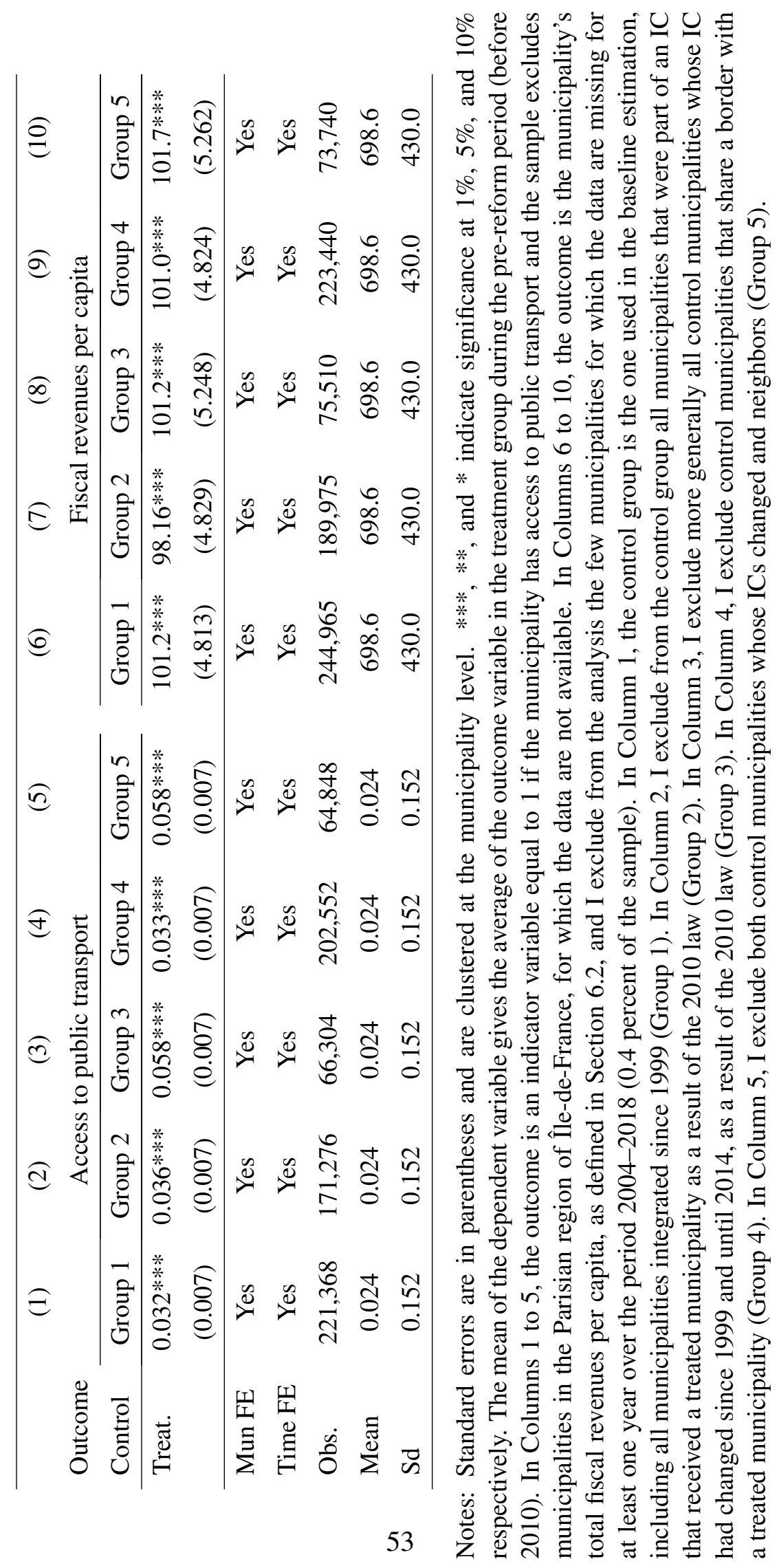




\section{Housing supply: Heterogeneity analysis}

In the main text, I report the impact on housing supply obtained by splitting the full sample according to the median value of the heterogeneity variable I consider. In this section, I explore the heterogeneity of the treatment impact by estimating the following equation:

$Y_{m t}=\alpha+\beta 1_{\{t>2010\}} 1_{\left\{\text {treated }_{m}=1\right\}}+\gamma Z_{m} 1_{\left\{\text {treated }_{m}=1\right\}}+\eta Z_{m} 1_{\{t>2010\}}+\psi Z_{m} 1_{\{t>2010\}} 1_{\left\{\text {treated }_{m}=1\right\}}+\delta_{t}+\theta_{m}+\varepsilon_{m t}$

where $m$ stands for the municipality and $t$ for the year. $1_{\{t>2010\}}$ is an indicator variable equal to 1 for years after the reform, starting in 2011. $1_{\left.\text {treated }_{m}=1\right\}}$ is an indicator variable equal to 1 for municipalities that were isolated in 2010 and thus forced to join an IC (treatment group), and 0 for municipalities already integrated since 1999 (control group). $\delta_{t}$ and $\theta_{m}$ are time and municipality fixed effects, respectively. $Z_{m}$ is the heterogeneity variable measured in 2010. I standardize each heterogeneity variable, subtracting its mean in the treatment group and dividing it by its standard error. As a result, in the tables below, the impact of the treatment $\beta$ can be interpreted as the impact for a treated municipality with an average value of $Z_{m}$ and $\psi$ can be interpreted as the change in the treatment effect due to a one-standard-deviation increase in $Z_{m}$. 
Table C1: Distance to the core of the urban area

\begin{tabular}{lcc}
\hline \multirow{2}{*}{ Outcome } & $\begin{array}{c}(1) \\
\text { Heterogeneity }\end{array}$ & \multicolumn{2}{c}{$\begin{array}{c}\text { Distance to urban core } \\
\text { Ratio }\end{array}$} & Log ratio \\
& $9.473^{* * *}$ & $10.434^{* * *}$ \\
Treatment & $(1.913)$ & $(1.918)$ \\
& $-3.635^{*}$ & $-6.663^{* * *}$ \\
Interaction & $(1.906)$ & $(2.011)$ \\
& Yes & Yes \\
\hline Municipality FE & Yes & Yes \\
Time FE & 121,560 & 121,350 \\
Observations & 63.195 & 63.195 \\
Mean DepVar & 85.954 & 85.954 \\
Sd DepVar & &
\end{tabular}

Notes: Standard errors are in parentheses and are clustered at the municipality level. ***, **, and * indicate significance at $1 \%, 5 \%$, and $10 \%$ respectively. The mean of the dependent variable gives the average of the outcome variable in the treatment group during the pre-reform period (before 2010). The outcome is the number of housing building permits delivered in the municipality per year per 10,000 inhabitants (using the 2010 population). The sample includes only municipalities that are part of one urban area. It excludes municipalities outside of any urban areas or that are part of several urban areas, such that we cannot identify the core to which they are linked. The heterogeneity variable is the ratio between the municipality's Euclidean distance to the core divided by the average distance to the core of the other municipalities from the same urban area. The coordinates of the core are computed as the average coordinates of the different municipalities composing the core, weighted by their population. In Column 2, I consider the log of the ratio, thus excluding 14 municipalities in the control group that constitute the core of their urban area and for which the distance is thus 0 . 
Table C2: Residents' income

(1)

\begin{tabular}{lc}
$\begin{array}{l}\text { Outcome } \\
\text { Heterogeneity }\end{array}$ & $\begin{array}{c}\text { Number of housing building permits } \\
\text { Residents' income }\end{array}$ \\
\hline Treatment & $5.407^{* * *}$ \\
& $(1.560)$ \\
Interaction & $3.734^{* *}$ \\
& $(1.856)$ \\
\hline Municipality FE & Yes \\
Time FE & Yes \\
Observations & 245,700 \\
Mean DepVar & 64.780 \\
Sd DepVar & 90.330 \\
\hline
\end{tabular}

Notes: Standard errors are in parentheses and are clustered at the municipality level. ***, **, and * indicate significance at $1 \%, 5 \%$, and $10 \%$ respectively. The mean of the dependent variable gives the average of the outcome variable in the treatment group during the pre-reform period (before 2010). The outcome is the number of housing building permits delivered in the municipality per year per 10,000 inhabitants (using the 2010 population). The heterogeneity variable is the per capita residents' annual taxable income in 2010. Data on taxable income in 2010 are missing for the 16 municipalities with the smallest populations. 


\section{Table C3: Housing density}

For this heterogeneity test, in the second column, I also include the interaction between the treatment variable and the square value of the housing density. Indeed, even if we expect the impact on housing to be larger in denser municipalities, we might not expect the densest places to experience the largest increase, as they may be too dense for their housing supply to increase as much as elsewhere. As a result, the effect is likely to rise non monotonically with the housing density. The results confirm this hypothesis: while in the first column the interaction is close to zero and not significant, in the second column it is large and significant and the estimate associated to the interaction with the square value is negative and significant.

\begin{tabular}{lcc}
\hline & $(1)$ & $(2)$ \\
Outcome & Number of housing building permits \\
Heterogeneity & \multicolumn{2}{c}{ Housing density } \\
\hline Treatment & $10.395^{* * *}$ & $12.126^{* * *}$ \\
& $(1.787)$ & $(1.838)$ \\
Interaction & -0.220 & $9.966^{* * *}$ \\
& $(1.896)$ & $(3.636)$ \\
Interaction ${ }^{2}$ & & $-1.435^{* * *}$ \\
& & $(0.463)$ \\
\hline Municipality FE & Yes & Yes \\
Time FE & Yes & Yes \\
Observations & 151,500 & 151,500 \\
Mean DepVar & 63.660 & 63.660 \\
Sd DepVar & 85.197 & 85.197 \\
\hline
\end{tabular}

Notes: Standard errors are in parentheses and are clustered at the municipality level. ***,**, and * indicate significance at $1 \%, 5 \%$, and $10 \%$ respectively. The mean of the dependent variable gives the average of the outcome variable in the treatment group during the pre-reform period (before 2010). The outcome is the number of housing building permits delivered in the municipality per year per 10,000 inhabitants (using the 2010 population). The heterogeneity variable is the number of housing units per square kilometer in 2010. In Column 2, I also include the interaction between the treatment variable and the square of the housing density. 
Table C4: Neighbors' characteristics: Département

(1)

Outcome

Heterogeneity

Treatment

Interaction

$(1.590)$

(2)

(3)

(4)

(5)

Number of housing building permits

\begin{tabular}{lccccc} 
& $(1.590)$ & $(2.210)$ & $(1.713)$ & $(1.666)$ & $(1.889)$ \\
\hline Mun. FE & Yes & Yes & Yes & Yes & Yes \\
Time FE & Yes & Yes & Yes & Yes & Yes \\
Obs. & 245,700 & 245,940 & 245,940 & 245,940 & 245,940 \\
Mean & 64.780 & 64.836 & 64.836 & 64.836 & 64.836 \\
Sd & 90.330 & 90.844 & 90.844 & 90.844 & 90.844 \\
\hline
\end{tabular}

Notes: Standard errors are in parentheses and are clustered at the municipality level. ***, **, and * indicate significance at $1 \%, 5 \%$, and $10 \%$ respectively. The mean of the dependent variable gives the average of the outcome variable in the treatment group during the pre-reform period (before 2010). The outcome is the number of housing building permits delivered in the municipality per year per 10,000 inhabitants (using the 2010 population). Each ratio (Columns 1 to 3) divides the value of the heterogeneity variable in the municipality by the average value in the other municipalities from the same département, weighted by their population. In Column 1, the heterogeneity variable used to compute the ratio is the residents' average annual taxable income. Data on taxable income in 2010 are missing for the 16 smallest municipalities. In Column 2 (resp. 3, 4), the heterogeneity variable is the share of all immigrants (resp. non-European immigrants, unemployed workers) in 2010. In Column 5, the heterogeneity variable is the absolute difference in the right-wing vote share in the 2007 presidential election, between the municipality and the other municipalities in the same département. 
Table C5: Neighbors' characteristics: Direct neighbors

(1)

Outcome

Heterogeneity

Treatment

Interaction

(1.646)

Mun. FE
Time FE

Yes

Obs.

Yes

Mean

245,700

64.780

90.330
(3)

(4)

(5)

Number of housing building permits

$\begin{array}{lll}\mathrm{Sd} & 90.330 & 90.844\end{array}$

1.296 (1.705)

$(1.502)$

(1.527)

0.551

(1.518)

$7.991 * * *$

$3.025 *$

(1.590)

$(1.523)$

(2.030)

Yes

Yes
Yes

Yes

Yes

Yes

242,865

Yes

245,940

65.219

245,940

64.836

Notes: Standard errors are in parentheses and are clustered at the municipality level. ***,**, and * indicate significance at $1 \%, 5 \%$, and $10 \%$ respectively. The mean of the dependent variable gives the average of the outcome variable in the treatment group during the pre-reform period (before 2010). The outcome is the number of housing building permits delivered in the municipality per year per 10,000 inhabitants (using the 2010 population). Each ratio (Columns 1 to 3) divides the value of the heterogeneity variable in the municipality by the average value in neighboring municipalities (defined as sharing a border), weighted by their population. In Column 1, the heterogeneity variable used to compute the ratio is the residents' average annual taxable income. Data on taxable income in 2010 are missing for the 16 smallest municipalities. In Column 2 (resp. 3,4), the heterogeneity variable is the share of all immigrants (resp. non-European immigrants, unemployed workers) in 2010. In Column 5, the heterogeneity variable is the absolute difference in the right-wing vote share in the 2007 presidential election, between the municipality and the other municipalities in the same département. The ratio considering the share of non-European immigrants (Column 3) is missing for 205 municipalities for which neighboring municipalities had zero non-European immigrants. 
Table C6: Share of homeowners

(1)

\begin{tabular}{lc}
$\begin{array}{l}\text { Outcome } \\
\text { Heterogeneity }\end{array}$ & $\begin{array}{c}\text { Number of housing building permits } \\
\text { Share of homeowners }\end{array}$ \\
\hline Treatment & $8.789 * * *$ \\
& $(1.509)$ \\
Interaction & -1.462 \\
& $(1.672)$ \\
\hline Municipality FE & Yes \\
Time FE & Yes \\
Observations & 245,940 \\
Mean DepVar & 64.836 \\
Sd DepVar & 90.844 \\
\hline
\end{tabular}

Notes: Standard errors are in parentheses and are clustered at the municipality level. ***, **, and * indicate significance at $1 \%, 5 \%$, and $10 \%$ respectively. The mean of the dependent variable gives the average of the outcome variable in the treatment group during the pre-reform period (before 2010). The outcome is the number of housing building permits delivered in the municipality per year per 10,000 inhabitants (using the 2010 population). The heterogeneity variable is the share of homeowners in the municipality in 2010. 


\section{Housing price indices}

\section{Description of the method}

Following Combes et al. (2018), I built the housing price indices using official transaction records. These data come from an annual census conducted by the regional notary associations, which report the transactions of non-new dwellings. Although reporting is voluntary, it covers about 65 percent of all transactions. I built the indices separately for the Parisian region of Île-de-France and for the rest of France, as the two databases come from two distinct notary associations and do not use the same definitions for the dwellings' characteristics. The data are made available by the Ministry of Sustainable Development for every even year since 2000. They are available until 2014 for Île-de-France and 2016 for the rest of France.

I first run hedonic regressions, separately for houses and apartments. Following Gouriéroux and Laferrère (2009)'s and Musiedlak and Vignolles (2016)'s guidelines, I excluded some outliers from the transaction databases. Next, I regressed the $\log$ of the price per square meter of the dwelling on several characteristics. To build the baseline index, I regressed the log of the price per square meter on indicator variables for the quarter of the transaction and the construction period (Combes et al., 2018). I built a second index (which I refer to as the "augmented index") using additional characteristics. For houses, I added the floorspace, the size of the land, the number of rooms, bathrooms and floors; and whether the house has parking. For apartments, I added the floorspace, the floor on which it is located, the number of rooms and bathrooms, whether the building has an elevator, and whether the apartment has parking and a cellar.

While the price of the transaction is never missing, the floorspace is missing for 10 percent of the apartments and 36 percent of the houses. To compute the price per square meter, I replaced the missing floorspace by the average floorspace of an apartment or a house with the same number of rooms in the same département. Results are unchanged if I instead drop the transactions for which the floorspace is missing. Regarding the right-hand variables (the dwelling's characteristics), I replaced the missing values by the average of that variable and added an indicator variable equal to 1 if the variable was missing. I also centered all explanatory variables by subtracting the means and dividing by the standard errors.

After running the hedonic regressions, I computed the mean of the residuals over both houses and apartments for each year and municipality separately, after having added the regression constant. Since the explanatory variables are centered, we can interpret the resulting indices as the price per square meter of a reference dwelling. 
Figure D1: Impact on prices: Unbalanced panel
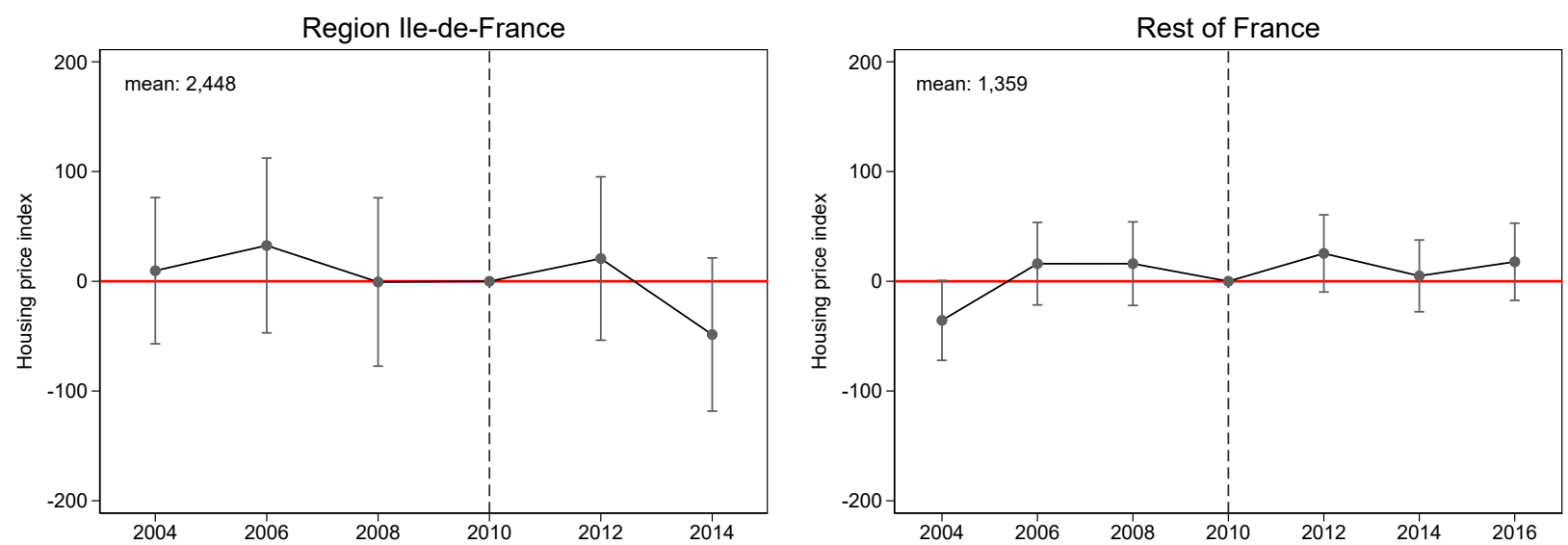

Notes: These graphs plot the estimates and 95-percent-confidence intervals from the leads-and-lags regression. The outcome is the municipality housing price index giving the price per square meter of a reference dwelling. The sample includes all municipalities in which at least one housing transaction took place during the period studied. The graph on the left-hand side includes only municipalities in the Parisian region of Île-de-France, while the graph on the right-hand side includes all the other municipalities. On each graph, the average value of the price index in the treatment group before 2010 is displayed on the top left corner.

\section{Figure D2: Impact on prices: Augmented index}
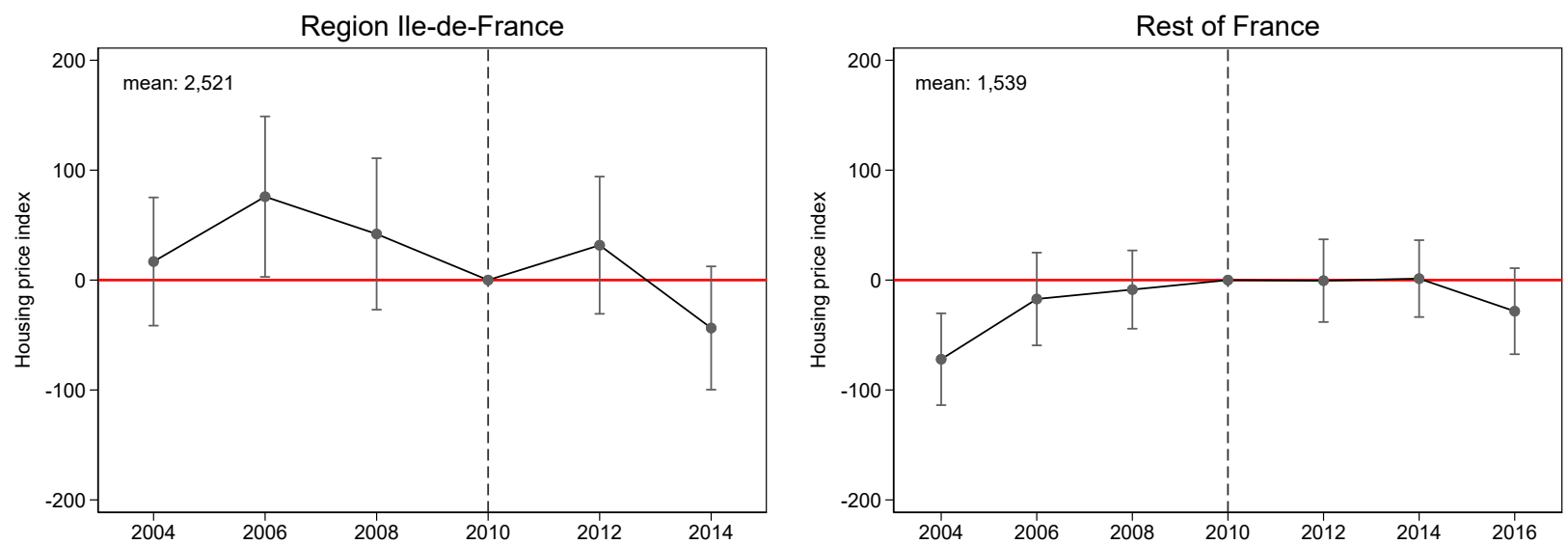

Notes: These graphs plot the estimates and 95-percent-confidence intervals from the leads-and-lags regression. The outcome is the municipality housing price index giving the price per square meter of a reference dwelling. For these graphs, I use an alternative version of the indices for which I include additional apartment and house characteristics in the hedonic regressions. The sample includes only municipalities in which at least one housing transaction took place each even year over the period studied. The graph on the left-hand side includes only municipalities in the Parisian region of Île-de-France, while the graph on the right-hand side includes all the other municipalities. On each graph, the average value of the price index in the treatment group before 2010 is displayed on the top left corner. 
Figure D3: Impact on prices: Urban area
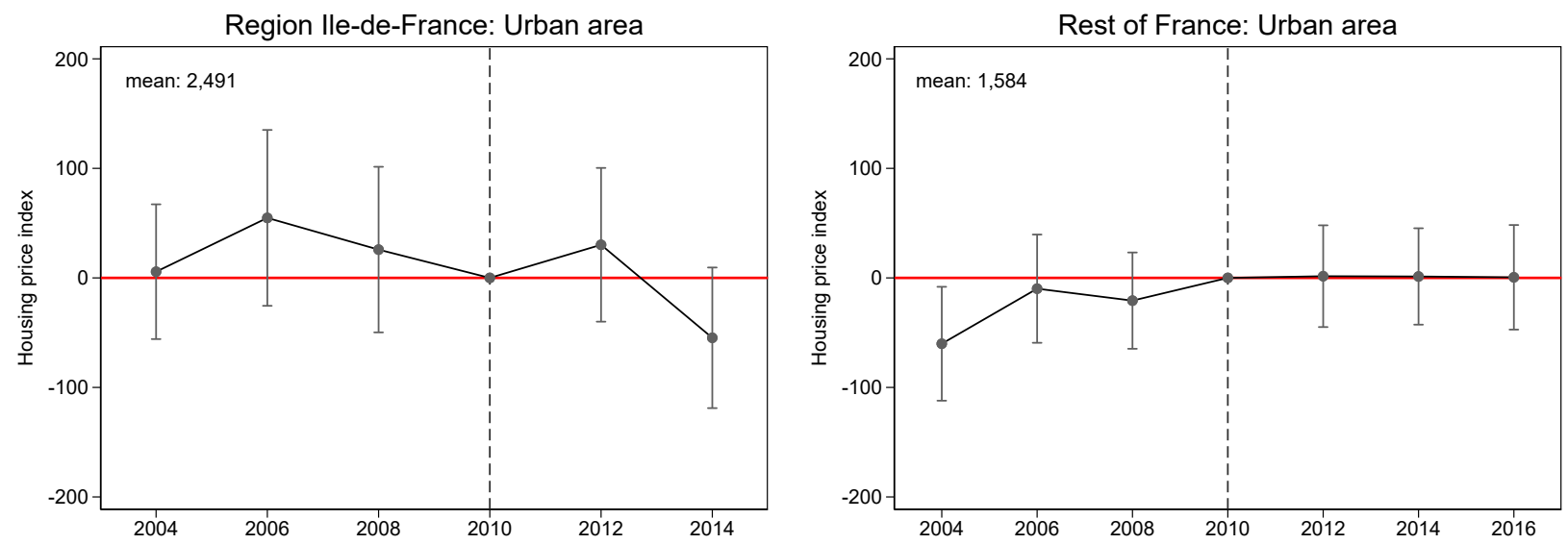

Notes: These graphs plot the estimates and 95-percent-confidence intervals from the leads-and-lags regression. The outcome is the municipality housing price index giving the price per square meter of a reference dwelling. The sample includes only municipalities that are part of an urban area and in which at least one housing transaction took place each even year over the period studied. The graph on the left-hand side includes only municipalities in the Parisian region of Île-de-France, while the graph on the right-hand side includes all the other municipalities. On each graph, the average value of the price index in the treatment group before 2010 is displayed on the top left corner. 


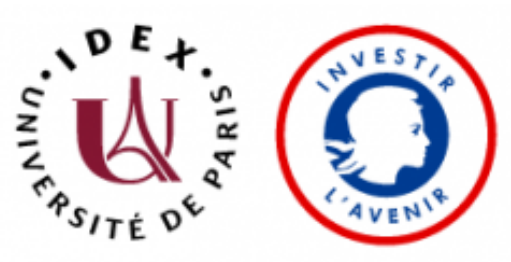

Le LIEPP (Laboratoire interdisciplinaire d'évaluation des politiques publiques) est un laboratoire d'excellence (Labex) distingué par le jury scientifique international désigné par l'Agence nationale de la recherche (ANR). II est financé dans le cadre des investissements d'avenir (ANR-11-LABX-0091, ANR-11-IDEX-0005-02) et de I'IdEX Université de Paris (ANR-18-IDEX-0001).

www.sciencespo.fr/liepp

\section{A propos de la publication}

Procédure de soumission :

Rédigé par un ou plusieurs chercheurs sur un projet en cours, le Working paper vise à susciter la discussion scientifique et à faire progresser la connaissance sur le sujet étudié. Il est destiné à être publié dans des revues à comité de lecture (peer review) et à ce titre répond aux exigences académiques. Les textes proposés peuvent être en français ou en anglais. En début de texte doivent figurer : les auteurs et leur affiliation institutionnelle, un résumé et des mots clefs.

Le manuscrit sera adressé à : liepp@sciencespo.fr

Les opinions exprimées dans les articles ou reproduites dans les analyses n'engagent que leurs auteurs.

Directrice de publication :

Anne Revillard

Comité de rédaction :

Sofia Cerda Aparicio, Andreana Khristova

Sciences Po - LIEPP

27 rue Saint Guillaume 75007 Paris - France +33(0)1.45.49.83.61

liepp@sciencespo.fr

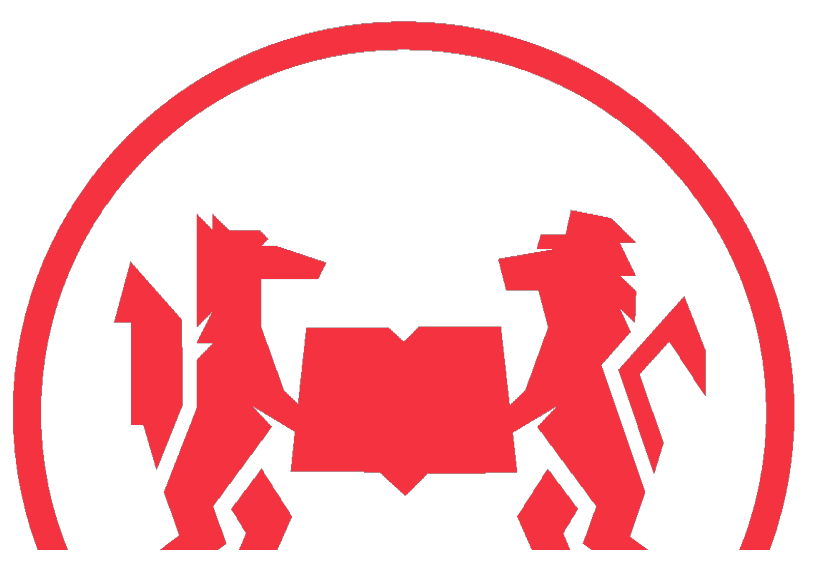

